OECD/G20 Base Erosion and Profit Shifting Project

\title{
Addressing the Tax Challenges of the Digital Economy
}

\section{ACTION 1: 2014 Deliverable}

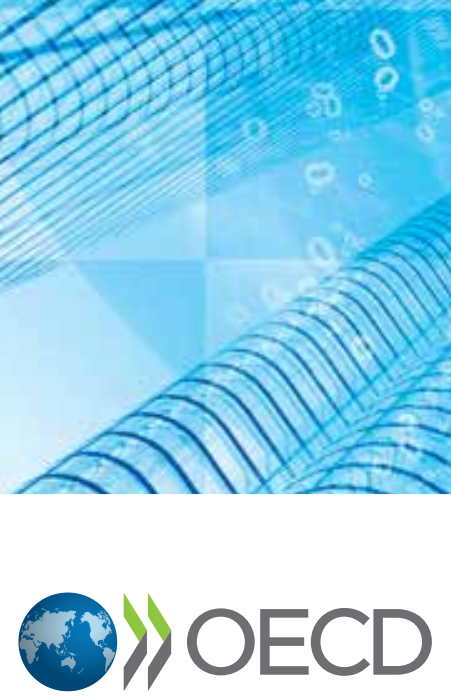



OECD/G20 Base Erosion and Profit Shifting Project

\section{Addressing the Tax Challenges of the Digital Economy}

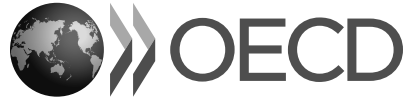


This document and any map included herein are without prejudice to the status of or sovereignty over any territory, to the delimitation of international frontiers and boundaries and to the name of any territory, city or area.

\section{Please cite this publication as:}

OECD (2014), Addressing the Tax Challenges of the Digital Economy, OECD/G20 Base Erosion and Profit Shifting Project, OECD Publishing. http://dx.doi.org/10.1787/9789264218789-en

ISBN 978-92-64-21877-2 (print)

ISBN 978-92-64-21878-9 (PDF)

Series: OECD/G20 Base Erosion and Profit Shifting Project

ISSN 2313-2604 (print)

ISSN 2313-2612 (online)

The statistical data for Israel are supplied by and under the responsibility of the relevant Israeli authorities. The use of such data by the OECD is without prejudice to the status of the Golan Heights, East Jerusalem and Israeli settlements in the West Bank under the terms of international law.

Photo credits: Cover @ archerix / Fotolia.

Corrigenda to OECD publications may be found on line at: www.oecd.org/about/publishing/corrigenda.htm.

(c) OECD 2014

You can copy, download or print OECD content for your own use, and you can include excerpts from OECD publications, databases and multimedia products in your own documents, presentations, blogs, websites and teaching materials, provided that suitable acknowledgment of the source and copyright owner is given. All requests for public or commercial use and translation rights should be submitted to rights@oecd.org. Requests for permission to photocopy portions of this material for public or commercial use shall be addressed directly to the Copyright Clearance Center (CCC) at info@copyright.com or the Centre français d'exploitation du droit de copie (CFC) at contact@cfcopies.com. 


\section{Foreword}

Addressing base erosion and profit shifting (BEPS) is a key priority of governments around the globe. In 2013, OECD and G20 countries, working together on an equal footing, adopted a 15-point Action Plan to address BEPS. The Action Plan aims to ensure that profits are taxed where economic activities generating the profits are performed and where value is created. It was agreed that addressing BEPS is critical for countries and must be done in a timely manner, not least to prevent the existing consensusbased international tax framework from unravelling, which would increase uncertainty for businesses at a time when cross-border investments are more necessary than ever. As a result, the Action Plan provides for 15 actions to be delivered by 2015, with a number of actions to be delivered in 2014 .

The OECD Committee on Fiscal Affairs (CFA), bringing together 44 countries on an equal footing (all OECD members, OECD accession countries, and G20 countries), has adopted a first set of seven deliverables described in the Action Plan and due in 2014. This report is part of these deliverables and is an output of Action 1.

Developing countries and other non-OECD/non-G20 economies have been extensively consulted through regional and global fora meetings and their input has been fed into the work. Business representatives, trade unions, civil society organisations and academics have also been very involved through opportunities to comment on discussion drafts. These have generated more than 3500 pages of comments and were discussed at five public consultation meetings and via three webcasts that attracted more than 10000 viewers.

The first set of reports and recommendations, delivered in 2014, addresses seven of the actions in the BEPS Action Plan published in July 2013. Given the Action Plan's aim of providing comprehensive and coherent solutions to BEPS, the proposed measures, while agreed, are not yet formally finalised. They may be affected by some of the decisions to be taken with respect to the 2015 deliverables with which the 2014 deliverable will interact. They do reflect consensus, as of July 2014, on a number of solutions to put an end to BEPS. 
The adoption of this first set of deliverables and the implementation of the relevant measures by national governments mean that: hybrid mismatches will be neutralised; treaty shopping and other forms of treaty abuse will be addressed; abuse of transfer pricing rules in the key area of intangibles will be greatly minimised; and country-by-country reporting will provide governments with information on the global allocation of the profits, economic activity and taxes of MNEs. Equally, OECD and G20 countries have agreed upon a report concluding that it is feasible to implement BEPS measures through a multilateral instrument. They have also advanced the work to fight harmful tax practices, in particular in the area of IP regimes and tax rulings. Finally, they have reached a common understanding of the challenges raised by the digital economy, which will now allow them to deepen their work in this area, one in which BEPS is exacerbated.

By its nature, BEPS requires co-ordinated responses. This is why countries are investing time and resources in developing shared solutions to common problems. At the same time, countries retain their sovereignty over tax matters and measures may be implemented in different countries in different ways, as long as they do not conflict with countries' international legal commitments. 


\section{Table of contents}

Abbreviations and acronyms

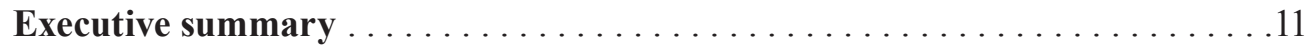

Chapter 1. Introduction to tax challenges of the digital economy . . . . . . 23

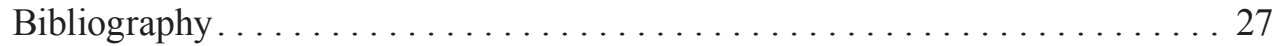

Chapter 2. Fundamental principles of taxation. . . . . . . . . . . . . . 29

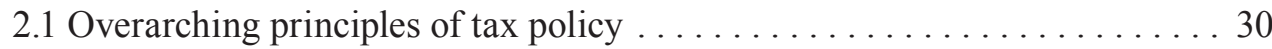

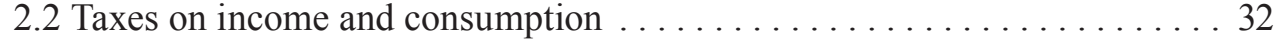

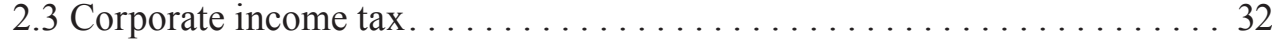

2.4 Value added taxes and other indirect consumption taxes $\ldots \ldots \ldots \ldots .41$

Bibliography................................. 49

Chapter 3. Information and communication technology and its impact on

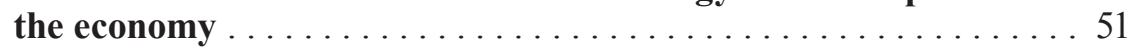

3.1 The evolution of information and communication technology ....... 52

3.2 Emerging and potential future developments . . . . . . . . . . . . 59

3.3 The interactions between various layers of information and communication technology (ICT): a conceptual overview . . . . . . . . 64

Bibliography.................................... 67

Chapter 4. The digital economy, new business models and key features . . . . 69

4.1 The spread of ICT across business sectors: the digital economy. . . . . . . . 70

4.2 The digital economy and the emergence of new business models. . . . . 73

4.3 Key features of the digital economy $\ldots \ldots \ldots \ldots \ldots \ldots \ldots \ldots$

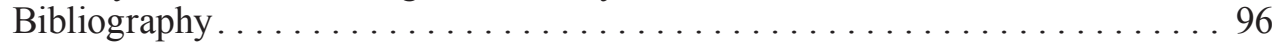


Chapter 5. Identifying opportunities for BEPS in the digital economy . . . . 99

5.1 Common features of tax planning structures raising BEPS concerns . . . . 100

5.2 BEPS in the context of direct taxation . . . . . . . . . . . . . . . 101

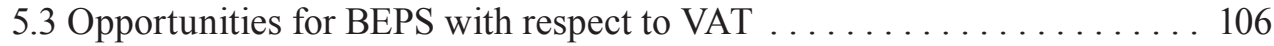

Bibliography.................................. 109

Chapter 6. Tackling BEPS in the digital economy $\ldots \ldots \ldots \ldots \ldots \ldots \ldots 11$

6.1 Introduction . . . . . . . . . . . . . . . . . . . . . . . . . . 112

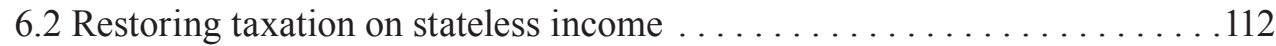

6.3 Addressing BEPS issues in the area of consumption taxes . . . . . . 120

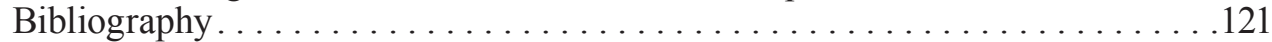

Chapter 7. Broader tax challenges raised by the digital economy . . . . . . 123

7.1 The digital economy and the challenges for policy makers . . . . . . . . 124

7.2 An overview of the tax challenges raised by the digital economy. . . . . . 124

7.3 Nexus and the ability to have a significant presence without being liable to tax 127

7.4 Data and the attribution of value created from the generation of marketable location-relevant data through the use of digital products and services . . . . 129

7.5 Characterisation of income derived from new business models . . . . . . . . . 132

7.6 Collection of VAT in the digital economy $\ldots \ldots \ldots \ldots \ldots \ldots \ldots \ldots \ldots \ldots \ldots$

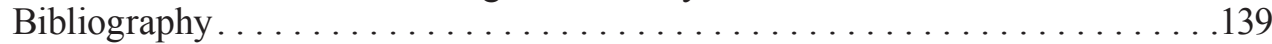

Chapter 8. Potential options to address the broader tax challenges raised

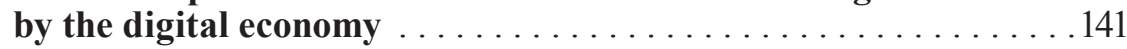

8.1 Introduction . . . . . . . . . . . . . . . . . . . . . . . . . . . . . . . . . . . 142

8.2 Options proposed to the Task Force...................... 143

8.3 Framework for evaluating potential options $\ldots \ldots \ldots \ldots \ldots \ldots \ldots \ldots \ldots$

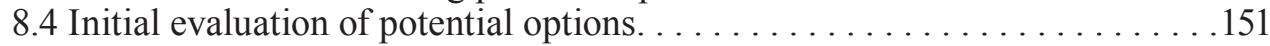

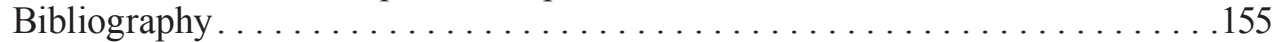

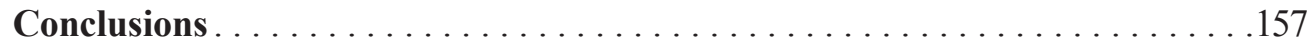

The digital economy, its business models, and its key features. . . . . . . . . .157

BEPS issues in the digital economy and how to address them . . . . . . . . 157

Broader tax policy challenges raised by the digital economy $\ldots \ldots \ldots \ldots \ldots 158$

Next steps . . . . . . . . . . . . . . . . . . . . . . . . . . . . . . . . . . . . . .

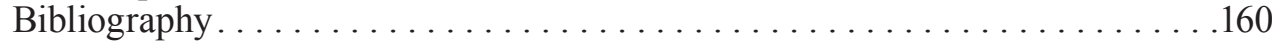

Annex $A$. Prior work on the digital economy $\ldots \ldots \ldots \ldots \ldots \ldots \ldots \ldots \ldots \ldots$

A.1 1996-98: Work leading to the Ottawa Ministerial Conference on Electronic Commerce . . 
A.2 1998: The Ottawa Ministerial Conference on Electronic Commerce. . . . . . 162 A.3 Post-Ottawa: CFA work and technical advisory groups . . . . . . . . . . . 163 Bibliography. . . . . . . . . . . . . . . . . . . . . . . . . . . 179

Annex B. Typical tax planning structures in integrated business models . . . .181

B.1 Online retailer . . . . . . . . . . . . . . . . . . . . . . . . 182

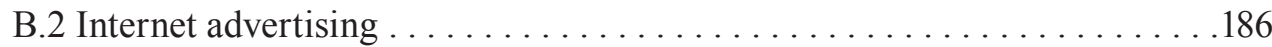

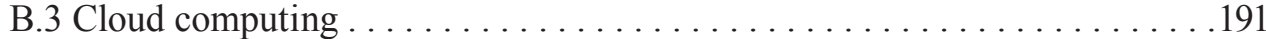

B.4 Internet app store . . . . . . . . . . . . . . . . . . . . . . 194

\section{Figures}

Figure 3.1 Total fixed, mobile and broadband access paths $\ldots \ldots \ldots \ldots \ldots 5$

Figure 3.2 Personal data. . . . . . . . . . . . . . . . . . . . 57

Figure 3.3 How bitcoins enter circulation and are used in transactions . . . . . 60

Figure 3.4 A layered view of ICT . . . . . . . . . . . . . . . . 64

Figure 4.1 Enterprises with broadband connection, by employment size, 2012 . 70

Figure 4.2 Turnover from e-commerce, by enterprise size, $2012 \ldots \ldots \ldots \ldots 76$

Figure 4.3 OECD and major exporters of ICT services, 2000 and $2012 \ldots \ldots$. . 86

Figure 4.4 Average annual revenue per employee of the top 250 ICT firms by

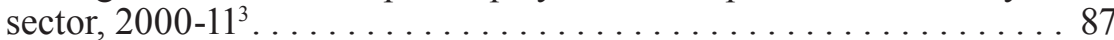

Figure 4.5 Estimated worldwide data storage $\ldots \ldots \ldots \ldots \ldots \ldots \ldots \ldots$

Figure 4.6 Average data storage cost for consumers $1998-2012 \ldots \ldots \ldots \ldots . .90$

Figure 5.1 BEPS planning in the context of income tax . . . . . . . . . . 101

Figure B.1 Online retailer. . . . . . . . . . . . . . . . . . . . . . . . . . . . 184

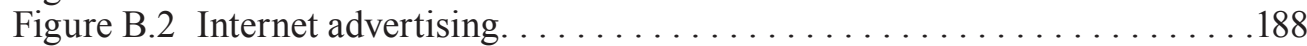

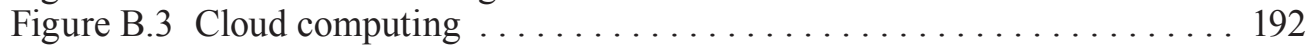

Figure B.4 Internet app store . . . . . . . . . . . . . . . . . . . 196

\section{Boxes}

Box 1.1 Ottawa Taxation Framework Conditions - Principles . . . . . . . . 25

Box $4.1 \quad$ Diversity of revenue models . . . . . . . . . . . . . . . 8 83

Box 7.1 Administrative challenges in the digital economy. . . . . . . . . . . 137

Box $8.1 \quad$ Fully dematerialised digital activities . . . . . . . . . . . . . 144

Box 8.2 Significant digital presence . . . . . . . . . . . . . . . . . . 145

Box A.1 Ottawa taxation framework conditions - Principles . . . . . . . . . 163

Box A.2 Commentary on Article 5 of the OECD Model Tax Convention. . . . . 169

Box A.3 Commentary on Article 12 - Payment for the use of, or the right

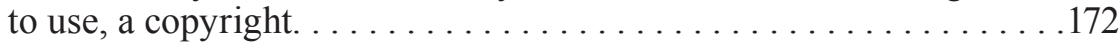

Box A.4 Change to the Commentary on Article 12 - Payments for know-how. . 174 Box A.5 Commentary on Article 12 - Mixed payments .............. 176 



\section{Abbreviations and acronyms}

ANBPPI Association des Bureaux pour la Protection de la

Propriété Industrielle

API Application programming interface

ASP Application service provider

BEPS Base erosion and profit shifting

BIAC Business and Industry Advisory Committee to the OECD

BP Business profit

B2B Business-to-business

B2C Business-to-consumer

CFA Committee on Fiscal Affairs

CFC Controlled foreign company

CIT Corporate income tax

CPA Cost-per-action

CPC Cost-per-click

CPM Cost-per-mille

C2C Consumer-to-consumer

DDME Data-Driven Marketing Economy

EC European Community

HTML Hypertext Markup Language

HTTP Hypertext Transfer Protocol

IaaS Infrastructure as a service

ICT Information and communication technology 


$\begin{array}{ll}\text { IMAP } & \text { Internet Message Access Protocol } \\ \text { IP } & \text { Internet Protocol } \\ \text { ISP } & \text { Internet service provider } \\ \text { MLE } & \text { Multi-location enterprise } \\ \text { MNE } & \text { Multinational enterprise } \\ \text { NIST } & \text { National Institute of Standards and Technology } \\ \text { OECD } & \text { Organisation for Economic Co-operation and } \\ \text { OTT } & \text { Development } \\ \text { PE } & \text { Over-the-top } \\ \text { POP } & \text { Permanent establishment } \\ \text { SDK } & \text { Post Office Protocol } \\ \text { SME } & \text { Software development kits } \\ \text { SMTP } & \text { Small and medium enterprise } \\ \text { TAG } & \text { Simple Mail Transfer Protocol } \\ \text { TFDE } & \text { Technical Advisory Group } \\ \text { UCC } & \text { Task Force on the Digital Economy } \\ \text { VAT } & \text { User created content } \\ \text { VAT/GST } & \text { Value added tax } \\ \text { VLAN } & \text { Value added tax/Goods and services tax } \\ \text { WTO } & \text { Virtual local area network } \\ \text { XaaS } & \text { World Trade Organisation } \\ \text { XML } & \text { X-as-a Service } \\ \end{array}$




\title{
Executive summary
}

\begin{abstract}
Action 1 of the base erosion and profit shifting (BEPS) Action Plan deals with the tax challenges of the Digital Economy. Political leaders, media outlets, and civil society around the world have expressed growing concern about tax planning by multinational enterprises that makes use of gaps in the interaction of different tax systems to artificially reduce taxable income or shift profits to low-tax jurisdictions in which little or no economic activity is performed. In response to this concern, and at the request of the G20, the Organisation for Economic Co-operation and Development (OECD) published an Action Plan on Base Erosion and Profit Shifting (BEPS Action Plan, OECD, 2013) in July 2013. Action 1 of the BEPS Action Plan calls for work to address the tax challenges of the digital economy. The Task Force on the Digital Economy (TFDE), a subsidiary body of the Committee on Fiscal Affairs (CFA) in which non-OECD G20 countries participate as Associates on an equal footing with OECD member countries, was established in September 2013 to develop a report identifying issues raised by the digital economy and detailed options to address them by September 2014. The Task Force consulted extensively with stakeholders and analysed written input submitted by business, civil society, academics, and developing countries before reaching its conclusions regarding the digital economy, the BEPS issues and the broader tax challenges it raises, and the recommended next steps.
\end{abstract}

\section{A. The digital economy, its business models, and its key features}

The digital economy is the result of a transformative process brought by information and communication technology (ICT). The ICT revolution has made technologies cheaper, more powerful, and widely standardised, improving business processes and bolstering innovation across all sectors of the economy. For example, retailers allow customers to place online orders and are able to gather and analyse customer data to provide personalised service and advertising; the logistics sector has been transformed by the ability to track of vehicles and cargo across continents; financial services providers increasingly enable customers to manage their finances, conduct transactions and access new products on line; in manufacturing, the digital 
economy has enhanced the ability to remotely monitor production processes and to control and use robots; in the education sector, universities, tutoring services and other education service providers are able to provide courses remotely, which enables them to tap into global demand; in the healthcare sector, the digital economy is enabling remote diagnosis and the use of health records to enhance system efficiencies and patient experience. The broadcasting and media industry have been revolutionised, expanding the role in news media of non-traditional news sources, and expanding user participation in media through user-generated content and social networking.

Because the digital economy is increasingly becoming the economy itself, it would be difficult, if not impossible, to ring-fence the digital economy from the rest of the economy for tax purposes. Attempting to isolate the digital economy as a separate sector would inevitably require arbitrary lines to be drawn between what is digital and what is not. As a result, the tax challenges and BEPS concerns raised by the digital economy are better identified and addressed by analysing existing structures adopted by multinational enterprises (MNEs) together with new business models and by focusing on the key features of the digital economy and determining which of those features raise or exacerbate tax challenges or BEPS concerns. Although many digital economy business models have parallels in traditional business, modern advances in ICT have made it possible to conduct many types of business at substantially greater scale and over longer distances than was previously possible. These include several varieties of e-commerce, online payment services, app stores, online advertising, cloud computing, participative networked platforms, and high-speed trading.

The digital economy is in a continuous state of evolution and possible future developments need to be monitored to evaluate their impact on tax systems. The rapid technological progress that has characterised the digital economy has led to a number of emerging trends and potential developments. Although this rapid change makes it difficult to predict future developments with any degree of reliability, these potential developments should be monitored closely as they may generate additional challenges for tax policy makers in the near future. These developments include the Internet of Things, referring to the dramatic increase in networked devices; virtual currencies, including bitcoin; developments in advanced robotics and $3 D$ printing, which have the potential to bring manufacturing closer to consumers, altering where and how value is created within manufacturing supply chains, as well as the characterisation of business income; the sharing economy which allows peerto-peer sharing of goods and services; increased access to government data, which has the potential to improve accountability and performance, and to allow participation of third parties in government business; and reinforced protection of personal data, which is more widely available in the digital economy. 
The digital economy and its business models present some key features which are potentially relevant from a tax perspective. These features include mobility, with respect to (i) the intangibles on which the digital economy relies heavily, (ii) users, and (iii) business functions; reliance on data, the massive use of which has been facilitated by an increase in computing power and storage capacity and a decrease in data storage cost; network effects, which refer to the fact that decisions of users may have a direct impact on the benefit received by other users; the spread of multisided business models, in which multiple distinct groups of persons interact through an intermediary or platform, and the decisions of each group of persons affect the outcome for the other groups of persons through a positive or negative externality; tendency toward monopoly or oligopoly in certain business models relying heavily on network effects; and volatility due to lower barriers to entry into markets and rapidly evolving technology, as well as the speed with which customers can choose to adopt new products and services at the expense of older ones.

The digital economy has also accelerated and changed the spread of global value chains in which MNEs integrate their worldwide operations. In the past, it was common for an MNE group to establish a subsidiary in each country in which it did business to manage the group's business in that country. This structure was dictated by a number of factors, including slow communications, currency exchange rules, customs duties, and relatively high transportation costs that made integrated global supply chains difficult to operate. Advances in ICT, reductions in many currency and custom barriers, and the move to digital products and a service-based economy, however, combined to break down barriers to integration, allowing MNE groups to operate much more as global firms. This integration has made it easier for business to adopt global business models that centralise functions at a regional or global level, rather than at a country-by-country level. Even for small and medium enterprises (SMEs), it has now become possible to be "micro-multinationals" that operate and have personnel in multiple countries and continents. ICT technologies have been instrumental in this major trend, which was further exacerbated by the fact that many of the major digital companies are young and were designed from the beginning to operate on an integrated basis at a global scale.

\section{B. BEPS issues in the digital economy and how to address them}

While the digital economy does not generate unique BEPS issues, some of its key features exacerbate BEPS risks. The Task Force discussed a number of tax and legal structures that can be used to implement business models in the digital economy. These structures highlight existing opportunities to achieve BEPS to reduce or eliminate tax in jurisdictions across the whole supply chain, including both market and residence countries. For example, the importance of 
intangibles in the context of the digital economy, combined with the mobility of intangibles for tax purposes under existing tax rules, generates substantial BEPS opportunities in the area of direct taxes. Further, the ability to centralise infrastructure at a distance from a market jurisdiction and conduct substantial sales of goods and services into that market from a remote location, combined with increasing ability to conduct substantial activity with minimal use of personnel, generates potential opportunities to achieve BEPS by fragmenting physical operations to avoid taxation. Some of the key characteristics of the digital economy also exacerbate risks of BEPS in the context of indirect taxation, in particular in relation to businesses that perform value added tax (VAT) exempt activities (exempt businesses).

These BEPS risks are being addressed in the context of the BEPS Project, which will align taxation with economic activities and value creation. Structures aimed at artificially shifting profits to locations where they are taxed at more favourable rates, or not taxed at all, will be addressed by ongoing work in the context of the BEPS Project. This will help restore taxing rights at the level of both the market jurisdiction and the jurisdiction of the ultimate parent company. Taxation in the market jurisdiction should be restored by preventing treaty abuse (Action 6, due by September 2014) and preventing the artificial avoidance of PE Status (Action 7, due by September 2015). Taxation in the ultimate residence jurisdiction should be restored by strengthening controlled foreign company (CFC) rules (Action 3, due by September 2015). Both market and residence taxation should be restored by neutralising the effects of hybrid mismatch arrangements (Action 2, due by September 2014), by limiting the base erosion via interest deductions and other financial payments (Action 4, due by September 2015), by countering harmful tax practices more effectively (Action 5, due by September 2014 and 2015), and by assuring that transfer pricing outcomes are in line with value creation (Actions 8-10, due by September 2015). In the context of VAT, under certain conditions opportunities for tax planning by businesses and corresponding BEPS concerns for governments may arise to the extent that the OECD's Guidelines on place of taxation for business-to-business (B2B) supplies of services and intangibles are not implemented.

Work on the BEPS Project also must examine a number of issues specifically linked to the digital economy, its business models and its key features. The Task Force has identified certain specific issues generated by the key features of the digital economy that warrant attention from a tax perspective. Work on the actions of the BEPS Action Plan will take these issues into account to ensure that the proposed solutions fully address BEPS in the digital economy. These include:

- Ensuring that core activities cannot inappropriately benefit from the exception from permanent establishment (PE) status, and that artificial arrangements relating to sales of goods and 
services cannot be used to avoid PE status. The work on Action 7 (preventing the artificial avoidance of PE Status) should consider whether certain activities that were previously considered preparatory or auxiliary for the purposes of these exceptions may be increasingly significant components of businesses in the digital economy. If so, the work should also consider the circumstances under which such activities may be considered core activities and whether a reasonable, administrable rule to this effect can be developed. For example, that work should consider whether and under what circumstances the maintenance of a local warehouse may constitute a core activity such that it should be outside the scope of the exceptions in Article 5 of the OECD Model Tax Convention. In addition to broader tax challenges, these issues raise BEPS concerns when the lack of taxation in the market country is coupled with techniques that reduce or eliminate tax in the country of the recipient or of the ultimate parent. The work would also consider whether and how the definition of PE may need to be modified to address circumstances in which artificial arrangements relating to the sales of goods or services of one company in a multinational group effectively result in the conclusion of contracts, such that the sales should be treated as if they had been made by that company. This would be relevant where, for instance, an online seller of tangible products or an online provider of advertising services uses the sales force of a local subsidiary to negotiate and effectively conclude sales with prospective large clients.

- The importance of intangibles, the use of data, and the spread of global value chains, and their impact on transfer pricing: Companies in the digital economy rely heavily on intangibles in creating value and producing income. A key feature of many BEPS structures adopted by participants in the digital economy involves the transfer of intangibles or rights to intangibles to tax-advantaged locations. Further, it is then often argued that these contractual allocations, together with legal ownership of intangibles, justify large allocations of income to the entity allocated the risk even if it performs little or no business activity. Often this is accomplished by arguing that other entities in the group are contractually insulated from risk so that a low-tax affiliate is entitled to all residual income after compensating other low risk group members for their functions even if this affiliate has no capacity to control the risk. In addition to the existing transfer pricing guidelines, the BEPS work in the area of transfer pricing should take these issues in account and also consider the relationship between that work and the heavy reliance on collection, analysis and monetisation of data that characterises many companies in the digital economy. In addition, work in this area should devote attention to the 
implications of the increased integration of MNEs and the spread of global value chains, in which various stages of production are spread across multiple countries. In this context, the work should evaluate the need for greater reliance on functional analyses (assets used, functions performed, and risks assumed) and on value chain analyses and should also address situations where comparables are not available because of the structures designed by taxpayers and the unique intangibles involved. In specific situations the functional analysis may show that the use of profit split methods or valuation techniques (e.g. discounted cash flow method) is appropriate. For these situations, it would be helpful to provide simpler and clearer guidance on the application of transfer pricing methods, including profit splits in the context of global value chains.

- The possible need to adapt CFC rules to the digital economy: Although CFC rules vary significantly from jurisdiction to jurisdiction, income from digital products and services provided remotely is frequently not subject to current taxation under CFC rules. Such income may be particularly mobile due to the importance of intangibles in the provision of such goods and services and the relatively few people required to carry out online sales activities. Accordingly, a multinational enterprise in a digital business can earn income in a CFC in a low-tax jurisdiction by locating key intangibles there and using those intangibles to sell digital goods and services without that income being subject to current tax, even if the CFC itself does not perform significant activities in its jurisdiction. In developing recommendations regarding the design of CFC rules, consideration should be given to CFC rules that target income typically earned in the digital economy, such as income earned from the remote sale of digital goods and services.

- Addressing opportunities for tax planning by businesses engaged in VAT-exempt activities: The digitisation of the economy has greatly facilitated the ability of businesses to acquire a wide range of services and intangibles from suppliers in other jurisdictions around the world and to structure their operations in a truly global manner. These developments have allowed exempt businesses to avoid or minimise the amount of unrecoverable VAT they incur on the inputs used for their exempt activities. The implementation of Guidelines 2 and 4 of the OECD's International VAT/GST Guidelines on place of taxation for B2B supplies of services and intangibles will minimise BEPS opportunities for supplies of remotely delivered services made to exempt businesses, including exempt entities that operate through establishments ("branches") in multiple jurisdictions. 


\section{Broader tax policy challenges raised by the digital economy}

The digital economy also raises broader tax challenges for policy makers. These challenges relate in particular to nexus, data, and characterisation for direct tax purposes. These challenges trigger more systemic questions about the ability of the current international tax framework to deal with the changes brought about by the digital economy and the business models that it makes possible and hence to ensure that profits are taxed in the jurisdiction where economic activities occur and where value is generated. They therefore have a broad impact and relate primarily to the allocation of taxing rights among different jurisdictions. These challenges also raise questions regarding the paradigm used to determine where economic activities are carried out and value is generated for tax purposes, which is based on an analysis of the functions, assets and risks involved. At the same time, when these challenges create opportunities for achieving double non-taxation, for example due to the lack of nexus in the market country under current rules coupled with lack of taxation in the jurisdiction of the income recipient and of that of the ultimate parent company, they also generate BEPS issues. In addition, in the area of indirect taxes, the digital economy raises policy challenges regarding the collection of VAT.

The challenges related to nexus, data and characterisation overlap with each other to a certain extent. Although the challenges related to direct tax are distinct in nature, they often overlap with each other. For example, the collection of data from users located in a jurisdiction may trigger questions regarding whether that activity should give rise to nexus with that jurisdiction and regarding how data should be treated for tax purposes.

Evolving ways of carrying on business raise questions about whether current nexus rules continue to be appropriate. The continual increase in the potential of digital technologies and the reduced need in many cases for extensive physical presence in order to carry on business in a jurisdiction, combined with the increasing role of network effects generated by customer interactions, raise questions as to whether rules that rely on physical presence continue to be appropriate. The number of firms carrying out business transactions over the Internet has increased dramatically over the last decade. According to estimates, the size of total worldwide e-commerce, when global $\mathrm{B} 2 \mathrm{~B}$ and consumer transactions are added together, equalled USD 16 trillion in 2013.

Increasing reliance on data collection and analysis, and the growing importance of multi-sided business models raise questions about valuation of data, nexus, and profit attribution, as well as characterisation. The appropriate allocation of taxable income among locations in which economic activities take place and value is created may not always be clear in the 
digital economy, particularly in cases where users and customers become an important component of the value chain, for example in relation to multi-sided business models and the sharing economy. The growth in sophistication of information technologies has permitted companies in the digital economy to gather and use information to an unprecedented degree. This raises the issues of how to attribute value created from the generation of data through digital products and services, whether remote collection of data should give rise to nexus for tax purposes, and of ownership and how to characterise for tax purposes a person or entity's supply of data in a transaction, for example, as a free supply of a good, as a barter transaction, or some other way.

The development of new business models raises questions regarding characterisation of income. The development of new digital products or means of delivering services creates uncertainties in relation to the proper characterisation of payments made in the context of new business models, particularly in relation to cloud computing. Further, to the extent that $3 \mathrm{D}$ printing becomes increasingly prevalent, it may raise characterisation questions as well, as direct manufacturing for delivery could effectively evolve into licensing of designs for remote printing directly by consumers.

Cross-border trade in goods, services and intangibles creates challenges for VAT collection, particularly where such products are acquired by private consumers from suppliers abroad. This is partly due to the absence of an effective international framework to ensure VAT collection in the market jurisdiction. For economic actors, and in particular small and medium enterprises, the absence of an international standard for charging, collecting and remitting the tax to a potentially large number of tax authorities creates large revenue risks and high compliance costs. For governments, there is a risk of loss of revenue and trade distortion, and the challenge of managing tax liabilities generated by a high volume of low value transactions, which can create a significant administrative burden but marginal revenues.

The Task Force discussed and analysed a number of potential options proposed by country delegates and other stakeholders to address these challenges. Options discussed regarding nexus and data in particular range from changes to the definition of PE to the introduction of a new nexus based on a "significant presence" in a market, and also include the introduction of a withholding tax on sales of digital goods and services. Because of the overlap between the issues of nexus, data, and characterisation, the options to address each of them would inevitably affect the others. For purposes of evaluating potential options, the Task Force agreed on a framework based on the overarching tax principles of neutrality, efficiency, certainty and simplicity, effectiveness and fairness, flexibility and sustainability, in light of the proportionality of the changes in relation to the tax challenges they are intended to address in the context of the existing international tax framework. 


\section{Next steps: Undertake further work to complete evaluation of the broader tax challenges related to nexus, data, and characterisation and potential options to address them, and ensure that BEPS issues in the digital economy are tackled effectively.}

Based on its discussion of these challenges and potential options to address them, the Task Force reached the following conclusions:

- The collection of VAT in business-to-consumer (B2C) transactions is a pressing issue that needs to be addressed urgently to protect tax revenue and to level the playing field between foreign suppliers relative to domestic suppliers. Work in this area by the Working Party No. 9 of the OECD CFA shall be completed by the end of 2015, with the Associates in the BEPS Project participating on an equal footing with the OECD member countries.

- The work in the context of Action 7 of the BEPS Action Plan (preventing the artificial avoidance of PE Status) shall consider whether activities that once may have been preparatory or auxiliary should be denied the benefit of the exceptions to the permanent establishment definition because they are core components of the business, and whether a reasonable, administrable rule to this effect can be developed.

- Working Party No. 1 of the CFA shall clarify the characterisation under current tax treaty rules of certain payments under new business models, especially cloud computing payments (including payments for infrastructure-as-a-service, software-as-a-service, and platformas-a-service transactions,) with the Associates in the BEPS Project participating on an equal footing with the OECD member countries.

- The staggered time frame of the BEPS Project and interaction among the various BEPS outputs make it difficult at the time this report is delivered to analyse how effective the work on the BEPS Action Plan will be in addressing BEPS concerns in the digital economy, as well as to evaluate the ultimate scope of the more systemic tax challenges in the area of nexus, data, and characterisation, and potential options to address them.

- In that context, it is important for the Task Force to continue its work in order to ensure that work carried out in other areas of the BEPS Project tackles BEPS issues in the digital economy, and that it can assess the outcomes of that work, continue to work on the broader tax challenges and potential options related to nexus, data, and characterisation, evaluate how the outcomes of the BEPS Project impact their relevance, urgency, and scope, and complete 
the evaluation of the options to address them. Specifically, the Task Force shall:

i. Continue to work on the broader tax challenges of the digital economy, including nexus, data, and characterisation, advance the work and refine technical details related to potential options to address those challenges, with appropriate focus on multi-sided business models and the participation of users and consumers in value creation, and evaluate how the outcomes of the BEPS Project affect these broader tax and administrative challenges.

ii. Act as a centre of expertise on the digital economy throughout the duration of the BEPS Project to ensure that work carried out in other areas of the BEPS Project tackles BEPS issues in the digital economy.

iii. Assess the degree to which completed work with respect to the other actions of the BEPS Project addresses BEPS with respect to the digital economy.

iv. Consider the economic incidence of VAT and corporate income taxation and its impact on the options to address the tax challenges raised by the digital economy.

v. If further actions are necessary in the area of direct taxation to address BEPS concerns with respect to the digital economy, consider limiting the application of potential options to address broader tax challenges (either under tax treaties or through design of domestic law rules) to situations in which such BEPS concerns arise, for example in cases of double non-taxation of income from sales of digital goods and services.

Accordingly, the Task Force will:

- Advance the work on nexus, data, multi-sided business models, characterisation and potential options to address the broader tax challenges of the digital economy to ensure that these options are viable and fair, avoid double taxation, and can be implemented without exacerbating costs of compliance and administration.

- Provide input to the work carried out in the other areas of the BEPS Project to ensure that it appropriately takes into account and addresses the key features of the digital economy that exacerbate BEPS concerns. This work relates in particular to the work on the Artificial Avoidance of PE, on Transfer Pricing and on CFC rules and it will be carried out together with the work on the economic incidence of corporate income tax and VAT. 
- Evaluate how the outcomes of the BEPS Project affect the broader tax challenges raised by the digital economy and complete the evaluation of the options to address them.

This work will be completed by December 2015 and a supplementary report reflecting the outcomes of the work will be finalised by that time. 



\section{Chapter 1}

\section{Introduction to tax challenges of the digital economy}

This chapter discusses the background leading to the adoption of the BEPS Action Plan, including the work to address the tax challenges of the digital economy. It then summarises the work of the Task Force on the Digital Economy leading to the production of the report. Finally, it provides an overview of the contents of the report. 
Political leaders, media outlets, and civil society around the world have expressed growing concern about tax planning by multinational enterprises that makes use of gaps in the interaction of different tax systems to artificially reduce taxable income or shift profits to low-tax jurisdictions in which little or no economic activity is performed. In response to this concern, and at the request of the G20, the Organisation for Economic Co-operation and Development (OECD) published an Action Plan on Base Erosion and Profit Shifting (BEPS Action Plan, OECD, 2013) in July 2013. The BEPS Action Plan identifies 15 actions to address BEPS in a comprehensive manner, and sets deadlines to implement those actions.

As noted in the BEPS Action Plan, "the spread of the digital economy also poses challenges for international taxation. The digital economy is characterised by an unparalleled reliance on intangible assets, the massive use of data (notably personal data), the widespread adoption of multi-sided business models capturing value from externalities generated by free products, and the difficulty of determining the jurisdiction in which value creation occurs. This raises fundamental questions as to how enterprises in the digital economy add value and make their profits, and how the digital economy relates to the concepts of source and residence or the characterisation of income for tax purposes. At the same time, the fact that new ways of doing business may result in a relocation of core business functions and, consequently, a different distribution of taxing rights which may lead to low taxation is not per se an indicator of defects in the existing system. It is important to examine closely how enterprises of the digital economy add value and make their profits in order to determine whether and to what extent it may be necessary to adapt the current rules in order to take into account the specific features of that industry and to prevent BEPS."

Against this background, the BEPS Action Plan includes the following description of the work to be undertaken in relation to the digital economy:

\section{Action 1 -Address the tax challenges of the digital economy}

Identify the main difficulties that the digital economy poses for the application of existing international tax rules and develop detailed options to address these difficulties, taking a holistic approach and considering both direct and indirect taxation. Issues to be examined include, but are not limited to, the ability of a company to have a significant digital presence in the economy of another country without being liable to taxation due to the lack of nexus under current international rules, the attribution of value created from the generation of marketable location relevant data through the use of digital products and services, the characterisation of income derived from new business models, the application of related source rules, and how to ensure the effective collection of VAT/GST with respect to the cross-border 
supply of digital goods and services. Such work will require a thorough analysis of the various business models in this sector.

At their meeting in St. Petersburg on 5-6 September 2013, the G20 Leaders fully endorsed the BEPS Action Plan, and issued a declaration that included the following paragraph related to BEPS:

In a context of severe fiscal consolidation and social hardship, in many countries ensuring that all taxpayers pay their fair share of taxes is more than ever a priority. Tax avoidance, harmful practices and aggressive tax planning have to be tackled. The growth of the digital economy also poses challenges for international taxation. We fully endorse the ambitious and comprehensive Action Planoriginated in the OECD - aimed at addressing base erosion and profit shifting with mechanism to enrich the Plan as appropriate. We welcome the establishment of the G20/OECD BEPS project and we encourage all interested countries to participate. Profits should be taxed where economic activities deriving the profits are performed and where value is created [...] $(\mathrm{G} 20,2013)$.

The Task Force on the Digital Economy (TFDE), a subsidiary body of the Committee on Fiscal Affairs (CFA) was established in September 2013 to carry out the work, with the aim of developing a report identifying issues raised by the digital economy and possible actions to address them by September 2014.

The TFDE held its first Meeting on 29-31 October 2013 during which delegates discussed the scope of the work and heard presentations from experts on the digital economy. The Task Force also discussed the relevance of the work done in the past on this topic. In particular, the Task Force discussed the outcomes of the 1998 Ottawa Ministerial Conference on Electronic Commerce where Ministers welcomed the 1998 CFA Report "Electronic Commerce: Taxation Framework Conditions" setting out the following taxation principles that should apply to electronic commerce.

\section{Box 1.1. Ottawa Taxation Framework Conditions - Principles}

Neutrality: Taxation should seek to be neutral and equitable between forms of electronic commerce and between conventional and electronic forms of commerce. Business decisions should be motivated by economic rather than tax considerations. Taxpayers in similar situations carrying out similar transactions should be subject to similar levels of taxation. 


\section{Box 1.1. Ottawa Taxation Framework Conditions - Principles (continued)}

Efficiency: Compliance costs for taxpayers and administrative costs for the tax authorities should be minimised as far as possible.

Certainty and Simplicity: The tax rules should be clear and simple to understand so that taxpayers can anticipate the tax consequences in advance of a transaction, including knowing when, where and how the tax is to be accounted.

Effectiveness and Fairness: Taxation should produce the right amount of tax at the right time. The potential for tax evasion and avoidance should be minimised while keeping counteracting measures proportionate to the risks involved.

Flexibility: The systems for taxation should be flexible and dynamic to ensure that they keep pace with technological and commercial developments.

The Task Force considers that these principles are still relevant today and, supplemented as necessary, can constitute the basis to evaluate options to address the tax challenges of the digital economy. In addition, the Task Force discussed the post-Ottawa body of work and in particular the work of the Technical Advisory Group on Business Profits (TAG BP) relating to the attribution of profits to permanent establishments (PEs), the place of effective management concept and treaty rules in the context of e-commerce. For an overview of this prior work, please refer to Annex A.

Considering the importance of stakeholders' input, the OECD issued a public request for input on 22 November 2013. Input received was discussed at the second meeting of the TFDE on 2-3 February 2014. The Task Force discussed the evolution and pervasiveness of the digital economy as well as the key features of the digital economy and tax challenges raised by them. The Task Force heard presentations from delegates outlining possible options to address the BEPS and tax challenges of the digital economy and agreed on the importance of publishing a discussion draft for public comments and input. The input received was discussed by the Task Force and contributed to the finalisation of its report.

This report provides first an overview of the fundamental principles of taxation, focusing on the difference between direct and indirect taxes and the concepts that underlie them as well as double tax treaties (Chapter 2). It then examines the evolution over time of information and communication technology (ICT), including emerging and possible future developments (Chapter 3) and discusses the spread and impact of ICT across the economy, providing examples of new business models and identifying the key features of the digital economy (Chapter 4). It then provides a detailed description 
of the core elements of BEPS strategies in the digital economy (Chapter 5) and discusses how the development of the measures envisaged in the BEPS Action Plan and the OECD work on indirect taxation are expected to address them (Chapter 6). Finally, it identifies the broader tax challenges raised by the digital economy (Chapter 7) and summarises the potential options to address them that have been presented to, and initially discussed by, the Task Force (Chapter 8). The conclusions of the Task Force are included at the end of the report.

\section{Bibliography}

G20 (2012), Leaders' Declaration, St. Petersburg, Russia, https://www. g20.org/sites/default/files/g20_resources/library/Saint_Petersburg Declaration_ENG_0.pdf (accessed on 09 July 2014).

OECD (2013), Action Plan on Base Erosion and Profit Shifting, OECD

Publishing, Paris. http://dx.doi.org/10.1787/9789264202719-en. 



\section{Chapter 2}

\section{Fundamental principles of taxation}

This chapter discusses the overarching principles of tax policy that have traditionally guided the development of tax systems. It then provides an overview of the principles underlying corporate income tax, focusing primarily on the taxation of cross-border income both under domestic laws and in the context of tax treaties. Finally, it provides an overview of the design features of value-added tax (VAT) systems. 


\subsection{Overarching principles of tax policy}

In a context where many governments have to cope with less revenue, increasing expenditures and resulting fiscal constraints, raising revenue remains the most important function of taxes, which serve as the primary means for financing public goods such as maintenance of law and order and public infrastructure. Assuming a certain level of revenue that needs to be raised, which depends on the broader economic and fiscal policies of the country concerned, there are a number of broad tax policy considerations that have traditionally guided the development of taxation systems. These include neutrality, efficiency, certainty and simplicity, effectiveness and fairness, as well as flexibility. In the context of work leading up to the Report on the Taxation of Electronic Commerce (see Annex A for further detail), these overarching principles were the basis for the 1998 Ottawa Ministerial Conference, and are since then referred to as the Ottawa Taxation Framework Conditions. At the time, these principles were deemed appropriate for an evaluation of the taxation issues related to e-commerce. Although most of the new business models identified in Chapter 4 did not exist yet at the time, these principles, with modification, continue to be relevant in the digital economy, as discussed in Chapter 8. In addition to these well-recognised principles, equity is an important consideration for the design of tax policy.

- Neutrality: Taxation should seek to be neutral and equitable between forms of business activities. A neutral tax will contribute to efficiency by ensuring that optimal allocation of the means of production is achieved. A distortion, and the corresponding deadweight loss, will occur when changes in price trigger different changes in supply and demand than would occur in the absence of tax. In this sense, neutrality also entails that the tax system raises revenue while minimising discrimination in favour of, or against, any particular economic choice. This implies that the same principles of taxation should apply to all forms of business, while addressing specific features that may otherwise undermine an equal and neutral application of those principles.

- Efficiency: Compliance costs to business and administration costs for governments should be minimised as far as possible.

- Certainty and simplicity: Tax rules should be clear and simple to understand, so that taxpayers know where they stand. A simple tax system makes it easier for individuals and businesses to understand their obligations and entitlements. As a result, businesses are more likely to make optimal decisions and respond to intended policy choices. Complexity also favours aggressive tax planning, which may trigger deadweight losses for the economy. 
- Effectiveness and fairness: Taxation should produce the right amount of tax at the right time, while avoiding both double taxation and unintentional non-taxation. In addition, the potential for evasion and avoidance should be minimised. Prior discussions in the Technical Advisory Groups (TAGs) considered that if there is a class of taxpayers that are technically subject to a tax, but are never required to pay the tax due to inability to enforce it, then the taxpaying public may view the tax as unfair and ineffective. As a result, the practical enforceability of tax rules is an important consideration for policy makers. In addition, because it influences the collectability and the administerability of taxes, enforceability is crucial to ensure efficiency of the tax system.

- Flexibility: Taxation systems should be flexible and dynamic enough to ensure they keep pace with technological and commercial developments. It is important that a tax system is dynamic and flexible enough to meet the current revenue needs of governments while adapting to changing needs on an ongoing basis. This means that the structural features of the system should be durable in a changing policy context, yet flexible and dynamic enough to allow governments to respond as required to keep pace with technological and commercial developments, taking into account that future developments will often be difficult to predict.

Equity is also an important consideration within a tax policy framework. Equity has two main elements; horizontal equity and vertical equity. Horizontal equity suggests that taxpayers in similar circumstances should bear a similar tax burden. Vertical equity is a normative concept, whose definition can differ from one user to another. According to some, it suggests that taxpayers in better circumstances should bear a larger part of the tax burden as a proportion of their income. In practice, the interpretation of vertical equity depends on the extent to which countries want to diminish income variation and whether it should be applied to income earned in a specific period or to lifetime income. Equity is traditionally delivered through the design of the personal tax and transfer systems.

Equity may also refer to inter-nation equity. As a theory, inter-nation equity is concerned with the allocation of national gain and loss in the international context and aims to ensure that each country receives an equitable share of tax revenues from cross-border transactions (OECD, 2001). The tax policy principle of inter-nation equity has been an important consideration in the debate on the division of taxing rights between source and residence countries. At the time of the Ottawa work on the taxation of electronic commerce, this important concern was recognised by stating that "any adaptation of the existing international taxation principles should be 
structured to maintain fiscal sovereignty of countries, [...] to achieve a fair sharing of the tax base from electronic commerce between countries..." (OECD, 2001: 228).

Tax policy choices often reflect decisions by policy makers on the relative importance of each of these principles and will also reflect wider economic and social policy considerations outside the field of tax.

\subsection{Taxes on income and consumption}

Most countries impose taxes on both income and consumption. While income taxes are levied on net income (i.e. from labour and capital) over an annual tax period, consumption taxes operate as a levy on expenditure relating to the consumption of goods and services, imposed at the time of the transaction.

There are a variety of forms of income and consumption taxes. Income tax is generally due on the net income realised by the taxpayer over an income period. In contrast, consumption taxes find their taxable event in a transaction, the exchange of goods and services for consideration either at the last point of sale to the final end user (retail sales tax and VAT), or on intermediate transactions between businesses (VAT) (OECD, 2011), or through levies on particular goods or services such as excise taxes, customs and import duties. Income taxes are levied at the place of source of income while consumption taxes are levied at the place of destination (i.e. the importing country).

It is also worth noting that the tax burden is not always borne by those who are legally required to pay the tax. Depending on the price elasticity of the factors of production (which in turn depends on the preferences of consumers, the mobility of factors of production, the degree of competition etc.), the tax burden may be shifted and thus both income and consumption taxes can have a similar tax incidence. In general, it is said that the tax incidence falls upon capital, labour and/or consumption. For example, if capital were more mobile than labour and the market is a highly competitive and well-functioning one, most of the tax burden would be borne by workers.

\subsection{Corporate income tax}

Although the tax base can be defined in a great variety of ways, corporate income tax (CIT) generally relies on a broad tax base, formulated to encompass all types of income derived by the corporation whatever their nature, ${ }^{1}$ which encompasses the normal return on equity capital in addition to what can be described as "pure" or "economic rents" i.e. what the enterprise 
earns from particular competitive advantages which may be related to advantageous production factors (such as natural resources that are easily exploitable or low labour costs) or advantages related to the market in which the products will be sold (e.g. a monopolistic position).

At the time CIT systems were introduced, one of their primary objectives was to act as a prepayment of personal income taxes due by the shareholders (i.e. the "gap-filling" function (Bird, 2002), also referred to as the "deferral justification"), thereby preventing potentially indefinite deferral of personal income tax (Vann, 2010). As a result, the corporate tax base was seen as a proxy for the return on equity capital. It follows that corporate taxes are generally imposed on net profits, that is receipts minus expenses. Two basic models, different in their approach but similar in their practical result, are used to assess this taxable income:

- The receipts-and-outgoings system (or profit \& loss method): net income is determined as the difference between all recognised income derived by a corporation in the tax period and all deductible expenses incurred by the corporation in the same tax period.

- The balance-sheet system (or net-worth comparison method): net income is determined by comparing the value of the net assets in the balance sheet of the taxpayer at the end of the tax period (plus dividends distributed) with the value of the net assets in the balance sheet of the taxpayer at the beginning of the tax period.

Some countries have achieved substantial uniformity, except for some differences where the accounting treatment may be vulnerable to manipulations intended to distort the measurement of taxable income (e.g. denial of deduction of certain expenses, different method of recognition of capital expenditures, different timing in recognition of gains on certain fixed assets). In other countries tax and financial accounting are substantially independent, with tax law provisions addressing to a large extent the treatment of the transactions entered into by a corporation.

\subsubsection{The taxation of cross-border income under domestic corporate income tax laws}

It is commonly accepted that there are two aspects to a state's sovereignty: the power over a territory ("enforcement jurisdiction") and the power over a particular set of subjects ("political allegiance"). This binary nature of sovereignty was strongly rooted in the minds of the people during the 19th and 20th century and exercised a significant influence in the fashioning of one State's jurisdiction to tax. Conscious that taxes ought to be confined to taxable subjects and objects that have some sort of connection with the imposing State, policy makers reached the conclusion 
that a legitimate tax claim ought to be either based on the relationship to a person (i.e. a "personal attachment") or on the relationship to a territory (i.e. a "territorial attachment") (Schon, 2010; Beale, 1935).

Along the same line, the dual nature of sovereignty has also contributed to the formulation of the realistic doctrine, which is driven by concerns for the enforcement, administration, collection of taxes and came to limit the traditional notion of sovereignty (Tadmore, 2007). While a state's right to levy income taxes relies on territory or residence, the realistic doctrine advances that without the power to tax, there is no jurisdiction to tax and is more concerned with the exercise of taxing rights by the State in an effective manner (Tadmore, 2007). Under the realistic doctrine, a distinction is made between jurisdiction to impose taxes and jurisdiction to enforce them, also called "the enforcement jurisdiction" (Hellerstein, 2009) and emphasis is placed on practicality over theory.

Domestic tax rules for the taxation of cross-border income generally address two situations: the taxation of outbound investments of resident companies, and the taxation of inbound investments of non-resident companies. With respect to the former category, the definition of residence is a key notion. Some countries determine the residence of a corporation based on formal criteria such as place of incorporation. In other countries, the residence of a corporation is determined by reference factual criteria such as place of effective management or similar concepts. Some countries have mixed systems, where there is both a place of incorporation test and a place of effective management test.

With respect to taxation of outbound investments of resident companies, two broad models can be identified: the worldwide system and the territorial system. It should be noted that these categories are simplifications, as most countries in practice apply a combination of both systems.

A country employing a worldwide system subjects its residents to tax on their worldwide income whether derived from sources in or outside its territory. In order to implement the residence principle, the tax administration in the country of residence has to collect information with respect to the foreign-source income of their residents. As a result, countries rarely, if ever, adopt pure worldwide systems of taxation. Instead, under most of these systems foreign-sourced profits of foreign subsidiaries are taxed upon repatriation (the deferral system), and not on an accrual basis. In addition, the credit for tax paid on profits generated abroad is usually limited to the amount of taxation that would have been imposed on the foreign earnings by the residence country, thereby ensuring that the worldwide system does not impair the residence state's taxation of its own domestic source income. 
A country applying a territorial CIT system subjects its residents to tax only on the income derived from sources located in its territory. This means that resident companies are taxed only on their local income - i.e. income deemed to have their source inside the country. Determining the source of business income is therefore key in a territorial system.

\section{Controlled foreign company (CFC) rules}

CFC rules provide for the taxation of profits derived by non-resident companies in the hands of their resident shareholders. They can be thought of as a category of anti-avoidance rules, or an extension of the tax base, designed to tax shareholders on passive or highly mobile income derived by non-resident companies in circumstances where, in the absence of such rules, that income would otherwise have been exempt from taxation (e.g. under a territorial system) or only taxed on repatriation (e.g. under a worldwide tax system with a deferral regime).

CFC rules vary substantially in approach. In some instances, they seek to reduce tax incentives to undertake business or investment through a nonresident company. But they may also include provisions (such as the exclusion of active income) intended to ensure that certain types of investment in a foreign jurisdiction by residents of the country applying the CFC regime will be subject to no greater overall tax burden than investment in the same foreign jurisdiction by shareholders that are not residents. Most systems of CFC rules have the character of anti-avoidance rules targeting diverted income, and are not intended to deter genuine foreign investment.

CFC rules require some or all of the foreign company's profits to be included in the income of the resident shareholder, and thus may also have the effect of protecting the tax base of the source country by discouraging investments that erode its tax base or that are designed to shift profit to low-tax jurisdictions.

With respect to the taxation of inbound investments of non-resident companies, both a worldwide tax system and a territorial tax system impose tax on income arising from domestic sources. Hence, the determination of source of the income is key. Sourcing rules vary from country to country. With respect to business income, the concept of source under domestic law often parallels the concept of permanent establishment (PE) as defined under tax treaties. Such income is typically taxed on a net basis. For practical reasons however, it may be difficult for a country to tax certain items of income derived by non-resident corporations. It may also be difficult to know what expenses a non-resident incurred in earning such income. As a 
result, taxation at source of certain types of income (e.g. interest, royalties, dividends) derived by non-resident companies commonly occurs by means of withholding taxes at a gross rate. To allow for the fact that no deductions are allowed, gross-based withholding taxes are imposed at rates that are usually lower than standard corporate tax rates.

\subsubsection{The taxation of cross-border income under double tax treaties}

The exercise of tax sovereignty may entail conflicting claims from two or more jurisdictions over the same taxable amount, which may lead to juridical double taxation, which is the imposition of comparable taxes in two (or more) states on the same taxpayer in respect of the same income. Double taxation has harmful effects on the international exchange of goods and services and cross-border movements of capital, technology and persons. Bilateral tax treaties address instances of double taxation by allocating taxing rights to the contracting states. Most existing bilateral tax treaties are concluded on the basis of a model, such as the OECD Model Tax Convention or the United Nations Model, which are direct descendants of the first Model of bilateral tax treaty drafted in 1928 by the League of Nations. As a result, while there can be substantial variations between one tax treaty and another, double tax treaties generally follow a relatively uniform structure, which can be viewed as a list of provisions performing separate and distinct functions: (i) articles dealing with the scope and application of the tax treaty, (ii) articles addressing the conflict of taxing jurisdiction, (iii) articles providing for double taxation relief, (iv) articles concerned with the prevention of tax avoidance and fiscal evasion, and $(v)$ articles addressing miscellaneous matters (e.g. administrative assistance).

\subsubsection{A historical overview of the conceptual basis for allocating taxing rights}

As global trade increased in the early 20 th century, and concerns around instances of double taxation grew, the League of Nations appointed in the early 1920s four economists (Bruins et al., 1923) to study the issue of double taxation from a theoretical and scientific perspective. One of the tasks of the group was to determine whether it is possible to formulate general principles as the basis of an international tax framework capable of preventing double taxation, including in relation to business profits. ${ }^{2}$ In this context the group identified the concept of economic allegiance as a basis to design such international tax framework. Economic allegiance is based on factors aimed at measuring the existence and extent of the economic relationships between a particular state and the income or person to be taxed. The four economists identified four factors comprising economic allegiance, namely (i) origin of wealth or income, (ii) situs of wealth or income, (iii) enforcement of the rights 
to wealth or income, and (iv) place of residence or domicile of the person entitled to dispose of the wealth or income.

Among those factors, the economists concluded that in general, the greatest weight should be given to "the origin of the wealth [i.e. source] and the residence or domicile of the owner who consumes the wealth". The origin of wealth was defined for these purposes as all stages involved in the creation of wealth: "the original physical appearance of the wealth, its subsequent physical adaptations, its transport, its direction and its sale". In other words, the group advocated that tax jurisdiction should generally be allocated between the state of source and the state of residence depending on the nature of the income in question. Under this approach, in simple situations where all (or a majority of) factors of economic allegiance coincide, jurisdiction to tax would go exclusively with the state where the relevant elements of economic allegiance have been characterised. In more complex situations in which conflicts between the relevant factors of economic allegiance arise, jurisdiction to tax would be shared between the different states on the basis of the relative economic ties the taxpayer and his income have with each of them.

On the basis of this premise, the group considered the proper place of taxation for the different types of wealth or income. Business profits were not treated separately, but considered under specific classes of undertakings covering activities nowadays generally categorised as "bricks and mortar" businesses, namely "Mines and Oil Wells", "Industrial Establishments" or "Factories", and "Commercial Establishments". In respect of all those classes of activities, the group came to the conclusion that the place where income was produced is "of preponderant weight" and "in an ideal division a preponderant share should be assigned to the place of origin". In other words, in allocating jurisdiction to tax on business profits, greatest importance was attached to the nexus between business income and the various physical places contributing to the production of the income.

Many of the report's conclusions proved to be controversial and were not entirely followed in double tax treaties. In particular, the economists' preference for a general exemption in the source state for all "income going abroad" as a practical method of avoiding double taxation ${ }^{4}$ was explicitly rejected by the League of Nations, who chose as the basic structure for its 1928 Model the "classification and assignment of sources" method i.e. attach full or limited source taxation to certain classes of income and assign the right to tax other income exclusively to the state of residence. Nevertheless, the theoretical background enunciated in the 1923 Report has survived remarkably intact and is generally considered as the "intellectual base" (Ault, 1992: 567) from which the various League of Nations models 
(and consequently virtually all modern bilateral tax treaties) developed (AviYonah, 1996).

Before endorsing the economic allegiance principle, the group of four economists briefly discussed other theories of taxation, including the benefit principle (called at the time the "exchange theory"), and observed that the answers formulated by this doctrine had to a large extent been supplanted by the theory of ability to pay. Several authors consider that the decline of the benefit theory is undeniable as far as determination of the amount of tax liability is concerned, but not in the debate on taxing jurisdiction in an international context (Vogel, 1988). Under the benefit theory, a jurisdiction's right to tax rests on the totality of benefits and state services provided to the taxpayer that interacts with a country (Pinto, 2006), and corporations, in their capacity as agents integrated into the economic life of a particular country, ought to contribute to that country's public expenditures. In other words, the benefit theory provides that a state has the right to tax resident and non-resident corporations who derive a benefit from the services it provides. These benefits can be specific or general in nature. The provision of education, police, fire and defence protection are among the more obvious examples. But the state can also provide conducive and operational legal structures for the proper functioning of business, for example in the form of a stable legal and regulatory environment, the protection of intellectual property and the knowledge-based capital of the firm, the enforcement of consumer protection laws, or well-developed transportation, telecommunication, utilities and other infrastructure (Pinto, 2006).

\subsubsection{Allocation of taxing rights under tax treaties}

At the time the four economists presented their report, various jurisdictions had already started addressing juridical double taxation through bilateral and unilateral measures. The League of Nations Tax Committees built upon the practical experience of government experts with negotiating and administering contemporary treaties. Partly as a result of historic path dependence, and partly due to the need for an effective way to allocate taxing rights between tax systems that may diverge significantly, avoidance of double taxation was not addressed by an alternative system such as formulary apportionment, or another system based on the principles identified by the four economists. Instead, supported by the development of the OECD and UN Model treaties, the international tax framework developed around a vast network of bilateral tax treaties following the so-called "classification and assignment of sources" method, in which different types of income are subject to different distributive rules. This schedular nature of distributive rules entails a preliminary step, whereby the income subject to conflicting claims is first classified into one of the categories of income defined by 
the treaty. Where an item of income falls under more than one category of income, double tax treaties resolve the conflict through ordering rules. Once the income is characterised for treaty purposes, the treaty provides distributive rules that generally either grant one contracting state the exclusive right to exercise domestic taxing rights or grant one contracting state priority to exercise its domestic taxing right while reserving a residual taxing right to the other contracting state.

Treaty rules provide that business profits derived by an enterprise are taxable exclusively by the state of residence unless the enterprise carries on business in the other state through a PE situated therein. In the latter situation, the source state may tax only the profits that are attributable to the PE. The PE concept is thus used to determine whether or not a contracting state is entitled to exercise its taxing rights with respect to the business profits of a non-resident taxpayer. Special rules apply, however, to profits falling into certain enumerated categories of income, such as dividends, interest, royalties, and capital gains.

The PE concept effectively acts as a threshold which, by measuring the level of economic presence of a foreign enterprise in a given State through objective criteria, determines the circumstances in which the foreign enterprise can be considered sufficiently integrated into the economy of a state to justify taxation in that state (Holmes, 2007; Rohatgi, 2005). A link can thus reasonably be made between the requirement of a sufficient level of economic presence under the existing PE threshold and the economic allegiance factors developed by the group of economists more than 80 years ago. This legacy is regularly emphasised in literature (Skaar, 1991), as well as reflected in the existing OECD Commentaries when it is stated that the PE threshold "has a long history and reflects the international consensus that, as a general rule, until an enterprise of one State has a permanent establishment in another State, it should not properly be regarded as participating in the economic life of that other State to such an extent that the other State should have taxing rights on its profits". ${ }^{5}$ By requiring a sufficient level of economic presence, this threshold is also intended to ensure that a source country imposing tax has enforcement jurisdiction, the administrative capability to enforce its substantive jurisdiction rights over the non-resident enterprise.

The PE definition initially comprised two distinct thresholds: (i) a fixed place through which the business of the enterprise is wholly or partly carried on or, where no place of business can be found, (ii) a person acting on behalf of the foreign enterprise and habitually exercising an authority to conclude contracts in the name of the foreign enterprise. In both situations a certain level of physical presence in the source jurisdiction is required, either directly or through the actions of a dependent agent. Some extensions have been made over time to address changes in business conditions. For example, 
the development of the service industry has led to the inclusion in many existing bilateral treaties of an additional threshold whereby the performance of services by employees (or other persons receiving instructions) of a nonresident enterprise may justify source-based taxation as soon as the duration of such services exceeds a specific period of time, irrespective of whether the services are performed through a fixed place of business (Alessi, Wijnen and de Goede, 2011).

Treaty rules on business profits provide that only the profits "attributable" to the PE are taxable in the jurisdiction where the PE is located. These are the profits that the $\mathrm{PE}$ would be expected to make if it were a distinct and separate enterprise.

By virtue of separate distributive rules which take priority over the PE rule, some specific items of income may be taxed in the source jurisdiction even though none of the alternative PE thresholds are met in that country. These include:

- Income derived from immovable property (and capital gains derived from the sale thereof), which generally may be taxed by the country of source where the immovable property is located.

- Business profits that include certain types of payments which, depending on the treaty, may include dividends, interest, royalties or technical fees, on which the treaty allows the country of source to levy a limited withholding tax.

In the case of outbound payments of dividends, interest, and royalties, countries commonly impose tax under their domestic law on a gross basis (i.e. not reduced by the deduction of expenses) by means of a withholding tax. Bilateral tax treaties commonly specify a maximum rate at which the source state may impose such a withholding tax, with the residual right to tax belonging to the state of residence. ${ }^{6}$ However, where the asset giving rise to such types of income is effectively connected to a PE of the non-resident enterprise in the same state, the rules for attribution of profits to a PE control (Article 10(4), 11(4) and 12(3) of the OECD Model Tax Convention).

Where priority is given by bilateral tax treaties to the taxing rights of the source jurisdiction, the resident state must provide double taxation relief. Two mechanisms are generally available in bilateral tax treaties, namely the exemption method and the credit method. But in practice many jurisdictions, and accordingly existing bilateral tax treaties, use a mixture of these approaches - i.e. exemption method for income attributable to a PE, and credit method for items of income subject to a withholding - in relation to business profits (Rohatgi, 2005). 


\subsection{Value added taxes and other indirect consumption taxes}

Value added taxes (VAT) and other consumption taxes are generally designed to be indirect taxes. While they are generally intended to tax the final consumption of goods and services, they are collected from the suppliers of these goods and services rather than directly from the consumers. The consumers bear the burden of these taxes, in principle, as part of the market price of the goods or services purchased.

Two categories of consumption taxes are generally distinguished (OECD, 2013):

- General taxes on goods and services, consisting of VAT and its equivalent in several jurisdictions, sales taxes and other general taxes on goods and services.

- Taxes on specific goods and services, consisting primarily of excise taxes, customs and import duties, and taxes on specific services (e.g. taxes on insurance premiums and financial services).

This section focuses mainly on VAT, which is the primary form of consumption tax for countries around the world. The combination of the global spread of VAT and the rapid globalisation of economic activity, which resulted in increased interaction between VAT systems, and increasing VAT rates $(\mathrm{OECD}, 2012)$ have raised the profile of VAT as a significant issue in cross-border trade.

\subsubsection{Main design features of a VAT}

\subsubsection{Overarching purpose of a VAT-A broad-based tax on final consumption}

The term VAT is used here to cover all value added taxes, by whatever name, in whatever language, they are known. Note, for instance, that many countries refer to their value added taxes as a "goods and services tax" (GST) (e.g. Australia, Canada, India, New Zealand and Singapore). While there is considerable diversity in the structure of the VAT systems currently in place, most of these systems are grounded on certain fundamental design principles that are described in this section, at least in theory if not in practice. The overarching purpose of a VAT is to impose a broad-based tax on consumption, which is understood to mean final consumption by households.

In principle only private individuals, as distinguished from businesses, engage in the consumption at which a VAT is targeted. In practice, however, many VAT systems impose VAT burden not only on final household consumption, but also on various entities that are involved in non-business 
activities or in VAT-exempt activities. In such situations, VAT can be viewed alternatively as treating such entities as if they were end consumers, or as "input taxing" the supplies made by such entities on the presumption that the burden of the VAT imposed will be passed on in the prices of the outputs of those non-business activities.

\subsubsection{The central design feature of a VAT-Staged collection process}

The central design feature of a VAT, and the feature from which it derives its name, is that the tax is collected through a staged process. Each business (taxable person) in the supply chain is responsible for collecting the tax on its outputs (supplies) and remitting the proportion of tax corresponding to its margin, i.e. the value added, in a particular tax period. This means that the taxable person remits the difference between the VAT imposed on its taxed outputs (output tax) and the VAT imposed on its taxed inputs (input tax) for this period. Thus, the tax is in principle collected on the "value added" at each stage of production and distribution. In this respect, the VAT differs from a retail sales tax, which taxes consumption through a single-stage levy imposed in theory only at the point of final sale.

This central design feature of the VAT, coupled with the fundamental principle that the burden of the tax should not rest on businesses, requires a mechanism for relieving businesses of the burden of the VAT they pay when they acquire goods or services. There are two principal approaches to implementing the staged collection process while relieving businesses of the VAT burden. Under the invoice-credit method, each taxable person charges VAT at the rate specified for each supply and passes to the customer an invoice showing the amount of tax charged. If the customer is also a taxable person, it will be able to credit that input tax against the output tax charged on its sales, each being identified at the transaction level, remitting the balance to the tax authorities or receiving a refund of any excess credits. Under the subtraction method, the tax is levied directly on an accounts-based measure of value added, which is determined for each business by subtracting the taxable person's allowable expenditure on inputs for the tax period from taxable outputs for that period and applying the tax rate to the resulting amount (Cockfield et al., 2013). Almost all jurisdictions that operate a VAT use the invoice-credit method, the Japanese system being the most notable example of a subtraction method consumption tax.

VAT exemptions create an important exception to the neutrality of VAT. When a supply is VAT-exempt, this means that no output tax is charged on the supply and that the supplier is not entitled to credit the related input tax. Many VAT systems apply exemptions for activities that are hard to tax (the exemption for financial services being the most notable example) and/ or to pursue distributional objectives (agricultural and fuel exemptions and 
exemptions for basic health and education are commonly encountered). One adverse consequence of VAT exemptions is that they create "cascading" when applied in a business-to-business (B2B) context. The business making an exempt supply can be expected to pass on the uncreditable input tax in the price of this supply, while this "hidden tax" can subsequently not be credited by the recipient business.

\subsubsection{VAT on cross-border transaction - The destination principle}

The fundamental policy issue in relation to the international application of the VAT is whether the levy should be imposed by the jurisdiction of origin or by the jurisdiction of destination. Under the destination principle, tax is ultimately levied only on the final consumption that occurs within the taxing jurisdiction. Under the origin principle, the tax is levied in the various jurisdictions where the value was added.

Under the destination principle, no VAT is levied on exports and the associated input tax is refunded to the exporting business (this is often called "free of VAT" or "zero-rated"), while imports are taxed on the same basis and at the same rates as domestic supplies. Accordingly, the total tax paid in relation to the supply is determined by the rules applicable in the jurisdiction of its consumption and all revenue accrues to the jurisdiction where the supply to the final consumer occurs. The application of the destination principle in VAT thus achieves neutrality in international trade, as there is no advantage in buying from a low or no-tax jurisdiction, nor do high and/ or multiple VAT rates distort the level or composition of a country's exports.

By contrast, under the origin principle each jurisdiction would levy VAT on the value created within its own borders. Under an origin-based regime, exporting jurisdictions would tax exports on the same basis and at the same rate as domestic supplies, while importing jurisdictions would give a credit against their own VAT for the hypothetical tax that would have been paid at the importing jurisdiction's own rate. This approach runs counter to the core features of a tax on consumption, in which the revenue should accrue to the jurisdiction where the final consumption takes place. Under the origin principle, these revenues are shared amongst jurisdictions where value is added. By imposing tax at the various rates applicable in the jurisdictions where value is added, the origin principle could influence the economic or geographical structure of the value chain and undermine neutrality in international trade.

For these reasons, there is widespread consensus that the destination principle, with revenue accruing to the country where final consumption occurs, is preferable to the origin principle from both a theoretical and practical standpoint. In fact, the destination principle is the international 
norm and is sanctioned by World Trade Organisation (WTO) rules. Footnote 1 of the WTO's Agreement on Subsidies and Countervailing Measures provides that "...the exemption of an exported product from duties or taxes borne by the like product when destined for domestic consumption, or the remission of such duties or taxes in amounts not in excess of those which have accrued, shall not be deemed to be a subsidy."

\subsubsection{Implementing the destination principle}

While the destination principle has been widely accepted as the basis for applying VAT to international trade, its implementation is nevertheless diverse across jurisdictions. This can lead to double taxation or unintended non-taxation and to complexity and uncertainty for businesses and tax administrations. In order to apply the destination principle, VAT systems must have a mechanism for identifying the destination of supplies. Because VAT is generally applied on a transaction-by-transaction basis, VAT systems contain "place of taxation" rules that address all transactions, building on "proxies" that indicate where the good or service supplied is expected to be used by a business in the production and distribution process (if the supply is made to a business) or consumed (if the supply is made to a final consumer).

The following paragraphs provide a concise overview of the mechanisms for identifying the destination of a supply, first looking at supplies of goods and subsequently at supplies of services.

\subsubsection{Implementing the destination principle - Goods}

The term "goods" generally means "tangible property" for VAT purposes. The VAT treatment of supplies of goods normally depends on the location of the goods at the time of the transaction and/or their location as a result of the transaction. The supply of a good is in principle subject to VAT in the jurisdiction where the good is located at the time of the transaction. When a transaction involves goods being moved from one jurisdiction to another, the exported goods are generally free of VAT in the seller's jurisdiction (and are freed of any input VAT via successive businesses' deductions of input tax), whilst the imports are subject to the same VAT as equivalent domestic goods in the purchaser's jurisdiction. The VAT on imports is generally collected from the importer at the same time as customs duties, before the goods are released from customs control, although in some jurisdictions collection is postponed until declared on the importer's next VAT return. Allowing deduction of the VAT incurred at importation in the same way as input tax deduction on a domestic supply ensures neutrality and limits distortions in relation to international trade. 
Many VAT systems apply an exemption for the importation of relatively low value goods. These exemptions are generally motivated by the consideration that the administrative costs of bringing these low value items into the customs system are likely to outweigh the revenue gained. If these additional costs would be passed on to consumers, the charges could be disproportionally high compared to the value of the goods. Most OECD countries apply such a VAT relief arrangement, with thresholds varying widely across countries.

\subsubsection{Implementing the destination principle - Services}

The VAT legislation in many countries tends to define a "service" negatively as "anything that is not otherwise defined", or to define a "supply of services" as anything other than a "supply of goods". While this generally also includes a reference to intangibles, some jurisdictions regard intangibles as a separate category. For the purposes of this section references to "services" include "intangibles" unless otherwise stated.?

A wide range of proxies can be used by VAT systems to identify the place of taxation of services, including the place of performance of the service, the place of establishment or actual location of the supplier, the residence or the actual location of the consumer, and the location of tangible property (for services connected with tangible property, such as repair services). Many systems use multiple proxies before the place of taxation is finally determined and may use different rules for inbound, outbound, wholly foreign, and wholly domestic supplies (Cockfield et al., 2013).

The application of these principles for identifying the place of taxation has become increasingly difficult as volumes of cross-border services are growing. VAT systems have considerable difficulties to determine where services are deemed to be consumed, to monitor this and to ensure collection of the tax, particularly where businesses sell services in jurisdictions where they do not have a physical presence. In practice, broadly two approaches can be distinguished for applying VAT to cross-border supplies of services (Ebrill et al., 2001):

- The first approach focuses on the jurisdiction where the customer is resident (established, located). Under this approach, when the customer is resident in another jurisdiction than the supplier, the supply is free of VAT ("zero-rated") in the jurisdiction of the supplier and is subject to VAT in the jurisdiction of the customer. In principle, the supplier needs to register in the customer's jurisdiction and collect and remit the tax there. In practice, when the customer is a VAT-registered business, the VAT is often collected through a "reverse charge" mechanism. This is a tax mechanism that switches the liability to pay the tax from the supplier to the customer. The 
business customer will generally be able to credit the input tax on the acquired service immediately against the output tax liability. Some VAT systems therefore do not require the reverse charge to be made if the customer is entitled to a full input tax credit in respect of the purchase.

- Under the second approach, the supply of the service is subjected to VAT in the jurisdiction where the supplier is resident (established, located). Supplies of services are then subject to VAT in the supplier's jurisdiction, even when they are performed abroad or supplied to foreign customers. Customers that are taxable businesses are generally able to apply for a refund of the VAT paid on business inputs in the supplier's jurisdiction, from the tax authorities of that jurisdiction.

For B2B supplies, both approaches have ultimately the same effect, in that "exported" services are relieved from any VAT burden in the origin country and subject to VAT in the jurisdiction where the service is deemed to be used by the business customer. The first approach, which identifies the place of taxation by reference to the location of the customer, is recommended as the main rule for applying VAT to B2B supplies of services by the OECD's International VAT/GST Guidelines (OECD, 2014). It was also the recommended approach for "cross-border supplies of services and intangibles that are capable of delivery from a remote location" under the OECD's 2003 E-commerce Guidelines (OECD, 2003a). A key advantage of this approach is that it avoids the need for cross-border refunds of VAT to businesses that have acquired services abroad, which often involve considerable administrative and compliance burden and costs for tax administrations and businesses. In practice, however, many VAT systems apply the second approach, taxing services by reference to the location of the supplier, mainly to minimise the risk of fraud through claims of exported services which are typically difficult to verify.

Whereas both approaches lead to a result that is consistent with the destination principle in a $\mathrm{B} 2 \mathrm{~B}$ context, the situation is more complicated for business-to-consumer (B2C) supplies. Implementing the destination principle by zero-rating cross-border supplies to non-resident final consumers and relying on self-assessment by the consumer in its jurisdiction of residence, is likely to result in widespread non-taxation of these supplies in practice. While reverse charge methods operate relatively well in a B2B context, they are generally viewed as ineffectual for B2C supplies. Such a method would require final consumers to self-assess their VAT liability on services purchased abroad, e.g. through their income tax returns. The level of voluntary compliance can be expected to be low, as private consumers have no incentive to voluntarily declare and pay the tax due, unlike taxable persons who can credit input tax paid against output tax (Lamensch, 2012). Collecting 
and enforcing this VAT, which may be small amounts in many cases, from large numbers of people is likely to involve considerable complexity and costs for tax payers and tax authorities.

Most VAT systems therefore tax supplies of services to private consumers in the jurisdiction where the supplier is resident (established, located). Many jurisdictions that zero-rate cross-border supplies of services to non-resident customers, limit the application of this regime to B2B supplies, notably by applying it only to services that are typically supplied to businesses (advertising, consultancy, etc.) Supplies to foreign private consumers are then subject to VAT in the supplier's jurisdiction while services acquired from abroad by resident final consumers are not subject to VAT in the consumer's jurisdiction. While this approach, which effectively results in origin taxation, is likely to be less vulnerable to fraud, it may create an incentive for suppliers to divert their activities to jurisdictions where no or a low VAT is applied and to sell remote services into foreign markets VAT-free or at a low VAT rate. This potential distortion and the associated revenue losses become increasingly significant as volumes of cross-border supplies of services keep growing.

More and more jurisdictions therefore consider ways to implement a destination based approach for both $\mathrm{B} 2 \mathrm{~B}$ and $\mathrm{B} 2 \mathrm{C}$ cross-border supplies of services, thereby relying on a system that would require suppliers to collect and remit the tax in line with what was recommended by the OECD's E-commerce Guidelines (OECD, 2003a). As self-assessment methods are unlikely to offer an effective solution for collecting the tax at destination in a B2C-context, a system that requires suppliers to collect and remit the tax may appear the only realistic alternative. This was notably the conclusion of the OECD's Consumption Tax Guidance Series, which provided guidance for the implementation of the E-commerce Guidelines (OECD, 2003b-c-d). This guidance indicated that countries may consider it necessary for nonresident vendors to register and account for the tax in the jurisdiction of consumption, and it recommended the use of simplified registration regimes and registration thresholds to minimise the potential compliance burden. The most notable application of a destination-based approach for taxing B2C cross-border supplies of services relying on a simplified registration system for non-resident suppliers, is the European Union's "One Stop Shop" scheme. 


\section{Notes}

1. This global approach is generally co-ordinated with specific tax regimes applying to items of income derived from specific types of assets (e.g. participation shares, patents and trademarks).

2. Noteworthy, at the time the study was performed most of the industrialised countries had not yet introduced in their domestic legislation a modern corporate income tax system integrated with personal income taxes.

3. Professional earnings were considered separately, unless the concerned activity gives rise to a branch in another country, in which case the occupation becomes a commercial enterprise and, according to the economist, ought to fall under the same allocation rule as other businesses.

4. The predominant argument put forward by the economists to reach a conclusion (i.e. exclusive taxation in the state of residence) was convenience and practicability.

5. OECD Commentaries on Art. 7, par. 11; see also in relation to service activities, Commentaries on Art.5, par. 42.11.

6. These limitations on withholding at source generally do not apply, however, to excessive payments of interest or royalties to related parties. For instance, paragraph 6 of Article 11 of the OECD Model Convention provides that, if there is a special relationship between the payer and the recipient as a result of which the interest is higher than that which they would have agreed upon in the absence of such a relationship, the excess part remains taxable according to the laws of both the source state and the residence state. Similar rules apply with respect to excessive royalties under paragraph 4 of Article 12 of the OECD Model Tax Convention.

7. Many VAT systems define a "service" negatively as "anything that is not otherwise defined", or a "supply of services" as anything other than a "supply of goods". While this generally also includes a reference to intangibles, some jurisdictions regard intangibles as a separate category, and this is explicitly recognised in this report where relevant. It should be noted that the term 'intangibles' when used for transfer pricing and direct tax purposes has a different meaning than that used under certain VAT legislations. 


\section{Bibliography}

Alessi, A., J. de Goede and W. Wijnen (2011), "The Treatment of Services in Tax Treaties", Bulletin for International Taxation, 2012, Vol. 66, No. 1.

Ault, H.J. (1992), “Corporate Integration, Tax Treaties and the Division of the International Tax Base: Principles and Practice”, 47 Tax L. Review, p. 567.

Avi-Yonah, R.S. (1996), “The Structure of International Taxation: A Proposal for Simplification”, 74 Tax L. Review, p. 1301.

Beale, J.H (1935), A Treatise on the Conflict of Laws, Vol. 1, p. 275.

Bird, R.M. (2002), "Why Tax Corporations?” Bulletin for International Tax, Vol. 56, No. 5, IBFD, Amsterdam.

Bruins et al. (1923), Report on Double Taxation submitted to the Financial Committee, No. E.F.S. 73.F.19, League of Nations, Geneva.

Cockfield, A. et al. (2013), Taxing Global Digital Commerce, Kluwer Law International BV, the Netherlands.

Ebrill.L. et al. (2001), The Modern VAT, International Monetary Fund, Washington, DC.

Hellerstein, W. (2009), "Jurisdiction to Impose and Enforce Income and Consumption Taxes: Towards a Unified Conception of Nexus in Value Added Tax and Direct Tax: Similarities and Differences", IBFD, the Netherlands.

Holmes, K. (2007), International Tax Policy and Double Tax Treaties, IBFD Publications, the Netherlands.

Lamensch, M. (2012), “Are 'reverse charging' and the 'one shop scheme' efficient ways to collect VAT on digital supplies?" in World Journal of VAT Law, Vol 1, Isssue 1.

OECD (2014), International VAT/GST Guidelines, OECD, Paris.

OECD (2013), Revenue Statistics 1965-2012, OECD Publishing, Paris, http:// dx.doi.org/10.1787/rev_stats-2013-en-fr.

OECD (2012), Model Tax Convention on Income and Capital 2010 (updated 2010), OECD Publishing, Paris, http://dx.doi.org/10.1787/9789264175181-en.

OECD (2011), "Taxing Consumption" in Consumption Tax Trends 2010: VAT/GST and Excise Rates, Trends and Administration Issues, OECD Publishing, Paris, http://dx.doi.org/10.1787/ctt-2010-en 
OECD (2003a), Consumption Taxation of Cross Border Services and Intangible Property in the context of E-commerce, Guidelines on the Definition of Place of Consumption, OECD, Paris.

OECD (2003b), Electronic Commerce-Commentary on Place of Consumption for Business to Business Supplies (Business Presence), OECD, Paris.

OECD (2003c), Electronic Commerce-Simplified Registration Guidance, OECD, Paris.

OECD (2003d), Verification of Customer Status and Jurisdiction, OECD, Paris.

OECD (2001), Taxation and Electronic Commerce-Implementing the Ottawa Framework Conditions, OECD Publishing, Paris, http://dx.doi. org/10.1787/9789264189799-en.

Pinto, D. (2006), "The Need to Reconceptualise the Permanent Establishment Threshold", Bulletin for International Taxation. IBFD pp. 266-279.

Rohatgi, R. (2005), Basic International Taxation, Volume I: Principles, Second Edition, Richmond Law and Tax Ltd, United Kingdom.

Tadmore, N. (2007), "Source Taxation of Cross-Border Intellectual SuppliesConcepts, History and Evolution into the Digital Age", Bulletin for International Taxation, pp. 2-16.

Vann, R.J. (2010), “Taxing International Business Income: Hard-Boiled Wonderland and the End of the World", World Tax Journal, Vol. 2, No. 3.

Vogel, K. (1988), "Worldwide vs. source taxation of income - A review and re-evaluation of arguments (Part 3)", Intertax, Vol. 11, pp. 393-402.

Schon, W. (2010), "Persons and territories: on international allocation of taxing rights", British Tax Review, pp. 554-562.

Skaar, A.A. (1991), Permanent Establishment, Erosion of a Tax Treaty Principle, Series on International Taxation, Kluwer Law and Taxation Publishers, The Netherlands. 


\section{Chapter 3}

\section{Information and communication technology and its impact on the economy}

This chapter examines the evolution over time of information and communication technology (ICT), including emerging and possible future developments. It then provides a conceptual overview, highlighting interactions between various layers of information and communication technology.

The statistical data for Israel are supplied by and under the responsibility of the relevant Israeli authorities. The use of such data by the OECD is without prejudice to the status of the Golan Heights, East Jerusalem and Israeli settlements in the West Bank under the terms of international law. 


\subsection{The evolution of information and communication technology}

The development of ICT has been characterised by rapid technological progress that has brought prices of ICT products down rapidly, ensuring that technology can be applied throughout the economy at low cost. In many cases, the drop in prices caused by advances in technology and the pressure for constant innovation have been bolstered by a constant cycle of commoditisation that has affected many of the key technologies that have led to the growth of the digital economy. As products become successful and reach a greater market, their features have a tendency to solidify, making it more difficult for original producers to change those features easily. When features become more stable, it becomes easier for products to be copied by competitors. This is stimulated further by the process of standardisation that is characteristic of the ICT sector, which makes components interoperable, making it more difficult for individual producers to distinguish their products from others. Unless the original producer can differentiate its product from the copies (for example, by bundling its product with services or other features that are not easily duplicated), or otherwise find a way to maintain a dominant position in the market, it will be forced to compete solely on price or move to other market segments.

This process tends to cause prices of the commoditised goods or services to fall, and innovation to move elsewhere in the value chain. This does not necessarily mean that every single component of the commoditised product becomes a commodity. A producer of a component of the overall product can maintain or create a proprietary advantage by enhancing some elements or subsystems of that component. This can "decommoditise" those elements or subsystems of the commoditised product, creating new opportunities at a different stage of the value chain.

\subsubsection{Personal computing devices}

Early in the life of the digital economy, many manufacturers of computing hardware used proprietary hardware components, which meant that the computers of different manufacturers operated on entirely different standards. When the architecture of personal computers was largely standardised thirty years ago, however, many market participants started competing on price. That, combined with rapid technological progress, resulted in substantial drops in the price of personal computing hardware. In the period that followed, the most successful manufacturers succeeded in large part because their products integrated best with other products or because they developed the strongest marketing and distribution strategies, rather than primarily because the hardware they produced was distinguishable from those of their competitors. As mentioned above, this cycle has been paralleled at various 
points throughout the evolution of the digital economy, resulting in substantial changes in the digital value chain over time.

A relatively recent development is the advent of innovative integrated packages of hardware and software, such as smartphones and tablets (and increasingly, connected wearable devices). Designing, manufacturing and selling these devices has allowed companies to improve their position in the value chain and on the market. There appear to be two major trends that confirm the growing importance of devices. The first trend is the diversification of devices. Consumers initially accessed the Internet almost exclusively through personal computers. Now the industry has designed a wide variety of devices providing access to the web, such as smartphones, tablets, and connected TVs. The second trend is the growing specialisation in devices of businesses formerly specialised in software or other parts of the value chain. Several businesses have launched their own tablets or other devices. These devices allow them to establish a closer relationship with their customers, allowing them to collect more detailed information so that they may provide customised service with even more relevance and added value.

Over time, hardware devices have both multiplied and diversified in terms of features and technical characteristics. As shown in Figure 3.1, the number of mobile devices connected to the Internet keeps rising, forming an interconnected infrastructure colloquially referred to as the Internet of Things (see section 3.2 on discussion of emerging and potential future developments below). After a long period of personal computer commoditisation, hardware has regained

Figure 3.1. Total fixed, mobile and broadband access paths subscriptions (millions)

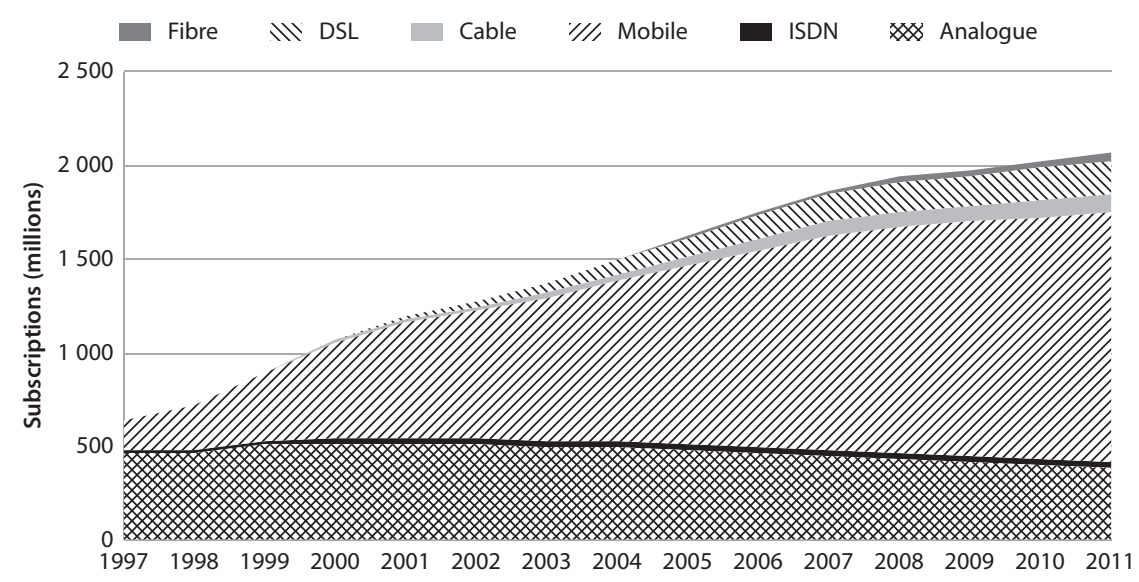

Source: OECD (2013a), OECD Communications Outlook 2013, OECD Publishing, Paris, http://dx.doi.org/10.1787/comms_outlook-2013-en. 
importance in the value chain. At the same time, the price of devices continues to fall over time. Devices connected through the Internet operate within certain standards that accelerate their commoditisation, if only because individuals own more and more devices that must be synchronised around the same set of content and data. In addition, connected objects and devices facilitate sales of intangible goods and services (for example, a connected car becomes a point of sale for services based on geo-location, including driving assistance). For this reason, a number of businesses now use hardware devices as loss leaders in their business model, aimed at expanding the market of customers for goods and services available through those devices, or at otherwise leveraging their growing network of end users. Assuming these trends continue, it appears that for many businesses, revenue from connected devices may ultimately flow primarily from the operation rather than the continued sales of these devices.

\subsubsection{Telecommunications networks}

As the Internet turned into a major business phenomenon and adoption rates accelerated, the network component providers, infrastructure intermediaries, and Internet service providers (ISPs) that powered and operated the infrastructure of the telecommunications networks that form the Internet became central to the digital economy. The interconnection of networks initially gave birth to a specific economy organised around the status of such infrastructure providers as the primary points of contact with the ultimate end users, through peering points, data centres, and the data routes that form the Internet backbone.

The strength of ISPs, however, has traditionally been primarily in providing network access rather than in providing services across these networks. As a result, unless the ISPs could leverage their control of access to telecommunications networks, they had difficulty maintaining their status as the sole access point to the end user against competition from third-party businesses that provided content and services directly to users over the Internet. The providers of this content (sometimes called over-the-top (OTT) content), were able to deliver services more responsive to demand. Thus, while ISPs remain privileged points of contact with end users and have in general been able to maintain high profit margins, leveraging control of network access was not possible in most cases because ISPs were generally operating in increasingly competitive markets due to sector regulation and were essentially local in their reach (although some ISPs operated across borders, and many, such as mobile network providers, still do).

In contrast, OTT content providers could offer an unified experience to users at scale, since their reach was global, unlike network providers whose reach was limited to the length of their network. As a result, providers of OTT content increasingly took on a direct relationship with the end users. 
The development of open source software accelerated the pace of innovation on top of the networks. As a consequence, while the success of OTT content providers has increased aggregate demand for networks, in markets where there is sufficient competition, prices have declined. While a compelling hardware device or new network service can still give a particular firm a short term lead and introduce new business models (such as "app stores", for example), experience has shown that no single player in the value chain can entirely control access to customers as long as there is sufficient competition.

\subsubsection{Software}

The World Wide Web, initially made of websites and webpages, marked the emergence of Internet-powered software applications. Software has therefore been regarded from the beginning as an important component of the value chain. Even some software, however, is becoming commoditised. This commoditisation has, once again, been driven by standards, starting with those of the Internet: the Hypertext Transfer Protocol (HTTP), the Hypertext Markup Language (HTML) and later Extensible Markup Language (XML) data formats, email exchange protocols such as Simple Mail Transfer Protocol (SMTP), Post Office Protocol (POP), and Internet Message Access Protocol (IMAP). On top of these standards, communities of open source developers needed to accelerate the speed to market and constantly iterate newer versions of their software. In order to innovate at this pace, they chose to share their source code rather than redevelop it. Although some major software vendors have countered the process of commoditisation with innovation and differentiation, large-scale differentiation and advanced positions have become increasingly difficult to sustain.

As growing competition in the development of operating systems, databases, web servers, and browsers reduced profits in many companies' core business, it also created new opportunities. Just as commoditisation in the hardware market cut profit margins for traditional manufacturers while creating new opportunities for low-cost low-margin manufacturers, growing competition in the software market has forced software companies to become more creative and more responsive to consumers' needs, all of which benefited the consumer.

\subsubsection{Content}

Content gained attention at the end of the 1990s, when content production, consumption and, above all, indexation appeared to drive the digital economy's growth. It saw the rise of first content portals and then search engines as the main gatekeepers to accessible content on the Internet. Today, many major players in the digital economy are content providers. 
The definition of content in that regard is quite large: it includes both copyrighted content produced by professionals, enterprise-generated content, and non-copyrighted user-generated content (such as consumer reviews or comments in online forums). The importance of content flows from the fact that it is important to attract an audience and provoke interactions between users. In addition, more content updated more frequently increases a website's visibility in search results. Content has hence been a driving force behind the advertising industry: it has become a key asset to attract an audience and monetise it with advertisers. Content has also become a way to advertise in and of itself, with classification into three categories: owned content (content distributed by the brand on its own channels), paid content (content distributed by other media in exchange of a payment by the brand), and earned content (content willingly created and shared by customers without direct payment by the brand, such as customer product reviews, videos, and social media sharing).

Content is more and more often produced by users, resulting in greater volumes of content. The success of sites predicated on massive online collaboration by users, such as Wikipedia and YouTube, has proven that an entire experience can be built around content primarily generated by individual users. Further, the emergence of the social networking phenomenon, and the success of major applications in which links and interactions between users matter more than any primary content put forward to attract an audience show the same path. Even advertising relies increasingly on user-generated content, through the concept of earned content, one of the pillars of content marketing. The sophistication of techniques designed to customise services, including cookies (technical tools used by businesses to collect user data, notably for commercial purposes such as behavioural advertising), targeting and retargeting, and collaborative filtering, is also relevant. The amount of content available online has become so vast that relatively few businesses have succeeded online by offering premium content, unless they can leverage that content through a service that prevents competition on volume.

\subsubsection{Use of data}

Users of applications provide businesses with access to substantial amounts of data, which are often personal and are used in a variety of ways that continue to be developed. ${ }^{1}$ Collected data can be used not only to customise the experience, but also to generate productivity and quality gain at scale, through controlled experimentation. Personal data is acquired in multiple ways; it can be: provided voluntarily by users (for example, when registering for an online service); observed (for example, by recording Internet browsing activities, location data, etc.), or inferred (for example, based on analysis of online activities). The chart below, which is non-exhaustive, provides illustrations of the ways in which data is collected, stored, analysed, and used. Capacity to 
collect useful data is increasing as the number of Internet-connected devices increases. Businesses of all sorts make use of user data, as it allows them to tailor their offerings to customers. As increasing amounts of potentially useful data are collected, more and more sophisticated techniques must be developed in order to collect, usefully process and analyse that data.

Figure 3.2. Personal data

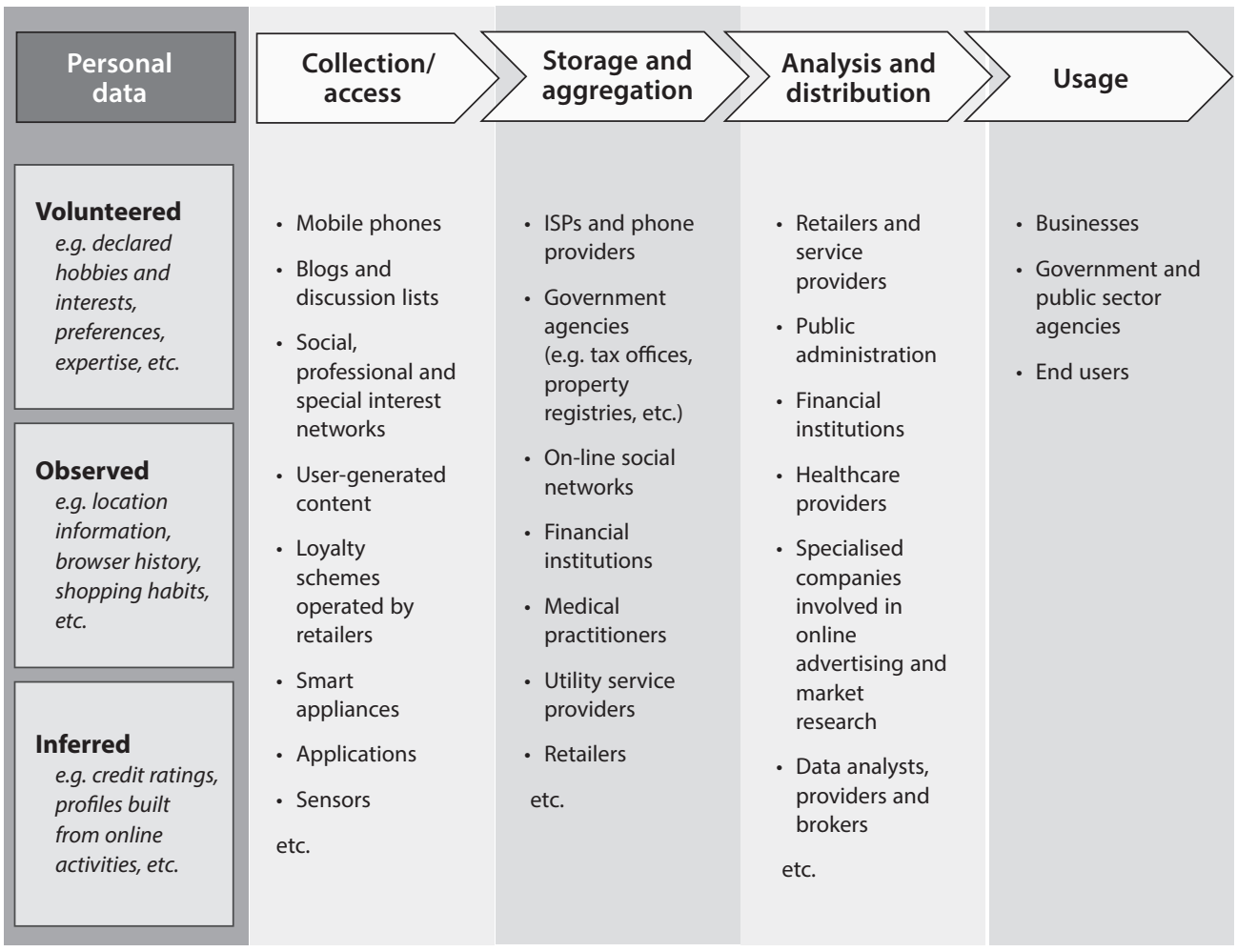

Source: OECD, based on World Economic Forum (2011), Personal Data: The Emergence of a New Asset Class. www3.weforum.org/docs/WEF_ITTC_PersonalDataNewAsset_Report_2011.pdf.

\subsubsection{Cloud-based processes}

As a result of the standardisation and commoditisation of different individual resources, such as hardware, network infrastructure, and software, some businesses have been able to combine those resources and make them available through the Internet as services. 
Centralised hosting of software resources dates back to the 1960s, when mainframe providers conducted a service bureau business, also referred to as time-sharing or utility computing. Such services included offering computing power and database storage to banks and other large organisations from their worldwide data centres. Cloud computing at scale is the result of several trends related to both technology and business models: growing availability of highcapacity networks, low-cost computers and storage devices as well as the widespread adoption of hardware virtualisation, service-oriented architecture, and utility computing. As a result, value has migrated to new proprietary applications that are not stand-alone software products, but Internet-based applications that combine executable code, dynamically updated databases, and user participation. Although the term "cloud computing" has become commonplace, these applications have also at various points been referred to as "infoware", "computing on demand" or "pervasive computing".

The X-as-a Service (XaaS) acronym has been introduced to refer to the trending transformation of software products from goods to services. The Internet essentially accelerated a transition from traditional software business to XaaS models. A website is essentially a software application providing a service delivered over the Internet rather than provided locally or on-site. The service can be about providing access to content (as a portal), or about providing access to executable code performing certain features. Thus the expansion of the Internet brought a new class of centralised computing providers, called application service providers (ASP). ASPs provided businesses with the service of hosting and managing specialised business applications, with the goal of reducing costs through central administration and through the ASP's specialisation in a particular business application.

As of today, many business-to-consumer (B2C) applications are also delivered as software as a service: search engines, social networking applications are mainly used through a web browser, without any need to download any executable code beforehand. Although applications continue to be downloaded and installed locally, this is done primarily when there is a frequent need to use them offline. Even some locally-installed applications, however, require an Internet connection to provide full functionality. The growing popularity of smart phones and other devices that use frequently interrupted mobile Internet connections, however, has made downloading applications prominent again.

Focusing on value created through cloud-based processes is particularly useful to analyse the ultimate development of the Internet of Things (discussed below), which refers to the Internet as a network connecting individuals, content, and things in everyday lives. At the centre of this complex network of interconnections are powerful software-powered processes whose resources can only be stored and executed in the cloud. 


\subsection{Emerging and potential future developments}

The rapid technological progress that has characterised the development of ICT has led to a number of emerging trends and potential developments that may prove influential in the near future. Although this rapid change makes it difficult to predict future developments with any degree of reliability, these potential developments are discussed below.

\subsubsection{Internet of Things}

The number of devices connected to the Internet is expanding rapidly, but substantial room for expansion remains. While Cisco has estimated that between 10 and 15 billion devices are currently connected to the Internet, that figure represents less than $1 \%$ of the total devices and things that could ultimately be connected (Evans, 2012). Within the area of the Organisation for Economic Co-operation and Development (OECD), households alone currently have approximately 1.8 billion connected devices. This figure could reach as many as 5.8 billion by 2017, and as many as 14 billion by 2022 (OECD, 2013a). As increasing numbers of connected devices are developed and sold, the expansion of machine-to-machine communication appears likely to dramatically expand and improve the ability of businesses to collect and analyse relevant data.

A major feature of the Internet of Things is the widened ability to collect and share data through powerful information systems connected to a multitude of devices, censors, and cloud computing components. The analysis and use of the data collected and transmitted by connected devices can help individuals and organisations use their resources more accurately, make informed purchasing decisions, ramp up productivity, and respond faster to changing environments. As devices increasingly transmit more detailed data, the processing of this data can be used automatically to change the behaviour of those devices in real time. It can also make training workers for skilled positions an easier and more cost-effective process. This trend, so far primarily contained in data-intensive industries such as finance, advertising, or entertainment, is likely to penetrate more traditional industries in the future.

\subsubsection{Virtual currencies}

Recent years have been marked by the appearance and development of "virtual currencies", meaning digital units of exchange that are not backed by government-issued legal tender. These currencies have taken various forms. Some virtual currencies are specific to a single virtual economy, such as an online game, where they are used to purchase in-game assets and services. In 
some cases, these economy-specific virtual currencies can be exchanged for real currencies or used to purchase real goods and services, through exchanges which may be operated by the creators of the game or by third parties.

Other virtual currencies were developed primarily to allow the purchase of real goods and services. The most prominent example of this type are the various "cryptocurrencies", including in particular bitcoins, which rely on cryptography and peer-to-peer verification to secure and verify transactions. Many private operators have chosen to accept payment in bitcoins.

\section{Figure 3.3. How bitcoins enter circulation and are used in transactions}

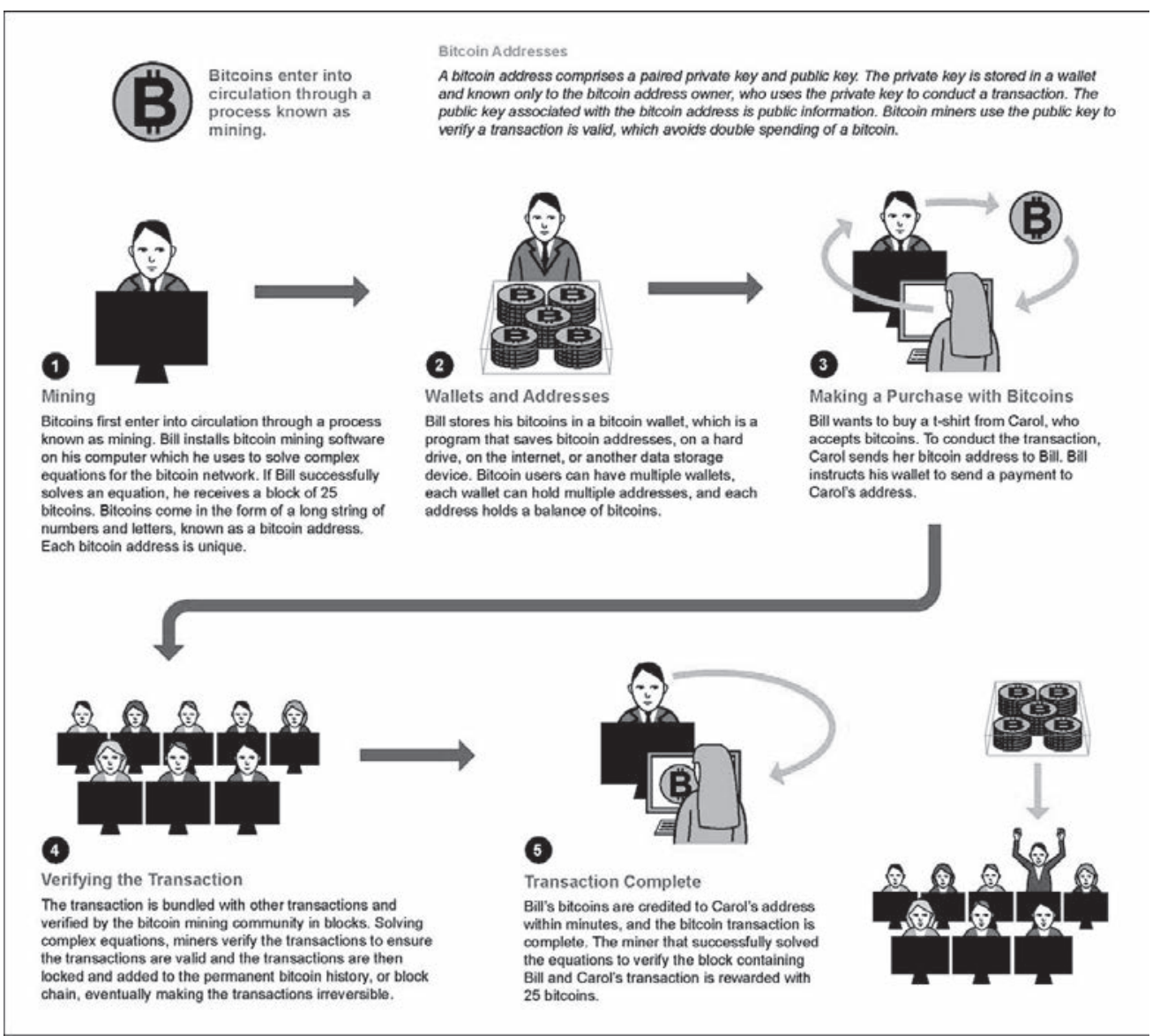

Source: U.S. Government Accountability Office (2013), Virtual Economies and Currencies, Report to the Committee on Finance, U.S Senate. 
As virtual currencies increasingly acquire real economic value, they raise substantial policy issues. Some of these stem from the anonymous nature of transactions. In the case of bitcoins, for example, transactions can be made on an entirely anonymous basis, since no personally identifying information is required to be provided to acquire or transact in bitcoins.

\subsubsection{Advanced robotics}

The development of new connected and smart robots is changing manufacturing profoundly. The increased productivity of new automated factories is already making it possible for some multinational enterprises that had previously moved manufacturing offshore to take advantage of lower labour costs to consider moving their manufacturing activities back to where most of their customers are.

Manufacturing will be further changed by the progress in robotics, as robots have the potential to make factories less labour intensive and force multinational enterprises to think about production and distribution at the same time. This trend has the potential to be felt particularly strongly in already machine-intensive industries, as automation increasingly centres on artificial cognition, sensors, machine learning, and distributed smart networks. It will also have a potential impact where automation has been scarce so far, especially in small factories and workshops, because software can help improve security and allow humans to work alongside automated systems. Also, as robots embed more software and are connected to cloudbased resources, it will become both easier and cheaper to programme them, which could lead to lowered prices, making them more accessible to small and middle-size operations. These lower costs have the potential to bring manufacturing activities increasingly closer to the customers.

In the future, progress in artificial intelligence and the emergence of cognitive computing may expand the influence of robots beyond the manufacturing sector and into broader segments of the economy, as well as into household applications such as assisting the elderly or disabled with manual tasks. As robots learn to do jobs that previously were solely done by humans, they can potentially generate productivity, help lower prices for customers, contribute to scaling up operations at a global level, and create innovation opportunities which will lead to the emergence of new activities that will require new skills and potentially create new jobs.

\subsubsection{D Printing}

Advances in $3 \mathrm{D}$ printing have the potential to enable manufacturing closer to the customer, with direct interaction with consumers impacting the design of product features. As a result, manufacturing could gradually move 
away from mass production of standardised products, and instead focus on shorter product lifecycle by adopting a strategy of constant experimentation at scale. In the healthcare industry, 3D printing of custom health products such as hearing aid earpieces is already heavily used. In addition, 3D printing has the potential to reduce environmental impact relative to traditional manufacturing, by reducing the number of steps involved in production, transportation, assembly, and distribution, and can reduce the amount of material wasted as well (Manika, 2013). Beyond that, it is conceivable that some manufacturers could eventually transition away from assembling products themselves, and could instead license plans and specifications to third party manufacturers or even retailers who will "print" the products on demand, closer to the customers, but at their own risks and with a very low margin. Alternatively, consumers may be able to assemble products themselves by using 3D printers, further increasing the possibility of locating business activities at a location that is physically remote from the ultimate customer.

\subsubsection{The sharing economy}

The sharing economy, or collaborative consumption, is another potentially significant trend within the digital economy. The "sharing economy" refers to peer-to-peer sharing of goods and services. The sharing economy is not new, but advances in technology have reduced transaction costs, increased availability of information, and provided greater reliability and security. Recent years have seen the emergence of numerous innovative sharing applications using different business models and focusing on one particular service or product, such as cars, spare rooms, food, or clothes. Most individuals who participate in the sharing economy do not do so mainly to make a living, but to entertain relationships with others, to serve a cause that inspires them, or simply to make ends meet. Because the supplementary income is a net benefit and often does not involve much quantitative costbenefit analysis, amateur providers have a tendency to share their available resources at a lower price than what a professional might have billed, thus bringing down overall prices, including those of the professionals. Through time, as certain platforms attract substantial number of individuals, these platforms become the prime access point for customers on the online market and have the potential to provide substantial competition for traditional e-commerce applications operated by professionals, which may cut their profit margins further. 


\subsubsection{Access to government data}

Governments are making progress at making machine-readable resources, notably data, publicly available in what has been alternatively labelled as open data policy, open government or government as a platform. There are three main goals assigned to open government policies:

- Accountability: Making government resources available allows the public to have direct access to these resources in order to track, document, and evaluate public policy cost, efficiency, and effectiveness. When it comes to accountability, open government strategies are meant to providing tools for transparency and to improving democracy as a whole.

- Better performance: Opening government resources also is intended to provide the means for government agencies to better co-operate with one using cross-agency software applications.

- Participation of third parties in government business: When government resources are made available to others outside government, third parties can combine these resources with their own to create hybrid applications that allow better and more personalised service.

\subsubsection{Reinforced protection of personal data}

Under most legal systems, personal data supplied by users is protected by privacy rules and remains the property of those users. Personal data is regarded as an asset owned by the individual to whom it relates, such that it is considered their choice, rather than that of the organisation that holds it, to use, exchange, or make this information available. Data protection rules usually specify what constitutes personal data, how it is gathered, the standards companies must follow with respect to secure storage and the requirement to notify individuals of the personal data held and their rights of access to it. In many countries, rules require adequate data security provisions in regard to transfer of personal data to third countries. Compliance costs are usually borne by the public authorities, companies and other organisations that collect data from individuals.

As individuals become more sensitive to the use of their personal data and expect their privacy to be protected, discussions are ongoing in a number of countries to strengthen applicable laws and regulate data collection and exploitation by organisations (OECD, 2012, 2013b). Increasingly, these rules are imposing requirements as to how and where data is stored and processed. As exemplified by the bills currently discussed in the European Union, and in several countries, this trend could lead to a significant change in business models that rely on the use of personal data. For example, the 
obligation to make sure an individual has expressed consent for the collection of anonymous data, notably in cookies, could affect the user experience while surfing on web pages and make it more difficult to target or retarget advertising banners or clicks.

\subsection{The interactions between various layers of information and communication technology (ICT): a conceptual overview}

One way to picture the ICT sector is to focus on interactions between different layers, each characterised by a mix of both hardware and software. This approach is illustrated in Figure 3.4.

Figure 3.4. A layered view of ICT

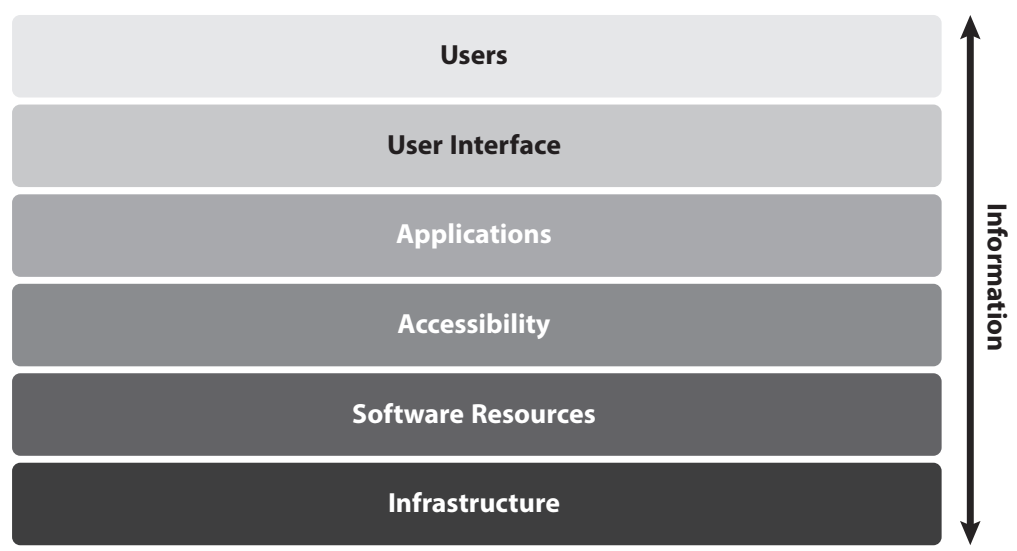

At the base lies the infrastructure of the Internet, which consists of the cables, tubes, routers, switches, and data centres that are designed and manufactured by firms specialised in network interconnection, and operated by ISPs, carriers, and network operators. Content delivery network operators, whose goal is to serve content to end users with high availability and high performance, pay ISPs, carriers, and network operators for hosting servers in their data centres. Internet protocol (IP) addresses and domain names are managed at this level.

Immediately above, stored in servers that are located in data centres and organisations all around the world, are the core software resources that enable organisations to create applications, which can consist of raw data, digital content, or executable code. These can include both resources produced by organisations and resources derived from individual users and collected and stored by organisations for later use. 
On top of these core resources is a layer of tools providing the fundamental accessibility necessary to allow software resources to be combined on top of the infrastructure to create applications usable by individual or business end users. This layer effectively provides the structure necessary for software applications to take advantage of the underlying infrastructure and core software resources of the Internet. This accessibility can be provided in many forms. An operating system that makes it possible to run applications on digital devices, for example, is one of the most familiar ways in which accessibility is provided: it allows a developer to design an application to be run on a certain device. The core higher-level protocols that allow communication of data between applications, such as the Hypertext Transfer Protocol (HTTP) that forms the foundation of data communication on the World Wide Web, or the SMTP that provides a standard for email transmission, are another form of accessibility. Other ways to provide accessibility include web services, application programming interfaces (API), and software development kits (SDKs), all of which provide ways for applications usable by end users to connect with the resources necessary to connect to underlying resources.

The accessibility layer effectively provides platforms for the creation of applications that are usable by end users, and that are able to access the core software resources on top of the infrastructure. Those applications form the fourth layer of the digital economy. An application is a combination of software resources creating value for the end user through the provision of goods or services. Applications can fit together or link to one another: for instance, a web browser is an application, and it gives access to websites that are themselves web-based applications; an app store is also an application with a value proposal that is to allow users to discover and purchase other applications. Within the application layer are applications performing a gatekeeping function, retaining user information and allowing it to be combined with other resources only when necessary and with the express consent of the end user. These gatekeeping activities include authentication of users, payment, and geolocation, all of which involve collection and use of data so sensitive that a certain level of trust is required between the organisation and the user.

The next conceptual layer is the machine-to-human interface layer. An interface represents the user experience. The interface is displayed through a physical point of contact that can be either a device or a whole place (such as a store). Devices are of two kinds: they are generic when they support many applications; they are non-generic when only one application can run on them. For instance, a computer, a smartphone or a tablet are generic devices. A connected thermostat is a non-generic device. Certain devices, like connected cars, were generally non-generic in the early stages of their development, but become progressively more generic as they are equipped with more accessibility features (such as an operating system). 
At the top of the chart, above the layers of functions, sit the users, who can be either individuals acting in their personal capacity or on behalf of a business. These individuals interact directly with the interface layer to access applications, either directly or through the services of another application acting as a gatekeeper.

Each layer is provided with hardware resources, software resources, and network connectivity. Resources can be stored at multiple levels: in data centres at the infrastructure level; in virtual servers located in the cloud; and on user devices (a computer or a tablet for instance). The business relationships between the layers are generally relationships between clients and providers: a company that operates a business in only one layer is generally paid by a company operating a business in the layer above. For instance, cloud computing operators that provide accessibility make payments to infrastructure operators and are paid by application developers. A company operating at the top layer derives payments directly from its interactions with end users, either by charging them money or through generation of value that can then be monetised by the company to derive income from another customer or business. The organisations that are paid at the top level are those operating connected devices, gate-keeping activities or an application that is tethered neither to a device nor to a gate-keeping capacity.

In general terms, several business models in the digital economy can be described in terms of vertical integration between layers. For example, traditional web businesses use software resources (layer 2) and rely on open protocols (like HTTP) (layer 3) to combine those resources into a web application (layer 4). They pay operators of the bottom layer to put their application on line, and their interactions with users generate revenue either directly from the user in the form of payment (which can be received directly or through a gatekeeping operator), or indirectly through the generation of value that can then be monetised elsewhere in the business model.

These interactions explain why some companies consider it critical to operate at the top, especially by providing applications performing gatekeeping functions. In fact gatekeepers are able to collect data from their users, analyse them and eventually make them available for developers to power even more applications (and collect even more data), or market them to other companies (advertising). This also explains the creation of large ecosystems based on a dominant position in the market of gatekeeping, accessibility and sometimes the operation of devices. 


\section{Note}

1. User sensitivity has triggered waves of protest against certain features, practices or terms of service carried out by some companies with respect to personal data. In reaction, companies have often rolled back the features and even set up new ones to help their users control and protect their private information. It is worth noting as well that the collection and use of personal data is a closely regulated area across the OECD, with most legislation tracking the main elements of the OECD Privacy Guidelines.

\section{Bibliography}

Evan, D. (2012), The Internet of Everything How more Relevant and Valuable Connections Will Change the World, Cisco IBSG.

Manika J. et al. (2013), Disruptive technologies: Advances that will transform life, business and the global economy, McKinsey Global Institute.

OECD (2013a), OECD Communications Outlook 2013, OECD Publishing, Paris, http://dx.doi.org/10.1787/comms_outlook-2013-en.

OECD (2013b), "Protecting and Empowering Consumers in the Purchase of Digital Content Products", OECD Digital Economy Papers, No. 219, OECD Publishing, Paris. http://dx.doi.org/10.1787/5k49czlc7wd3-en.

OECD (2012), "Report on Consumer Protection in Online and Mobile Payments", OECD Digital Economy papers, No. 2014, OECD Publishing, Paris. http://dx.doi.org/10.1787/5k9490gwp7f3-en.

Rosenstock, E. (n.d), "Paid, Owned, Earned Media Model will Disappear...It Will Just Be Called Marketing” http://elyrosenstock.com/blog/2011/05/13/ earned-media-will-disappear-it-will-just-be-called-marketing/ (accessed on May 15 2014).

U.S. Government Accountability Office (2013), Virtual Economies and Currencies, Report to the Committee on Finance, U.S Senate.

World Economic Forum (2011), Personal Data: The Emergence of a New Asset Class. www3.weforum.org/docs/WEF_ITTC_PersonalDataNewAsset Report 2011.pdf. 



\section{Chapter 4}

\section{The digital economy, new business models and key features}

This chapter discusses the spread of information and communication technology (ICT) across the economy, provides examples of business models that have emerged as a consequence of the advances in ICT, and provides an overview of the key features of the digital economy that are illustrated by those business models.

The statistical data for Israel are supplied by and under the responsibility of the relevant Israeli authorities. The use of such data by the OECD is without prejudice to the status of the Golan Heights, East Jerusalem and Israeli settlements in the West Bank under the terms of international law. 


\subsection{The spread of ICT across business sectors: the digital economy}

All sectors of the economy have adopted ICT to enhance productivity, enlarge market reach, and reduce operational costs. This adoption of ICT is illustrated by the spread of broadband connectivity in businesses, which in almost all countries of the Organisation for Economic Co-operation and Development (OECD) is universal for large enterprises and reaches $90 \%$ or more even in smaller businesses.

Figure 4.1. Enterprises with broadband connection, by employment size, 2012

Fixed and mobile connections, as a percentage of all enterprises

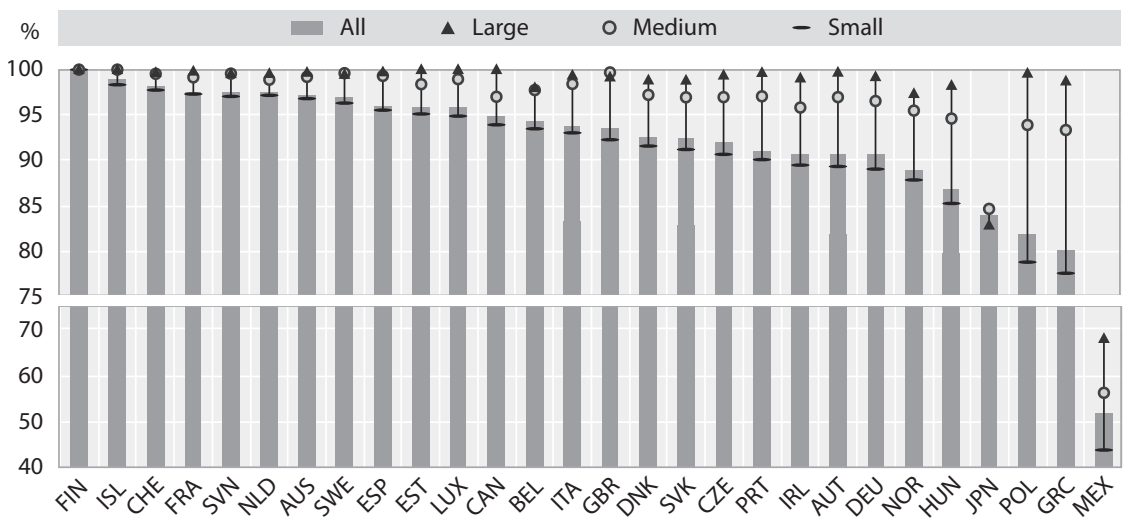

For Australia, data refer to 2010/11 (fiscal year ending 30 June 2011) instead of 2012. For Canada, medium-sized enterprises have 50-299 employees instead of 50-249 persons employed. Large enterprises have 300 or more employees instead of 250 or more persons employed. For Japan, all businesses with 100 or more persons employed instead of 10 or more, 100-299 instead of 50-249, and 300 or more instead of 250 or more. For Mexico, data refer to 2008 instead of 2012 and to businesses with 20 or more persons employed instead of 10 or more. For Switzerland, data refer to 2011 instead of 2012.

Source: OECD (2013), OECD Science, Technology and Industry Scoreboard 2013: Innovation for Growth, OECD Publishing, Paris, www.oecd.org/sti/scoreboard.htm based on OECD ICT Database and Eurostat.

The widespread adoption of ICT, combined with the rapid decline in price and increase in performance of these technologies, has contributed to the development of new activities in both the private and public sector. Together, these technologies have expanded market reach and lowered costs, and have enabled the development of new products and services. These technologies have also changed the ways in which such products and services are produced and delivered, as well as the business models used in companies 
ranging from multinational enterprises (MNEs) to start-ups. They also support activity by individuals and consumers, and have led to the creation of new payment mechanisms including new forms of digital currencies. The advent of the Internet brought major changes first to the entertainment, news, advertising, and retail industries. In those industries, the first major digital players initially started from traditional business models, adapting them to better end-user equipment (both inside and outside organisations) and more extensive interconnection through the Internet.

For example, online retailers initially adapted the business model of brick-and-mortar stores by selling traditional physical goods (for example, books) digitally. Online intermediaries that allowed the discovery, sale, and purchase of goods and services such as vehicles, homes, and jobs were another early category. Other digital players specialised in the online selling of traditional services (for example, online insurance brokers). Retailers then began selling digital products and services, like downloadable and streaming music and movies, executable code, games, and services based on data processing, increasingly blurring the line between goods and services as businesses continued to develop. Online advertising similarly started from traditional advertising business models, becoming more sophisticated as the potential of digital technology became fully integrated into the industry. New online services enabling a sharing and service economy have also appeared, allowing people to rent out their homes, vehicles and skills to third parties.

As technology has advanced and costs of ICT have continued to fall, ICT has proven to be general-purpose technology that has become embedded in and central to the business models of firms operating across the economy. Businesses across all sectors are now able to design and build their operating models around technological capabilities, in order to improve flexibility and efficiency and extend their reach into global markets. Businesses across all sectors have changed the way their business is conducted by taking advantage of advances in communications and data processing capacity to lower transaction costs and extend their reach into global markets.

These advances, coupled with liberalisation of trade policy and reduction in transportation costs, have expanded the ability of businesses in all sectors to take advantage of global value chains in which production processes can be geographically dispersed in locations around the world to take advantage of the features of local markets. For example, in sectors relying heavily on technology and research and development, design and production can be managed centrally, while the assembly can be fragmented in different countries to take advantage of skilled labour and local resources.

Sectors as diverse as retail, logistics and education have changed and keep changing due to the spread of ICT: 
- Retail: The digital economy has enabled retailers to allow customers to place online orders (often fulfilled from a local store) and has made it easier for retailers to gather and analyse data on customers, to provide personalised service and advertising. It has also enabled retailers to manage logistics and supply stores with products, which has had a significant, positive impact on productivity.

- Transport and Logistics: The logistics sector has been transformed by digital economy, which enables the tracking of both vehicles and cargo across continents, the provision of information to customers and facilitates the development of new operational processes such as Just In Time delivery in the manufacturing sector. Vehicle telemetry also helps maximise fuel efficiency, ensure efficient use of the transport network and support fleet maintenance activities. The information collected by fleets can also be used to create datasets with commercial value.

- Financial Services: Banks, insurance providers and other companies, including non-traditional payment service providers, increasingly enable customers to manage their finances, conduct transactions and access new products on line, although they still continue to support branch networks for operations. Better use of data also allows growth in customer insights and associated products, such as personalised spending analysis, which can be used to generate advertising revenue. The digital economy has also made it easier to track indices and manage investment portfolios and has enabled specialist businesses such as high-frequency trading.

- Manufacturing and Agriculture: The digital economy has enhanced design and development, as well as the ability to monitor production processes in factories and control robots, which has enabled greater precision in design and development and ongoing product refinement. The products being produced are also increasingly knowledge-intensive. In the automobile industry, for example, it is estimated that $90 \%$ of new features in cars have a significant software component. On farms, systems can monitor crops and animals, and soil/environmental quality. Increasingly, routine processes and agricultural equipment can be managed through automated systems.

- Education: As the digital economy spreads, universities, tutor services and other education service providers are able to provide courses remotely without the need for face to face interaction through technologies such as video conferencing and streaming and online collaboration portals, which enables them to tap into global demand and leverage brands in a way not previously possible. 
- Healthcare: The digital economy is revolutionising the healthcare sector, from enabling remote diagnosis to enhancing system efficiencies and patient experience through electronic health records. It also allows opportunities for advertising, for example of drugs and other treatments.

- Broadcasting and Media: The digital economy has dramatically changed the broadcasting and media industry, with increasing broadband access in particular opening new avenues for delivery of content for traditional media players, while also enabling the participation in the news media of non-traditional news sources, and expanding user participation in media through user-generated content and social networking. The digital economy has also enhanced the ability of companies to collect and use information about the viewing habits and preferences of customers, to enable them to better target programming.

As digital technology is adopted across the economy, segmenting the digital economy is increasingly difficult. In other words, because the digital economy is increasingly becoming the economy itself, it would be difficult, if not impossible, to ring-fence the digital economy from the rest of the economy. Attempting to isolate the digital economy as a separate sector would inevitably require arbitrary lines to be drawn between what is digital and what is not. As a result, the tax challenges and base erosion and profit shifting (BEPS) concerns raised by the digital economy are better identified and addressed by analysing existing structures adopted by MNEs together with new business models and by focusing on the key features of the digital economy and determining which of those features raise or exacerbate tax challenges or BEPS concerns, and developing approaches to address those challenges or concerns.

\subsection{The digital economy and the emergence of new business models}

The digital economy has given rise to a number of new business models. Although many of these models have parallels in traditional business, modern advances in ICT have made it possible to conduct many types of business at substantially greater scale and over longer distances than was previously possible. This section discusses several prominent examples of these new business models. Some of these business models may complement each other and in some cases overlap with each other (for example, payment services could be described under e-commerce or under cloud computing). The business models discussed below are by no means exhaustive. Indeed, just as innovation in the digital economy allows the rapid development of new business models, it can also quickly cause existing businesses to become obsolete. The types of business discussed include several varieties of e-commerce, app stores, online advertising, cloud computing, participative networked platforms, high speed trading, and online payment services. 


\subsubsection{Electronic commerce}

Electronic commerce, or e-commerce, has been defined broadly by the OECD Working Party on Indicators for the Information Society as "the sale or purchase of goods or services, conducted over computer networks ${ }^{1}$ by methods specifically designed for the purpose of receiving or placing of orders. The goods or services are ordered by those methods, but the payment and the ultimate delivery of the goods or service do not have to be conducted online. An e-commerce transaction can be between enterprises, households, individuals, governments, and other public or private organisations" (OECD, 2011). E-commerce can be used either to facilitate the ordering of goods or services that are then delivered through conventional channels (indirect or offline e-commerce) or to order and deliver goods or services completely electronically (direct or on-line e-commerce). Although e-commerce covers a broad array of businesses, this section provides an illustration of some of the more prominent types.

\subsubsection{Business-to-business models}

The vast majority of e-commerce consists of transactions in which a business sells products or services to another business (so-called business-tobusiness (B2B)) (OECD, 2011). This can include online versions of traditional transactions in which a wholesaler purchases consignments of goods online, which it then sells to consumers from retail outlets. It can also include the provision of goods or services to support other businesses, including, among others: (i) logistics services such as transportation, warehousing, and distribution; (ii) application service providers offering deployment, hosting, and management of packaged software from a central facility; (iii) outsourcing of support functions for e-commerce, such as web-hosting, security, and customer care solutions; (iv) auction solutions services for the operation and maintenance of real-time auctions via the Internet; $(v)$ content management services, for the facilitation of website content management and delivery; and (vi) web-based commerce enablers that provide automated online purchasing capabilities.

\subsubsection{Business-to-consumer models}

Business-to-consumer (B2C) models were among the earliest forms of e-commerce. A business following a B2C business model sells goods or services to individuals acting outside the scope of their profession. B2C models fall into several categories, including, for example, so-called "pureplay" online vendors with no physical stores or offline presence, "click-and-mortar" businesses that supplemented existing consumer-facing business with online sales, and manufacturers that use online business to allow customers to order and customise directly. 
The goods or services sold by a B2C business can be tangible (such as a $\mathrm{CD}$ of music) or intangible (i.e. received by consumers in an electronic format). Through digitisation of information, including text, sound, and visual images, an increasing number of goods and services can be delivered digitally to customers increasingly remote from the location of the seller. B2C e-commerce can in many cases dramatically shorten supply chains by eliminating the need for many of the wholesalers, distributors, retailers, and other intermediaries that were traditionally used in businesses involving tangible goods. Partly because of this disintermediation, $\mathrm{B} 2 \mathrm{C}$ businesses typically involve high investment in advertising and customer care, as well as in logistics. B2C reduces transaction costs (particularly search costs) by increasing consumer access to information. It also reduces market entry barriers, as the cost of maintaining a website is generally cheaper than installing a traditional brick-and-mortar retail shop.

\subsubsection{Consumer-to-consumer models}

Consumer-to-consumer $(\mathrm{C} 2 \mathrm{C})$ transactions are becoming more and more common. Businesses involved in $\mathrm{C} 2 \mathrm{C}$ e-commerce play the role of intermediaries, helping individual consumers to sell or rent their assets (such as residential property, cars, motorcycles, etc.) by publishing their information on the website and facilitating transactions. These businesses may or may not charge the consumer for these services, depending on their revenue model. This type of e-commerce comes in several forms, including, but not limited to: (i) auctions facilitated at a portal that allows online bidding on the items being sold; (ii) peer-to-peer systems allowing sharing of files between users; and (iii) classified ads portals providing an interactive, online marketplace allowing negotiation between buyers and sellers.

\subsubsection{Growth of e-commerce}

The Internet facilitates transactions such as ordering goods and services. This means that many transactions that would have taken place without the Internet can be conducted more efficiently and at less expense. In addition, the Internet has expanded the reach of smaller businesses, enabling them to reach markets that would not have been possible to reach without its existence. As a result, the number of firms carrying out business transactions over the Internet has increased dramatically over the last decade.

For example, e-commerce in the Netherlands has increased as a share of total company revenue from $3.4 \%$ in 1999 to $14.1 \%$ in 2009. Similarly, between 2004 and 2011 this share increased from $2.7 \%$ to $18.5 \%$ in Norway and from $2.8 \%$ to $11 \%$ in Poland. Based on comparable data, as illustrated in the chart below, e-commerce is nearing $20 \%$ of total turnover in Finland, Hungary, and Sweden, and 25\% in the Czech Republic (OECD, 2012). 
In 2012, B2C e-commerce sales were estimated to exceed USD 1 trillion for the first time. During 2013, they are estimated to grow an additional $18.3 \%$ to USD 1.298 trillion, with the Asia-Pacific region surpassing North America as the top market for B2C e-commerce sales (Emarketer, 2013). It is worth mentioning that at the moment $\mathrm{B} 2 \mathrm{C}$ e-commerce represents a small fraction of overall e-commerce, which is mainly made of $\mathrm{B} 2 \mathrm{~B}$ transactions. Global B2B e-commerce, particularly among wholesalers and distributors, was estimated to be approximately USD 12.4 trillion in 2012 (WTO, 2013). According to other estimates made by the International Data Corporation, the size of total worldwide e-commerce, when global B2B and consumer transactions are added together, equalled USD 6 trillion in 2013.

Figure 4.2. Turnover from e-commerce, by enterprise size, 2012

As a percentage of turnover in enterprises with 10 or more persons employed

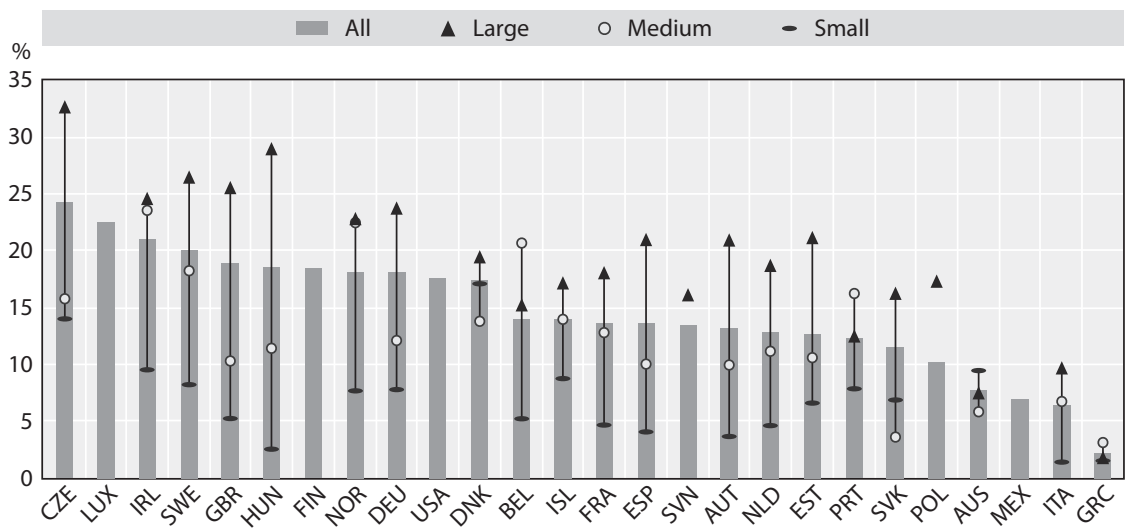

Where available, firm size classes are defined as: small (from 10 to 49 persons employed), medium (50 to 249), large (250 and more). Sector coverage consists of all activities in manufacturing and non-financial market services, but for Australia (where Agriculture, forestry and fishing is also included) and the United States (all market services are included but management of companies and enterprises - NAICS 55). For Australia, data refer to the fiscal year ending 30 June 2011 (2010/11) instead of 2012; for Denmark and Germany they refer to 2010; for Mexico, data refer to 2008 and include only businesses with 20 or more persons employed.

Source: OECD (2013), OECD Science, Technology and Industry Scoreboard 2013: Innovation for Growth, OECD Publishing, Paris, www.oecd.org/sti/scoreboard.htm based on OECD, ICT Database; Eurostat and national sources, June 2013. 


\subsubsection{Payment services}

Paying for online transactions traditionally required providing some amount of financial information, such as bank account or credit card information, to a vendor, which requires a high degree of trust that is not always present in the case of an unknown vendor, particularly in the case of a $\mathrm{C} 2 \mathrm{C}$ transaction. Online payment service providers help address this concern by providing a secure way to enable payments online without requiring the parties to the transaction to share financial information with each other.

A payment service provider acts as an intermediary (typically using a software-as-a-service model) between online purchasers and sellers, accepting payments from purchasers through a variety of payment methods, including credit card payments or bank-based payments like direct debit or real-time bank transfers, processing those payments, and depositing the funds to the seller's account. Electronic payment systems offer a number of benefits for users, such as (i) protection against fraud, since the seller and buyer do not exchange sensitive information; (ii) faster delivery of payment compared with traditional payment methods; and (iii) in many cases, the ability to transact in multiple currencies. Payment service providers typically charge a fee for each transaction completed, which can be either a fixed charge or a percentage of the value of the transaction, though some payment service providers also charge monthly fees or setup fees for certain additional services.

A number of other alternative online payment options are in use as well, including:

- Cash payment solutions, in which a customer buys online, and pays in cash with a barcode or payment code at participating shops or settlement agencies, offering a way for customers unwilling to use other online payment methods to make online purchases in a secure manner.

- E-wallets or cyber-wallets, which are previously charged with credits and can be spent online as an alternative to the use of a credit card. These are often used for micropayments because the use of a credit card for frequent small payments is not economical.

- Mobile payment solutions, which encompass all types of technologies that enable payment using a mobile phone or smartphone, including, among others, mobile card processing using card readers connected to smartphones, in-app payments for virtual products, and near-field communications solutions which use short-range wireless technology to exchange information.

As discussed in Chapter 3, the digital economy has also given rise to virtual currencies that can be used to purchase goods and services from 
businesses that agree to accept them, acting as an alternative to payment services. In some cases, exchanges have arisen to allow purchase and sale of these virtual currencies for real currency.

\subsubsection{App stores}

The growth of Internet access through smartphones and tablets has caused an increase in the frequency of use of online services and the development of application stores, a type of digital distribution platform for software, often provided as a component of an operating system. Application stores typically take the form of central retail platforms, accessible through the consumer's device, through which the consumer can browse, view information and reviews, purchase and automatically download and install the application on his/her device.

Accessibility to application stores varies. Some application stores are only usable by consumers with a particular device. These stores may represent the sole way for users of that device to obtain applications, or may represent one of several possible means for users to obtain applications. Some application stores are accessible by consumers of any device using a particular operating system. Others are usable by consumers with service contracts with a particular network operator. Finally, certain others are freely accessible and are not dependent on the type of device, proprietary software, or service provider.

App stores will typically include both applications developed by the business operating the app store (typically, an operating system developer, device manufacturer, or telecommunications network provider), or by a thirdparty developer. Applications may be downloaded for free or for a fee. Free applications may be supported by advertising. In addition, applications are increasingly moving to a "freemium" model, in which basic functionality is provided for free, but customers may pay for additional content or features.

An application store will typically feature applications produced by developers in multiple countries. In addition, while many app stores are targeted at customers in particular geographic markets, applications are often cross listed on multiple app stores targeted at multiple geographic regions.

Use of application stores is growing rapidly. Gartner, Inc., an information technology research and advisory company, estimated that downloads from app stores would reach 102 billion in 2013, up from 64 billion in 2012.

Total revenue from app store purchases was expected to exceed USD 26 billion in 2013, an increase of 31\% over the total in 2012. As noted above, free applications are becoming increasingly prevalent, and are expected by 2017 to account for $94.5 \%$ of total downloads, with in-app purchases accounting for $48 \%$ of total app store revenues. 


\subsubsection{Online advertising}

Online advertising uses the Internet as a medium to target and deliver marketing messages to customers. Internet advertising offers a number of advantages over traditional advertising. For example, many Internet advertisers have developed sophisticated methods for segmenting consumers in order to allow more precise targeting of ads. Many Internet advertising publishers have also developed ways for clients to monitor performance of ads, tracking how users interact with their brands and learning what is of interest to current and prospective customers. Online advertising takes a number of forms, the most prominent of which are display ads, in which an advertiser pays to display ads linked to particular content or user behaviour, and search engine ads, in which an advertiser pays to appear among Internet search results.

Online advertising involves a number of players, including web publishers, who agree to integrate advertisements into their online content in exchange for compensation, advertisers, who produce advertisements to be displayed in the web publisher's content and advertising network intermediaries, who connect web publishers with advertisers seeking to reach an online audience. Advertising network intermediaries include a range of players, including search engines, media companies, and technology vendors. These networks are supported by data exchanges, marketplaces in which advertisers bid for access to data about customers that has been collected through tracking and tracing of users' online activities. These data can be analysed, combined, and processed by specialist data analysers into a user profile.

In advertising-based business models, publishers of content are frequently willing to offer free or subsidised services to consumers in order to ensure a large enough audience to attract advertisers. The most successful advertising companies have been those that combine a large user base with sophisticated algorithms to collect, analyse, and process user data in order to allow targeted advertisements. While traditional advertising involved payment for display of ads for a specified period of time, with little way to monitor visibility or user response, online advertising has given rise to a number of new payment calculation methods, including cost-per-mille (CPM), in which advertisers pay per thousand displays of their message to users, cost-per-click (CPC), in which advertisers pay only when users click on their advertisements, and cost-per-action (CPA), in which advertisers only pay when a specific action (such as a purchase) is performed by a user.

Internet advertising is rapidly growing, both in terms of total revenues and in terms of share of the total advertising market. PwC estimates that Internet advertising reached USD 100.2 billion in 2012, which represented $17 \%$ growth from the previous year, and a $20 \%$ share of the total global advertising market. The market for Internet advertising is projected to grow at a rate of $13 \%$ per year during the period from 2012 to 2017, reaching 
USD 185.4 billion in 2017. Internet advertising would by that point become the second-largest advertising medium behind television advertising, with a $29 \%$ share of the overall global market. Within the online advertising market, search advertisement holds the greatest share at approximately $42 \%$ in 2013 , and is expected to continue to hold in excess of $40 \%$ of the market through 2017, although both mobile and video advertising are projected to grow substantially by 2017 (to $15 \%$ and $8 \%$, respectively) (PwC, 2013).

\subsubsection{Cloud computing}

Cloud computing is the provision of standardised, configurable, on-demand, online computer services, which can include computing, storage, software, and data management, using shared physical and virtual resources (including networks, servers, and applications). ${ }^{2}$ Because the service is provided online using the provider's hardware, users can typically access the service using various types of devices wherever they are located, provided they have a suitable Internet connection.

The resources to which cloud computing customers are granted access are not stored on a single computer. Instead, they are on many networked computers that are available to everyone who has access to that "cloud" of computing resources (which, depending on the cloud, could be a single organisation, a community of organisations, the general public, or some combination thereof). The system copies each user's data and software to other servers, which allows it to allocate requests for hardware resources to whatever physical location is best able to satisfy the demand efficiently. Each user has access to a large amount of computer resources when needed, and only when needed. This redundancy ensures that the failure of one machine will not lead to loss of data or software.

Cloud computing often provides customers with a cost effective alternative to purchasing and maintaining their own IT infrastructure, since the cost of the consumer resources is generally shared among a wide user base. The advantages of cloud computing are largely driven by economies of scale in setting up the infrastructure and maximising server usage by sharing space among clients whose needs for space and processing power may vary on a flexible basis.

The most common examples of cloud computing service models are:

- Infrastructure-as-a-service: In the most basic cloud-service model, providers of infrastructure as a service (IaaS) offer computers physical or (more often) virtual machines - and other fundamental computing resources. IaaS clouds often offer additional resources such as a virtual-machine disk image library, raw (block) and file-based storage, firewalls, load balancers, Internet Protocol (IP) 
addresses, virtual local area networks (VLANs), and software bundles. The customer does not manage or control the underlying cloud infrastructure, but has control over the operating system, storage, and deployed applications, and may be given limited control of select networking components (e.g. host firewalls).

- Platform-as-a-service: Platform as a service is a category of cloud computing services that provides a computing platform and programming tools as a service for software developers. Software resources provided by the platform are embedded in the code of software applications meant to be used by end users. The client does not control or manage the underlying cloud infrastructure, including the network, servers, operating systems, or storage, but has control over the deployed applications.

- Software-as-a-service: A common form of cloud computing in which a provider allows the user to access an application from various devices through a client interface such as a web browser (e.g. webbased email). It can be provided either to business customers (B2B) or individual customers (B2C). Unlike in the old software vendor models, the code is executed remotely on the servers, thereby freeing the user of the necessity to upgrade when a new version is available - the executed version is always the latest, which means that new features go instantaneously to market without friction. The consumer generally does not manage or control the underlying cloud infrastructure, including the network, servers, operating systems, storage, or individual application capabilities, with the possible exception of limited user-specific application configuration settings.

Other X-as-a Service (XaaS) concepts include content or data:

- Content-as-a-service: Where rights are obtained and software is provided to allow content to be embedded by purchasers, content can be purchased as a service. This has been used particularly in the case of user-created content.

- Data-as-a-service: Data from multiple sources can be aggregated and managed by a service provider, so that controlled access to that data can be granted to entities that may be geographically and organisationally removed from each other, without each entity needing to develop or acquire the infrastructure necessary to prepare and process that data.

In the consumer markets, many cloud services (e.g. email, photo storage, and social networks) have been provided free of charge, with revenue generated through advertising or the sale of data on user behaviour, or on a "freemium" basis in which basic services are provided for free and expanded 
services require payment. Other consumer cloud services, such as web hosting or hard drive backup, are sold on a monthly subscription basis. In B2B markets, cloud services are most typically sold by subscription, although "pay as you go" models are increasingly available.

\subsubsection{High frequency trading}

High frequency trading uses sophisticated technology, including complex computer algorithms, to trade securities at high speed. Large numbers of orders which are typically fairly small in size are sent into the markets at high speed, with round-trip execution times measured in microseconds. The parameters for the trades are set with algorithms run on powerful computers that analyse huge volumes of market data and exploit small price movements or opportunities for market arbitrage that may occur for only milliseconds. Typically, a high-frequency trader holds a position open for no more than a few seconds. In other words, high frequency trading firms profit mostly from small price changes exploited through small, but frequently executed trades.

Because trades are conducted entirely electronically, high frequency trading generally does not require personnel in the country where the infrastructure used to make trades is located. The implementation and execution of successful trading strategies depends on several factors, including the development of algorithms for trading, as well as writing programmes to monitor losses and performance and to automatically shut down trading to avoid fast-accruing losses. In addition, high frequency trading depends on the ability to be faster than competitors, which means that it is extremely sensitive to latency. As a result, the location of the server is extremely important to the business, with servers located close to the relevant exchange providing a meaningful advantage over servers located farther away. As a result, financial institutions offer installation of trading engines directly adjacent to their own infrastructure, minimising network latency.

\subsubsection{Participative networked platforms}

A participative networked platform is an intermediary that enables users to collaborate and contribute to developing, extending, rating, commenting on and distributing user-created content. User created content (UCC) comprises various forms of media and creative works (written, audio, visual, and combined) created by users. A range of different distribution platforms have been created, including text-based collaboration formats such as blogs or wikis, group-based aggregation and social bookmarking sites, social networking sites, podcasting, and virtual worlds. Social networking applications are possibly the best known participative networked platform but the same model is also used in other areas, like fashion design, toy design, and computer games just to 
name a few. In general, UCC is created without the expectation of profit. The participative platform featuring the UCC, however, may monetise the UCC in a variety of ways, including through voluntary contributions, charging viewers for access on a per-item or subscription basis, advertising-based models, licensing of content and technology to third parties, selling goods and services to the community, and selling user data to market research or other firms.

\section{Box 4.1. Diversity of revenue models}

The diversity of businesses in the current digital economy is illustrated by the variety of ways in which businesses turn value into revenue. The most common revenue models include the following:

i. Advertising-based revenues. One version of this model offers free or discounted digital content to users in exchange for requiring viewing of paid-for advertisements. Other models rely on providing advertising through mobile devices based on location or other factors. A third type concerns social media websites or platforms who typically build up a large online user community before monetising their captive audience through advertising opportunities.

ii. Digital content purchases or rentals. Users pay per item of download for instance, e-books, videos, apps, games and music would fall into this category.

iii. Selling of goods (including virtual items). This category, which overlaps to a degree with (1), would include online retailers of tangible goods but could also cover online gaming, where users are offered a free or discounted introductory product but are also offered purchasable access to additional content or virtual items to enhance the experience.

iv. Subscription-based revenues. Examples include annual payments for "premium delivery" with online retailers, monthly payments for digital content including news, music, video-streaming, etc. It could also include regular payments for software services and maintenance such as antivirus software, data storage, customer "help" services for operating systems, and payment for access to the Internet itself.

v. Selling of services. This category overlaps with (iv) but would include traditional services which can be delivered online such as legal services (e.g. e-conveyancing), financial services (e.g. brokerage), consultancy services, travel agency etc. It would also include a large range of B2B services linked to enterprises who provide core Internet access and act as Internet intermediaries (web hosting, domain registration, payment processing, platform access, etc.). 


\section{Box 4.1. Diversity of revenue models (continued)}

vi. Licensing content and technology. Again, this category overlaps with (iv) and (v) but might typically include access to specialist online content (e.g. publications and journals), algorithms, software, cloud based operating systems, etc., or specialist technology such as artificial intelligence systems.

vii. Selling of user data and customised market research. Examples include Internet service providers (ISPs), data brokers, data analytics firms, telemetrics and data gained from non-personal sources.

viii. "Hidden" fees and loss leaders. There may be instances in integrated businesses where profits or losses may be attributable to online operations but because of the nature of the business, cross-subsidy with physical operations occurs and it is difficult to separate and identify what should be designated as 'online revenue'. An example might include online banking, which is offered "free" but is subsidised through other banking operations and fees.

\subsection{Key features of the digital economy}

There are a number of features that are increasingly prominent in the digital economy and which are potentially relevant from a tax perspective. While these features may not all be present at the same time in any particular business, they increasingly characterise the modern economy. They include:

- Mobility, with respect to (i) the intangibles on which the digital economy relies heavily, (ii) users, and (iii) business functions as a consequence of the decreased need for local personnel to perform certain functions as well as the flexibility in many cases to choose the location of servers and other resources.

- Reliance on data, including in particular the use of so-called "big data".

- Network effects, understood with reference to user participation, integration and synergies.

- Use of multi-sided business models in which the two sides of the market may be in different jurisdictions.

- Tendency toward monopoly or oligopoly in certain business models relying heavily on network effects.

- Volatility due to low barriers to entry and rapidly evolving technology. 


\subsubsection{Mobility}

\subsubsection{Mobility of intangibles}

Development and exploitation of intangibles is a key feature of the digital economy. This investment in and development of intangibles is a core contributor to value creation and economic growth for companies in the digital economy. For example, digital companies often rely heavily on software, and will expend substantial resources on research and development to upgrade existing software or to develop new software products.

This heavy reliance on intangibles can be present even where technology is incorporated into a business model primarily to manage wholly tangible resources. For example, an online retailer may develop a multi-layer digital activity to manage a logistic platform including warehouses and shipping capacity. As businesses evolve, the relative importance of these intangibles frequently grows, resulting in further concentration of value in the intangibles. Under existing tax rules, the rights to those intangible assets can often be easily assigned and transferred among associated enterprises, with the result that the legal ownership of the assets may be separated from the activities that resulted in the development of those assets.

\subsubsection{Mobility of users}

Advances in ICT and the increased connectivity that characterises the digital economy mean that users are increasingly able to carry on commercial activities remotely while traveling across borders. An individual can, for example, reside in one country, purchase an application while staying in a second country, and use the application from a third country. Challenges presented by the increasing mobility of consumers are exacerbated by the ability of many consumers to use virtual personal networks or proxy servers that may, whether intentionally or unintentionally, disguise the location at which the ultimate sale took place. The fact that many interactions on the Internet remain anonymous may add to the difficulty of the identity and location of users.

\subsubsection{Mobility of business functions}

As noted above, improved telecommunications, information management software, and personal computing have significantly decreased the cost of organising and co-ordinating complex activities over long distances. As a result, businesses are increasingly able to manage their global operations on an integrated basis from a central location that may be removed geographically from both the locations in which the operations are carried out and the locations in which their suppliers or customers are located. 
One impact of these changes has been an expansion of the ability to access remote markets, which has substantially increased the ability to provide those goods and services across borders. This has been illustrated by the dramatic growth of international trade in ICT services in recent years. In particular, since 2000, the share of Computer and Information services on world exports of services doubled from 3\% to $6 \%$, while that of Telecommunication services increased from 2.2\% to 2.3\% (OECD, 2013). For the OECD, the combined share of Computer and Information and Communication services rose from $5.7 \%$ to $9.0 \%$ of total service exports.

Several important shifts in the provision of ICT services have occurred in recent years. India has quickly become the leading exporter of ICT services, followed by Ireland, the United States, Germany, and the United Kingdom. China as well became one of the major exporters. These six countries together represent about $60 \%$ of total exports of ICT services.

In addition, technological advances increasingly make it possible for businesses to carry on economic activity with minimal need for personnel to be present. In many cases, businesses are able to increase substantially in size and reach with minimal increases in the number of personnel required to manage day-to-day operation of the businesses (so-called "scale without mass"). This has been particularly true in the case of Internet businesses,

Figure 4.3. OECD and major exporters of ICT services, 2000 and 2012

Billions of USD and percentages of total world exports of ICT services

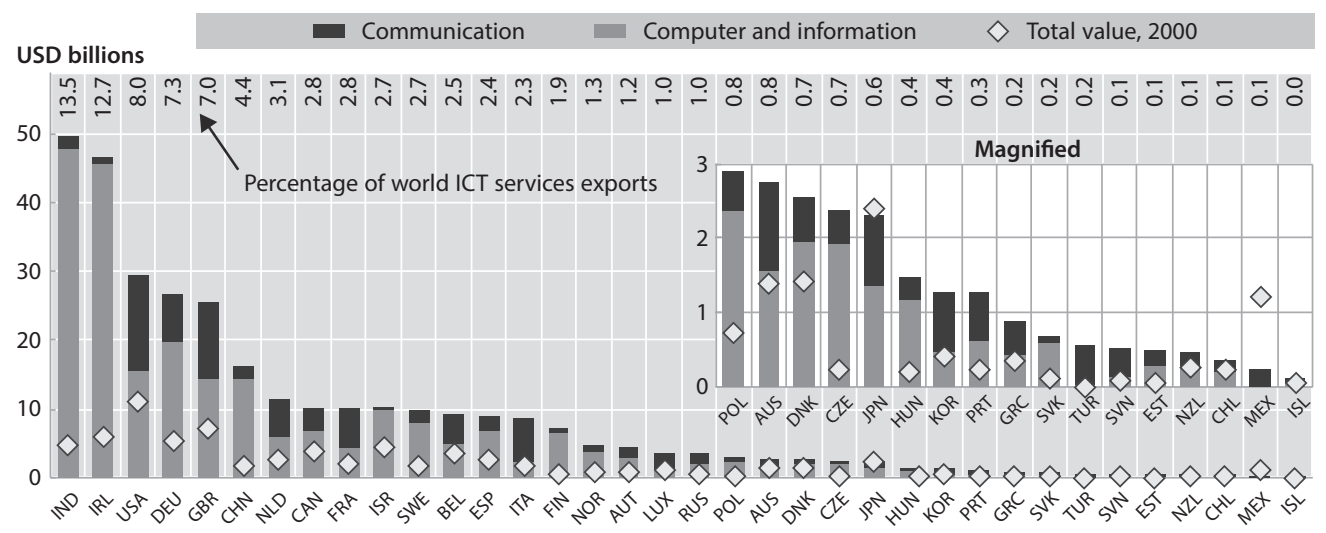

Data for Canada, Finland, Iceland, Israel, Mexico, Norway, Slovenia, Turkey and the United States refer to 2011 instead of 2012. For Luxembourg and Kuwait refer to 2002 instead of 2000, and for Denmark to 2004. Exports of computer and information services are not included for Mexico.

Source: OECD (2013), OECD Science, Technology and Industry Scoreboard 2013: Innovation for Growth, OECD Publishing, Paris, http://dx.doi.org/10.1787/sti_scoreboard-2013-en. 
which have in many cases quickly amassed huge numbers of users while maintaining modest workforces. As a result, the average revenue per employee of top Internet firms, as shown in Figure 4.4, is substantially higher than in other types of businesses within the ICT sector.

Figure 4.4. Average annual revenue per employee of the top 250 ICT firms by sector, 2000-11 ${ }^{3}$

USD thousands

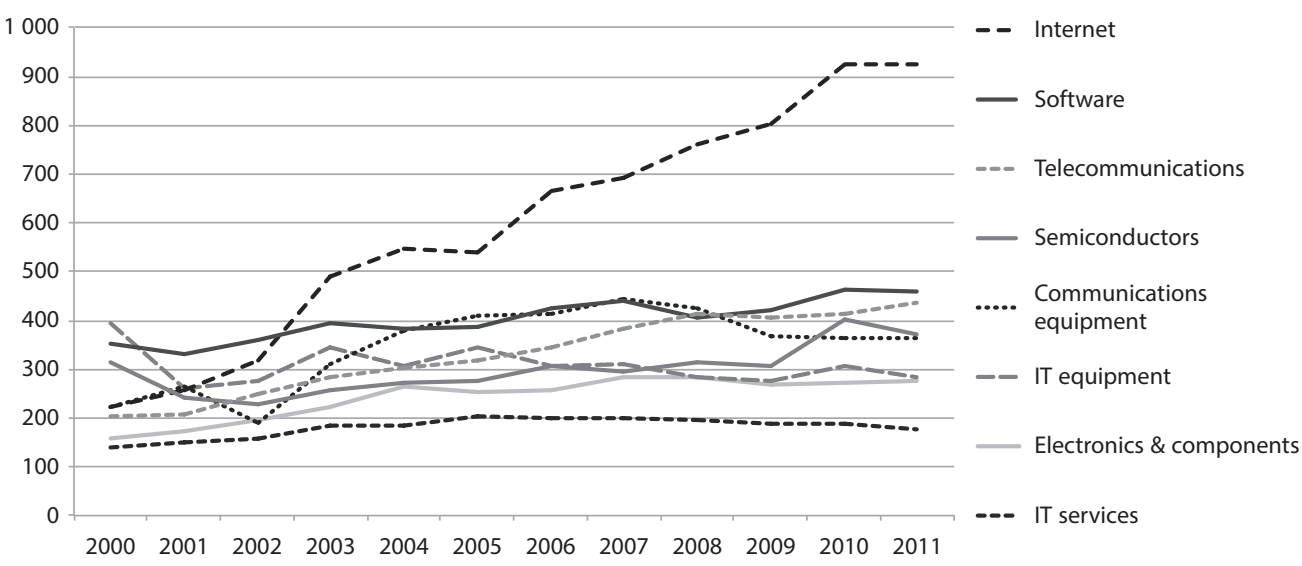

Source: OECD (2012), OECD Internet Economy Outlook 2012, OECD Publishing, Paris, http://dx.doi. org/10.1787/9789264086463-en.

The ability to manage business centrally while maintaining substantial flexibility over the location of business functions has increased the ability of businesses to spread functions and assets among multiple different countries. While such globalisation of business among larger organisations is certainly not a new phenomenon, the spread of the digital economy, combined with the growing importance of the service component, as well as reductions in trade costs due to trade and investment liberalisation and regulatory reforms, have helped to remove logistical barriers and increase the pace at which such globalisation is possible. Technological advances have also permitted greater integration of worldwide businesses, which has increased the flexibility of businesses to spread their activities among several locations worldwide, even if those locations may be distant from each other and from the physical location of their ultimate customers. In addition to improving the flexibility of larger, more established organisations, advances in information and communications technology have made it more possible for even small and 
mid-sized businesses to reach global markets from their inception. In short, global interconnectedness has grown to unprecedented levels.

Advances in technology have improved access to real-time market information and business analytics, and have improved communications within and between firms. These improvements have improved the capacity of businesses to manage their global operations on an integrated basis, with individual group companies exercising their functions within a framework of group policies and strategies set by the group as a whole and monitored centrally. Improved telecommunications, information management software, and personal computing have significantly decreased the cost of organising and co-ordinating complex activities over long distances, and enabled the creation of new and more efficient business models. This integration has made it easier for business to adopt global business models that centralise functions at a regional or global level, rather than at a country-by-country level. Even for small and medium enterprises (SMEs), it has now become possible to be "micro-multinationals" that operate and have personnel in multiple countries and continents.

As worldwide operations have become more integrated, production processes increasingly take place as part of global value chains in which various stages of production are spread across multiple different countries, and are performed by a mix of independent and affiliated suppliers. Businesses are increasingly able to choose the optimal location for productive activities and assets, even if that location may be distant from the location of customers or the location of other stages of production. In addition, rapid advances in information and communication technology have meant that services such as data entry, information processing, research, and consulting can increasingly be carried out remotely. These functions can be carried out by related parties, or, if a business determines that it is more advantageous to outsource the function, by an unrelated service provider.

There are limits to this flexibility, however. In general, fragmentation of activities among multiple locations involves trade-offs between lower costs for the activity itself and higher transaction and co-ordination costs. In addition, skills and talent remain a critical resource in the digital economy. Although many functions can be performed with limited personnel, managers, developers, software architects, and designers, among other key functions, remain instrumental. As a result, location of many of the substantial functions of a digital business must occur in locations in which these key people are willing to work. Further, although digital services can substantially expand the reach of businesses, these digital services often require a massive investment in infrastructure components. For example, cloud computing providers must build "server farms" of interconnected computers, and while there may be some flexibility as to where these 
resources are located, concerns like access to inexpensive and reliable sources of power and cooling may heavily influence the choice of location. In addition, in many businesses the user experience is meaningfully improved by proximity to the core infrastructure.

The result is that there are often compelling reasons for businesses to ensure that infrastructure resources are placed as close as possible to where key markets of users are, so that users experience less latency, shorter lag time, and higher quality. In addition, in some businesses, the need for a tangible presence in a jurisdiction for regulatory reasons may also limit choices about where to locate infrastructure and business activities.

\subsubsection{Reliance on data}

It is common in the digital economy for businesses to collect data about their customers, suppliers, and operations. For example, the use of a product or service by a user may provide data about the user that has value to the business as an input either in improving existing products and services or in providing products and services to another group of customers.

Data can include both personalised data and data that is not personalised, and can be obtained in a number of ways. In the case of personal data, as mentioned in Chapter 3 (3.1.5 Use of data), it can be obtained directly from customers (for example, when registering for an online service), observed (for example, by recording Internet browsing preferences, location data, etc.), or inferred based on analysis in combination with other data. It is estimated that sources such as online or mobile financial transactions, social media traffic, and GPS co-ordinates generate in excess of 2.5 exabytes (billions of gigabytes) of data every day (World Economic Forum, 2012). The dividing line between personal and non-personal data is not always clear; however, as data obtained from multiple private and public sources will frequently be combined in order to create value. A recent study quantifies the value of the Data-Driven Marketing Economy (DDME) and looks at the revenues generated for the US economy. The study found that the DDME added USD 56 billion in revenue to the United States economy in 2012 and notes that the real value of data is in its application and exchange across the DDME (Data-Driven Marketing Institute, 2013).

Although the use of data to improve products and services is not unique to the digital economy, the massive use of data has been facilitated by an increase in computing power and storage capacity and a decrease in data storage cost, as shown in Figures 4.5 and 4.6, which has greatly increased the ability to collect, store, and analyse data at a greater distance and in greater quantities than was possible before. The capacity to collect and analyse data is rapidly increasing as the number of sensors embedded in devices that are 
networked to computing resources increases. For example, while traditional data collection for utility companies was limited to yearly measurement, coupled with random samplings throughout the year, smart metering could increase that measurement rate to 15 minute samples, a 35000 time increase in the amount of data collected (OECD, 2013). This has manifested itself in particular in the concept of "big data", meaning datasets large enough that they cannot be managed or analysed using typical database management tools. The value of the ability to obtain and analyse data, and big data in particular, is increasingly well documented by market observers.

Figure 4.5. Estimated worldwide data storage

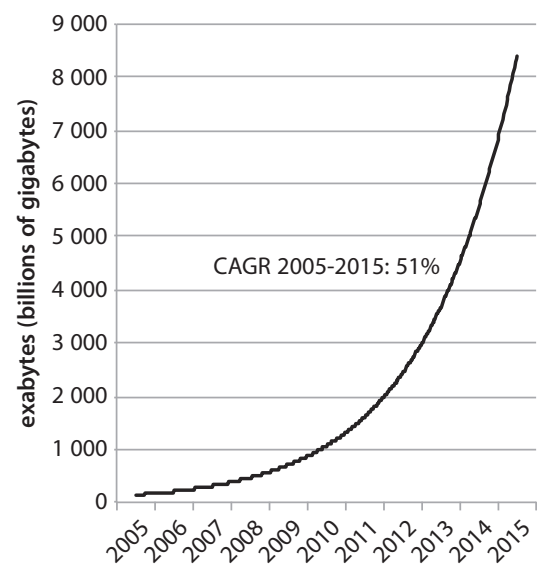

Figure 4.6. Average data storage cost for consumers 1998-2012

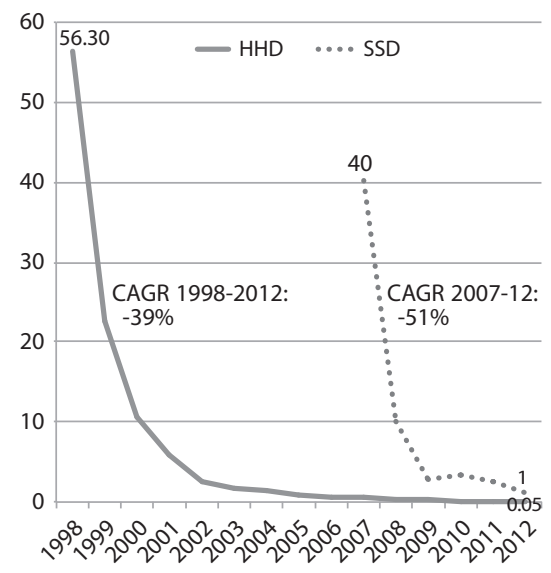

Source: OECD (2013), "Exploring Data-Driven Innovation as a New Source of Growth: Mapping the Policy Issues Raised by 'Big Data”, OECD Digital Economy Papers, No. 222, OECD Publishing, Paris, http://dx.doi.org/10.1787/5k47zw3fcp43-en.

For example, in a 2011 report on big data, the McKinsey Global Institute estimated the value that could be created through the analysis and use of big data at USD 300 billion in the health sector in the United States and at EUR 250 billion in the general government sector in Europe. The same report estimates that use of big data could generate a total consumer surplus of USD 600 billion. Big data has substantial application in targeting government aid and services as well. It has been used, for example, to monitor refugee movements following natural disasters, in order to ensure that health risks could be accurately predicted and aid could be well targeted (World Economic Forum, 2012). 
The McKinsey Global Institute Report notes five broad ways in which leveraging big data can create value for businesses:

i. Creating transparency by making data more easily accessible in a timely manner to stakeholders with the capacity to use the data.

ii. Managing performance by enabling experimentation to analyse variability in performance and understand its root causes.

iii. Segmenting populations to customise products and services.

iv. Improve decision making by replacing or supporting human decision making with automated algorithms.

v. Improve the development of new business models, products, and services.

\subsubsection{Network effects}

Networks effects refer to the fact that decisions of users may have a direct impact on the benefit received by other users. A simple example of this is the introduction of the fax machine. While a single fax machine had no utility by itself, users choosing to purchase a fax machine received the benefit of the decisions of earlier users to purchase a fax machine, in the form of the ability to communicate through this new technology with an existing network of potential counterparties.

These network effects are an important feature of many businesses in the digital economy. Network effects are seen whenever compatibility with other users is important, even where the primary purpose of a particular technology may not be to interact with others. For example, a widely-adopted operating system will generally have a larger amount of software written for it, resulting in a better user experience. These effects are known as positive externalities, meaning situations in which the welfare of a person is improved by the actions of other persons, without explicit compensation. For example, when additional people join a social network, the welfare of the existing users is increased, even though there is no explicit agreement compensation among the users for this improvement. Externalities can also be negative. For example, as an increasing number of persons use a communications network at the same time, congestion may decrease the value to each user of the network, with no compensation among the affected parties (Easley and Kleinberg, 2010).

Some network effects come from users' marginal utility to each other: the more users there are, the higher the value created is. A simple example is a media sharing site, in which all content is generated by users, and the experience of users is enhanced as additional users join and share content. 
Where a business model encourages interactivity among users, it tends to encourage these network effects. For example, in certain business models, network effects come from a competitive advantage gained from the critical mass of buyers and sellers. A retail site may develop an architecture that encourages users to review and tag products. These user reviews enhance the ability of users to make informed choices, while product tagging improves their ability to find products relevant to their interests.

Other network effects derive from vertical integration, relying on synergies between different layers or different applications to create added value and consolidate market position. This is particularly illustrated by the trend toward the "Internet of Things", in which companies deploy software in many devices and objects, and leverage this web of infrastructure to sell goods or services either to the owners of those devices or to advertisers. In this model, hardware and software infrastructure becomes a privileged channel to get in touch with end users and to create value by monetising their attention (advertising-based business models), the data that flows from them, or the externalities generated through network effects, or through selling them goods or services.

\subsubsection{Multi-sided business models}

A multi-sided business model is one that is based on a market in which multiple distinct groups of persons interact through an intermediary or platform, and the decisions of each group of persons affects the outcome for the other groups of persons through a positive or negative externality. In a multi-sided business model, the prices charged to the members of each group reflect the effects of these externalities. If the activities of one side create a positive externality for another side (for example more clicks by users on links sponsored by advertisers), then the prices to that other side can be increased.

An example of a multi-sided business model involving positive externalities for different sides of the market is a payment card system, which will be more valuable to merchants if more consumers use the card, and more valuable to consumers if more merchants accept the card. Similarly, an operating system is more valuable to end users if more developers write software for it, and more valuable to software developers if more potential software purchasers use the operating system.

A negative externality from one side for another side (e.g. displays of intrusive and unattractive advertising banners) can be offset by a lower price, or even no charge or a reward for the users. The classic case in which one side experiences negative externalities from the other side's participation is found in the media industry. In that case, a company attracts users by 
providing content (television or radio programming, a magazine, a trade publication, a phonebook, or a newspaper) for free or at a cost less than the cost of production. The media company displays advertisements to its readers/listeners/viewers and earns revenue from advertisers whose ads it displays. Alternatively, it might earn revenue from selling information about its readers/listeners/viewers to interested parties.

The rise of the digital economy made multi-sided business models more prevalent in a cross-border context. In this regard, two key characteristics of multi-sided business models in the digital economy should be noted:

- Flexibility: The nature of digital information and the infrastructure of the Internet greatly expand the facility to design and implement multi-sided business models. Resources such as content, user data, or executable code can be stored to create value long after they have been produced. This specific nature of digital resources makes them an asset in business models where the different sides of the market can be created then dynamically adapted based on evolving technology, the latest expression of consumer demand, and a firm's position on the market. In addition, as discussed below, digital technology has enhanced the ability to collect, analyse and manipulate user and market data, which has allowed platforms to enhance the value to one side of a market of the participation of the other side of the market.

- Reach: The digital economy also makes it easier to locate the different sides of the same business model in different countries. Whereas many traditional multi-sided business models such as broadcasting paid for by advertising, or shopping malls were confined to a limited perimeter due to physical constraints or to regulations, over-the-top businesses in the digital economy can more easily connect two sides that are located far from one another to maximise value on each side. For instance, resources designed to collect data can be located near individual users, whereas the infrastructure necessary to sell this data to paying customers can be located elsewhere.

The digital economy features two prominent categories of multi-sided business models. First, a business can operate several applications that provide complementary services. This creates two types of synergy: on the one hand, the various activities pool their resources such as executable code, content, or user data; on the other hand, the activities may be put into a package that is more attractive for users. Second, vertical platform models are used to make resources available for third-party developers so as to attract their creativity as part of open innovation strategies. A platform is often the result of the large-scale development of an application that gets 
commoditised. For example, a company may develop a social networking service, using internally produced applications to attract consumers and funding operations through the sale of advertising. The company may also choose to open an application programming interface (API) which allows developers to easily implement applications using the platform. Access to the API minimises the developers' initial investment and facilitates their access to the market of consumers that use the platform. The participation of the developers, in turn, enhances the user experience, thereby further strengthening the company's position in the marketplace.

\subsubsection{Tendency toward monopoly or oligopoly}

In some markets, particularly where a company is the first actor to gain traction on an immature market, network effects combined with low incremental costs may enable the company to achieve a dominant position in a very short time. This ability to gain traction can be enhanced where a patent or other intellectual property right grants one competitor the exclusive power to exploit a particular innovation in a particular market. The impact of these network effects tend to lead to this result, for example, where companies provide a platform or market in which users on one side of the market prefer to use only a single provider, so that value to those users is enhanced when a single standard is chosen, and the price that can be charged to the other side is enhanced because the platform becomes the only means of access to those users. Ease of adoption of a new platform means that some players, as a result of customer choices compounded by network effects, have been able to rise to a dominant market position extremely quickly. In some cases, despite the volatility outlined below, companies have been able to leverage that market position to secure dominance. In markets that feature this tendency, network effects are magnified. It should be noted, however, that in the digital economy, many networks operate simultaneously, with the result that in many cases competition in a monopolised market may be influenced by other markets, which combined with the reduced entry barriers, can moderate monopoly power in the first market.

\subsubsection{Volatility}

Technological progress has led to progress in miniaturisation and a downward trend in the cost of computing power. In addition, neither an Internet end user nor in many cases the service provider are required to pay a marginal price for using the network. These factors, combined with increased performance and capital expenditure have markedly reduced barriers to entry for new Internet-based businesses. These factors have combined to foster innovation and the constant development of new business models. As a result, in short periods of time, companies that appeared to control a substantial part 
of the market and enjoyed a dominant position for a short period of time have found themselves rapidly losing market share to challengers that built their businesses on more powerful technology, a more attractive value proposal, or a more sustainable business model. Due to the fast pace of innovation, the few companies that have managed long-term success typically have done so by investing substantial resources in research and development and in acquiring start-ups with innovative ideas, launching new features and new products, and continually evaluating and modifying business models in order to leverage their market position and maintain dominance in the market.

\section{Notes}

1. E-commerce includes orders made over the Internet, through an extranet (a network where outside business partners, supplier or customers can have limited access to a portion of enterprise intranet/network), or through an electronic data interchange (EDI - a proprietary electronic system used for exchanging business data over networks).

2. Cloud computing is defined in the report of the US National Institute of Standards and Technology (NIST) as "a model for enabling ubiquitous, convenient, on-demand network access to a shared pool of configurable computing resources (e.g. networks, servers, storage, applications, and services) that can be rapidly provisioned and released with minimal management effort or service provider interaction."

According to NIST, the cloud model is composed of five essential characteristics:

- On-demand self-service: A user can unilaterally act without requiring human interaction with each service's provider.

- Broad network access: Capabilities are available over the network and accessed through standard mechanisms that promote use by heterogeneous client platforms (e.g. mobile phones, laptops, and PDAs).

- Resource pooling: The provider's computing resources (e.g. storage, processing, memory, network bandwidth, and virtual machines) are pooled to serve multiple users using a multi-tenant model.

- Rapid elasticity: Capabilities can be rapidly and elastically provisioned.

- Measured Service: resources use can be monitored, controlled, and reported providing transparency for both the provider and consumer of the utilised service. 
3. The ICT Top 250 list is a well-established list compiled by the OECD since 2002 . The sources used to identify the top ICT firms include Business Week's Information Technology 100, Software Magazine's Top 50, Forbes 2000, Washington Post 200, Forbes Largest Private Firms, Top 100 Outsourcing, World Top 25 Semiconductors. The list relies on financial reports available publicly. The OECD defines ICT activities as production of goods or services "primarily...intended to fulfil or enable the function of information processing and communication by electronic means, including transmission and display" and therefore ICT firms are those that produce the equipment, software and services that enable those activities. Each of the top 250 firms is classified by ICT industry sector: $i)$ communication equipment and systems; ii) electronics; iii) semiconductors; iv) IT equipment and systems; v) IT services; vi) software; vii) Internet; and viii) telecommunication services. Note that these figures describe total revenue earned, rather than net profits.

\section{Bibliography}

Aubusson, M. et al. (2013), Global Entertainment and Media Outlook: 2013 - 2017, PwC.

DDMI (Data Driven Marketing Institute) (2013), "The Value of Data: Consequences for Insight, Innovation, and Efficiency in the U.S. Economy", DMA.

Emarketer.com (2013), "Ecommerce Sales Topped 1 Trillion-First-Time", www.emarketer.com/Article/Ecommerce-Sales-Topped-1-Trillion-FirstTime-2012/1009649 (accessed on 15 May 2012).

Easley. D, Kleinberg. J (2010), Networks, Clouds and Markets: Reasoning about a Highly Connected World, Cambridge University Press, United Kingdom.

Gartner, Inc. (2013), “Gartner says Mobile App Stores Will See Annual Downloads Reach 102 Billion in 2013"www.gartner.com/newsroom/ id/2592315 (accessed on 15 May 2014).

OECD (2011), OECD Guide to Measuring the Information Society 2011, OECD Publishing, Paris, http://dx.doi.org/10.1787/9789264113541-en.

OECD (2012), OECD Internet Economy Outlook 2012, OECD Publishing, Paris, http://dx.doi.org/10.1787/9789264086463-en. 
OECD (2013), OECD Science, Technology and Industry Scoreboard 2013: Innovation for Growth, OECD Publishing, Paris. http://dx.doi.org/10.1787/ sti_scoreboard-2013-en.

OECD (2013), "Exploring Data-Driven Innovation as a New Source of Growth: Mapping the Policy Issues Raised by "Big Data", OECD Digital Economy Papers, No. 222, OECD Publishing, Paris, http://dx.doi.org/10.1787/5k47zw3fcp43-en.

World Trade Organisation (2013), E-Commerce in Developing Countries: Opportunities and Challenges for Small and Medium-Sized Enterprises, World Trade Organisation, Geneva. 



\section{Chapter 5}

\section{Identifying opportunities for BEPS in the digital economy}

This chapter provides a general discussion of the common features of tax planning structures that raise base erosion and profit shifting (BEPS) concerns. It then provides a detailed description of the core elements of BEPS strategies with respect to both direct and indirect taxation. 


\subsection{Common features of tax planning structures raising BEPS concerns}

As noted in the BEPS Action Plan (OECD, 2013a), BEPS concerns are raised by situations in which taxable income can be artificially segregated from the activities that generate it, or in the case of value added tax (VAT), situations in which no or an inappropriately low amount of tax is collected on remote digital supplies to exempt businesses or multi-location enterprises (MLEs) that are engaged in exempt activities. These situations undermine the integrity of the tax system and potentially increase the difficulty of reaching revenue goals. In addition, when certain taxpayers are able to shift taxable income away from the jurisdiction in which income producing activities are conducted, other taxpayers may ultimately bear a greater share of the burden. BEPS activities also distort competition, as corporations operating only in domestic markets or refraining from BEPS activities may face a competitive disadvantage relative to multinational enterprises (MNEs) that are able to avoid or reduce tax by shifting their profits across borders. ${ }^{1}$

The Task Force discussed a number of tax and legal structures that can be used to implement business models in the digital economy. These structures are outlined in Annex B and show existing opportunities to achieve BEPS. In many cases, the nature of the strategies used to achieve BEPS in digital businesses is similar to the nature of strategies used to achieve BEPS in more traditional businesses. Some of the key characteristics of the digital economy may, however, exacerbate risks of BEPS in some circumstances, in the context of both direct and indirect taxation. Therefore, it is necessary to examine closely not only how business models may have evolved in the digital economy, but also how overall business models can be implemented in an integrated manner on an international scale from a legal and tax structuring perspective.

The following paragraphs consider in more detail how BEPS strategies manifest in the digital economy. The discussion below is intended to help identify the key elements of BEPS strategies in the context of direct taxation, and how those strategies take advantage of the key features of the digital economy. In addition, in the context of VAT, while there is considerable diversity in the structure of VAT systems and in how they operate in practice, the discussion below broadly illustrates ways in which the digital economy places pressure on VAT systems. 


\subsection{BEPS in the context of direct taxation}

The February 2013 Report Addressing Base Erosion and Profit Shifting (OECD, 2013b) identifies a number of co-ordinated strategies associated with BEPS in the context of direct taxation, which can often be broken down into four elements:

- Minimisation of taxation in the market country by avoiding a taxable presence, or in the case of a taxable presence, either by shifting gross profits via trading structures or by reducing net profit by maximising deductions at the level of the payer.

- Low or no withholding tax at source.

- Low or no taxation at the level of the recipient (which can be achieved via low-tax jurisdictions, preferential regimes, or hybrid mismatch arrangements) with entitlement to substantial non-routine profits often built-up via intra-group arrangements.

- No current taxation of the low-tax profits at the level of the ultimate parent.

Figure 5.1. BEPS planning in the context of income tax

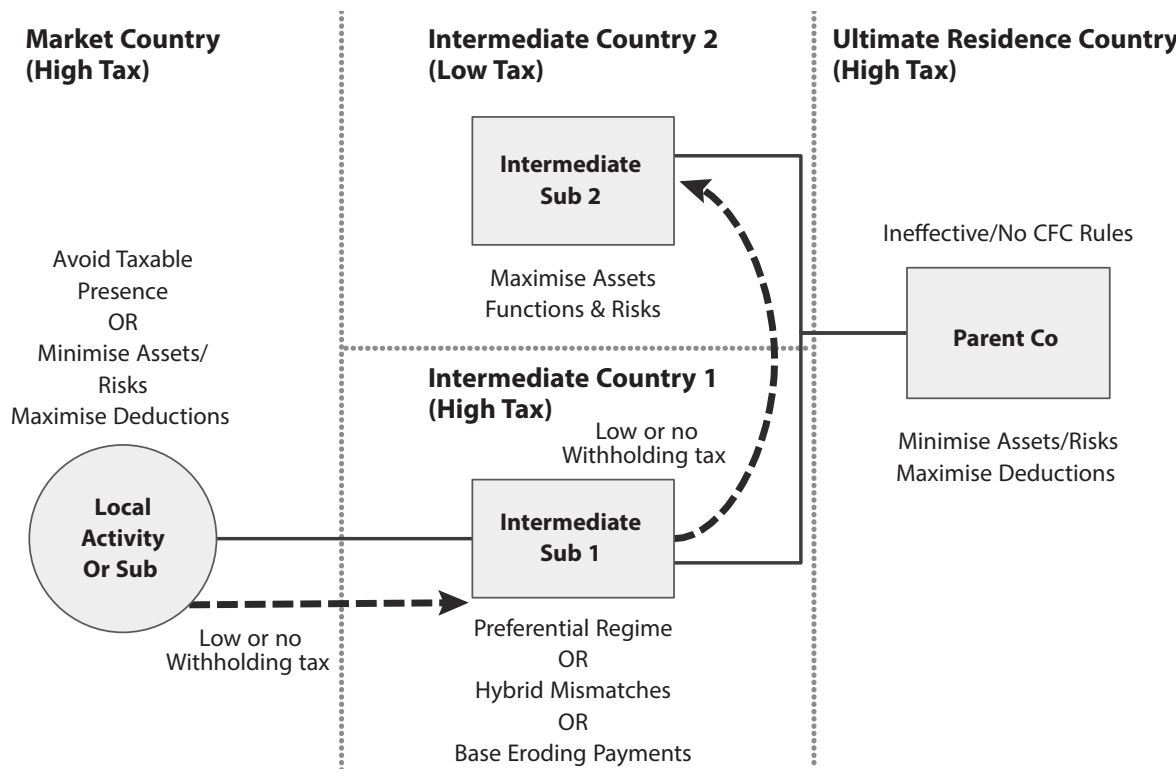




\subsubsection{Eliminating or reducing tax in the market country}

\subsubsection{Avoiding a taxable presence}

In many digital economy business models, a non-resident company may interact with customers in a country remotely through a website or other digital means (e.g. an application on a mobile device) without maintaining a physical presence in the country. Increasing reliance on automated processes may further decrease reliance on local physical presence. The domestic laws of most countries require some degree of physical presence before business profits are subject to taxation. In addition, under Articles 5 and 7 of the OECD Model Tax Convention, a company is subject to tax on its business profits in a country of which it is a non-resident only if it has a permanent establishment (PE) in that country. Accordingly, such non-resident company may not be subject to tax in the country in which it has customers.

Companies in many industries have customers in a country without a $\mathrm{PE}$ in that country, communicating with those customers via phone, mail, and fax and through independent agents. That ability to maintain some level of business connection within a country without being subject to tax on business profits earned from sources within that country is the result of particular policy choices reflected in domestic laws and relevant double tax treaties, and is not in and of itself a BEPS issue. However, while the ability of a company to earn revenue from customers in a country without having a $\mathrm{PE}$ in that country is not unique to digital businesses, it is available at a greater scale in the digital economy than was previously the case. Where this ability, coupled with strategies that eliminate taxation in the State of residence, results in such revenue not being taxed anywhere, BEPS concerns are raised. In addition, under some circumstances, tax in a market jurisdiction can be artificially avoided by fragmenting operations among multiple group entities in order to qualify for the exceptions to PE status for preparatory and auxiliary activities, or by otherwise ensuring that each location through which business is conducted falls below the PE threshold. Structures of this type raise BEPS concerns.

\subsubsection{Minimising the income allocable to functions, assets and risks in market jurisdictions}

In many cases, an MNE group does maintain a degree of presence in countries that represent significant markets for its products. In the context of the digital economy, an enterprise may establish a local subsidiary or a $\mathrm{PE}$, with the local activities structured in a way that generates little taxable profit. Where these structures accurately reflect the functions performed in each jurisdiction, the mere fact that business functions needed to conduct business in a particular country may be more limited in one type of business 
than in another does not raise BEPS issues in and of itself. This is true even if tax rates are among the factors taken into account when deciding to centralise business operations in a particular location. The ability to allocate functions, assets and risks in a way that minimises taxation does, however, create incentives to, for example, contractually allocate them in a way that does not fully reflect the actual conduct of the parties, and that would not be chosen in the absence of tax considerations. For example, assets, in particular intangibles, and risks related to the activities carried out at the local level may be allocated via contractual arrangements to other group members operating in a low-tax environment in a way that minimises the overall tax burden of the MNE group.

Under these structures, there is an incentive for the affiliate in the low-tax environment to undervalue (typically at the time of the transfer) the transferred intangibles or other hard-to-value income-producing assets, while claiming that it is entitled to have large portions of the MNE group's income allocated to it on the basis of its legal ownership of the undervalued intangibles, as well as on the basis of the risks assumed and the financing it provides. Operations in higher tax jurisdictions can be contractually stripped of risk, and can avoid claiming ownership of intangibles or other valuable assets or holding the capital that funds the core profit making activities of the group. Economic returns are thus reduced and income is shifted into low-tax environments.

Examples of digital economy structures that can be used to minimise the tax burden in market jurisdictions through contractual allocation of assets and risks include using a subsidiary or PE to perform marketing or technical support, or to maintain a mirrored server to enable faster customer access to the digital products sold by the group, with a principal company contractually bearing the risks and claiming ownership of intangibles generated by these activities. A company may, for example, limit risk at the local company level by limiting capitalisation of that entity so that it is financially unable to bear risk. In the case of businesses selling tangible products online, a local subsidiary or PE may maintain a warehouse and assist in the fulfilment of orders. These subsidiaries or PEs will be taxable in their jurisdiction on the profits attributable to services they provide, but the amount they earn may be limited. Alternatively, functions allocated to local staff under contractual arrangements may not correspond with the substantive functions performed by the staff. For example, staff may not have formal authority to conclude contracts on behalf of a non-resident enterprise, but may perform functions that indicate effective authority to conclude those contracts. If the allocations of functions, assets, and risks do not correspond to actual allocations, or if less-than-arm's length compensation is provided for intangible property of a principal company, these structures may present BEPS concerns. 


\subsubsection{Maximising deductions in market jurisdictions}

Once a taxable presence in the market country has been established, another common technique to reduce taxable income is to maximise the use of deductions for payments made to other group companies in the form of interest, royalties, service fees, etc. In many cases, MNEs engaging in BEPS practices attempt to reduce taxable income in a source country by maximising the amount of deductible payments made to affiliates in other jurisdictions. For example, an affiliate in a low-tax jurisdiction may, due to a favourable credit rating, be able to borrow money at a low rate. It may then lend money to its subsidiaries in high-tax jurisdictions at a higher rate, thereby reducing the income of those subsidiaries by the amount of the deductible interest payments. Alternatively, an affiliate may use hybrid instruments to create deductible payments for a subsidiary in a source country that result in no inclusion in the country of residence of the affiliate. Payments (including underpayments) for the use of intangibles held by low-tax group companies or for services rendered by other group companies can also be used to reduce taxable income in the market country. These techniques can be used to reduce the taxable income from the local operations to extremely low amounts.

\subsubsection{Avoiding withholding tax}

A company may be subject to withholding tax in a country in which it is not a resident if it receives certain payments, including interest or royalties, from payers in that country. If allowed under a treaty between the jurisdictions of the payer and recipient, however, a company in the digital economy may be entitled to reduced withholding or exemption from withholding on payments of profits to a lower-tax jurisdiction in the form of royalties or interest. Structures that involve treaty shopping by interposing shell companies located in countries with favourable treaty networks that contain insufficient protections against treaty abuse raise BEPS concerns.

\subsubsection{Eliminating or reducing tax in the intermediate country}

Eliminating or reducing tax in an intermediate country can be accomplished through the application of preferential domestic tax regimes, the use of hybrid mismatch arrangements, or through excessive deductible payments made to related entities in low or no-tax jurisdictions.

Companies may locate functions, assets, or risks in low-tax jurisdictions or countries with preferential regimes, and thereby allocate income to those locations. While functions are often located in a particular jurisdiction for nontax reasons such as access to skilled labour or necessary resources, as business functions grow increasingly mobile, taxpayers may increasingly be able to locate functions in a way that takes advantage of favourable tax regimes. 
In the context of the digital economy, for example, the rights to intangibles and their related returns can be assigned and transferred among associated enterprises, and may be transferred, sometimes for a less-than-arm's length price, ${ }^{2}$ to an affiliate in a jurisdiction where income subsequently earned from those intangibles is subject to unduly low or no-tax due to the application of a preferential regime. This creates tax planning opportunities for MNEs and presents substantial risks of base erosion. Heavy reliance in the digital economy on intangibles as a source of value may exacerbate the ability to concentrate value-producing intangibles in this way.

Companies may also reduce tax in an intermediate country by generating excessive deductible payments to related entities that are themselves located in low or no-tax jurisdictions or otherwise entitled to a low rate of taxation on the income from those payments. For example, an operating company located in an intermediate jurisdiction may use intangibles held by another affiliate in a low-tax jurisdiction. The royalties for the use of these intangibles may be used to effectively eliminate taxable profits in the intermediate jurisdiction. Alternatively, an entity in an intermediate jurisdiction may make substantial payments to a holding company located in a low or no-tax jurisdiction for management fees or head office expenses. Companies may also avoid taxes in an intermediate country by using hybrid mismatch arrangements to generate deductible payments with no corresponding inclusion in the country of the payee. Companies may also use arbitrage between the residence rules of the intermediate country and the ultimate residence country to create stateless income. In addition, companies may assert that the functions performed, assets used, and risks assumed in the intermediate country are limited.

\subsubsection{Eliminating or reducing tax in the country of residence of the ultimate parent}

Broadly speaking, the same techniques that are used to reduce taxation in the market country can also be used to reduce taxation in the country of the ultimate parent company of the group or where the headquarters are located. This can involve contractually allocating risk and legal ownership of mobile assets like intangibles to group entities in low-tax jurisdictions, while group members in the jurisdiction of the headquarters are undercompensated for the important functions relating to these risks and intangibles that continue to be performed in the jurisdiction of the headquarters. In this situation it can be claimed that a marginal remuneration for the important functions is arm's length and that all the remaining profits should be attributed to the legal owner of movable assets or to the party that is contractually bearing the risk.

In addition, companies may avoid tax in the residence country of their ultimate parent if that country has an exemption or deferral system for foreignsource income and either does not have a controlled foreign company (CFC) 
regime that applies to income earned by controlled foreign corporations of the parent, or has a regime with inadequate coverage of certain categories of passive or highly mobile income, including in particular certain income with respect to intangibles. For example, the parent company may transfer hardto-value intangibles to a subsidiary in a low or no-tax jurisdiction, thereby causing income earned with respect to those intangibles to be allocated to that jurisdiction without appropriate compensation to the parent company. In some cases, a CFC regime might permit the residence jurisdiction to tax income from these intangibles. Many jurisdictions, however, either do not have a CFC regime, have a regime that fails to apply to certain categories of income that are highly mobile, or have a regime that can be easily avoided using hybrid mismatch arrangements.

\subsection{Opportunities for BEPS with respect to VAT}

To the extent that Guidelines 2 and 4 of the OECD's "Guidelines on place of taxation for B2B supplies of services and intangibles" (see Chapter 6 below) are not implemented, under certain conditions opportunities for tax planning by businesses and corresponding BEPS concerns for governments in relation to VAT may arise with respect to (i) remote digital supplies to exempt businesses and (ii) remote digital supplies acquired by enterprises that have establishments (branches) in more than one jurisdiction (MLE) that are engaged in exempt activities.

\subsubsection{Remote digital supplies to exempt businesses}

VAT is generally not designed to be a tax on businesses as businesses are generally able to recover any tax they pay on their inputs. Many VAT jurisdictions using the destination principle for business-to-business (B2B) digital supplies will generally require a business customer in their jurisdiction to self-assess VAT on acquisitions of remotely delivered services and intangibles and then allow the business to claim a credit for this self-assessed VAT. The vast number of cross-border supplies made between businesses (other than businesses engaged in exempt activities) do not therefore, generally create BEPS concerns. BEPS concerns in a VAT context could arise however, with respect to offshore digital supplies made to exempt businesses (e.g. the financial services industry). Where a business is engaged in VAT-exempt activities, no VAT is levied on the exempt supplies made by the business, while VAT incurred by the business on the associated inputs is not deductible.

For example, a business acquiring a data processing service from a nonresident supplier would be required to self-assess VAT according to the rules of the jurisdiction in which it is located and could claim an off-setting credit for this self-assessed VAT (some jurisdictions may not require the business 
to self-assess tax as it is entitled to an offsetting credit). If the business customer is an exempt business, it is still required to self-assess VAT in these jurisdictions but would not be able to claim a credit for the self-assessed tax. The exempt business is then "input taxed" in its residence jurisdiction, where it is assumed to use the service for making exempt supplies.

However, some jurisdictions currently do not require the exempt business to self-assess VAT on the services and intangibles acquired from abroad. In such case, no VAT is levied on the transaction. BEPS concerns also arise if the data processing services would be subject to VAT in the jurisdiction where the supplier is resident (established, located). The VAT would then accrue to the jurisdiction in which the supplier is situated and not the jurisdiction of the exempt business. This is likely to raise concerns particularly where this jurisdiction has no VAT or a VAT rate lower than the rate in the jurisdiction of the exempt business customer. In these cases, the exempt business customer would pay no VAT or an inappropriately low amount of VAT. The above cases illustrate how an exempt business could pay no or an inappropriately low amount of VAT when acquiring digital supplies from suppliers abroad. They also illustrate how domestic suppliers of competing services could face potential competitive pressures from non-resident suppliers. Domestic suppliers are required to collect and remit VAT on their supplies of services to domestic businesses while non-resident suppliers could structure their affairs so that they collect no or an inappropriately low amount of VAT.

\subsubsection{Remote digital supplies to a multi-location enterprise}

BEPS concerns could also arise in cases where a digital supply is acquired by an MLE. It is common practice for multinational businesses to arrange for a wide scope of services to be acquired centrally to realise economies of scale. Typically, the cost of acquiring such a service or intangible is initially borne by the establishment that has acquired it and, in line with normal business practice, is subsequently recharged to the establishments using the service or intangible. The establishments are charged for their share of the service or intangible on the basis of the internal recharge arrangements, in accordance with corporate tax, accounting and other regulatory requirements. However, many VAT jurisdictions do not currently apply VAT to transactions that occur between establishments of one single legal entity.

This means that where an establishment of an MLE acquires a service, for instance data processing services, for use by other establishments in other jurisdictions, no additional VAT would apply on any internal cost allocations or recharges made within the MLE for the use of these services by other establishments. On the other hand, the establishment that acquired the service will be generally entitled to recover any input VAT on the acquisition of these services if it is a taxable business. In other words, the other establishments 
using the data processing services are able to acquire their portion of these services without incurring any VAT. This is generally not a great concern from a VAT perspective if all of the establishments of the MLE using the service are taxable businesses. This is because in this case they have a right to recover any input VAT. However, where the establishments using the data processing services are exempt businesses, they are not normally entitled to recover VAT paid on their inputs.

Take for example processing of data relating to banking transactions: if an establishment of a multinational bank would acquire such services directly from a local supplier, it would generally incur input VAT on these services; it would not be able to deduct this input VAT as it relates to VATexempt activities. Alternatively, this establishment of a multinational bank could acquire these processing services though another establishment of the same bank in another country and then reimburse this other establishment for the cost of acquiring these services on its behalf. This would allow the establishment of this bank to acquire the processing services without incurring any VAT in the jurisdiction where it is located, as no VAT is levied on the dealings between establishments of the same legal entity. If the acquiring establishment would be located in a country without a VAT, the multinational bank could acquire these services for all its establishments around the world without incurring any input VAT at all by channelling its acquisitions through its establishment in a no VAT jurisdiction. VAT-exempt businesses can make substantial VAT savings by using such channelling structures.

\section{Notes}

1. Such competitive disadvantages may also arise when competing enterprises are subject to different levels of taxation in their home jurisdictions, although that is beyond the concerns raised by BEPS.

2. Even when the country from which the Internet Protocol (IP) is transferred requires that transfers be made at arm's length, taxpayers may take aggressive positions that in fact result in less than an arm's length amount being recorded for tax purposes with respect to the transfer. 


\section{Bibliography}

OECD (2013a), Action Plan on Base Erosion and Profit Shifting, OECD

Publishing, Paris, http://dx.doi.org/10.1787/9789264202719-en.

OECD (2013b), Addressing Base Erosion and Profit Shifting, OECD

Publishing, Paris, http://dx.doi.org/10.1787/9789264192744-en. 



\section{Chapter 6}

\section{Tackling BEPS in the digital economy}

This chapter discusses how work on the actions of the base erosion and profit shifting (BEPS) Action Plan and in the area of indirect taxation will address BEPS issues arising in the digital economy. It also highlights the particular characteristics of the digital economy that must be taken into account to ensure that the measures developed effectively address BEPS in the digital economy. 


\subsection{Introduction}

Many of the key features of the digital economy, particularly those related to mobility, generate BEPS concerns in relation to both direct and indirect taxes. For example, the importance of intangibles in the context of the digital economy, combined with the mobility of intangibles for tax purposes under existing tax rules, generates substantial BEPS opportunities in the area of direct taxes. The mobility of users creates substantial challenges and risks in the context of the imposition of value added tax (VAT). The ability to centralise infrastructure at a distance from a market jurisdiction and conduct substantial sales into that market from a remote location, combined with increasing ability to conduct substantial activity with minimal use of personnel, generates potential opportunities to achieve BEPS by fragmenting physical operations to avoid taxation.

Work on the actions of the BEPS Action Plan (OECD, 2013) should take into account these key features in order to ensure that the proposed solutions fully address BEPS in the digital economy. The following sections describe how the work on the implementation of the BEPS Action Plan, as well as the work on consumption taxes, is expected to address these BEPS concerns.

\subsection{Restoring taxation on stateless income}

Structures aimed at artificially shifting profits to locations where they are taxed at more favourable rates, or not taxed at all, will be rendered ineffective by ongoing work in the context of the BEPS Project. At the same time, the work on BEPS will increase transparency between taxpayers and tax administrations and among tax administrations themselves. Risk assessment processes at the level of the competent tax administration will be enhanced by measures such as the mandatory disclosure of aggressive tax planning arrangements and uniform transfer pricing documentation requirements, coupled with a template for country-by-country (CBC) reporting. The comprehensiveness of the BEPS Action Plan will ensure that, once the different measures are implemented in a co-ordinated manner, taxation is more aligned with where economic activities take place. This will restore taxing rights at the level of both the market jurisdiction and the jurisdiction of the ultimate parent company, with the aim to put an end to the phenomenon of so-called stateless income.

\subsubsection{Measures that will restore taxation in the market jurisdiction}

A number of measures of the BEPS Action Plan will in effect restore source taxation, in particular Action 6 (prevent treaty abuse) and Action 7 (prevent the artificial avoidance of PE status). 


\subsubsection{Prevent treaty abuse (Action 6)}

Effective rules to tackle the abuse of tax treaties are under development and model provisions will be delivered by September 2014. These rules will first address treaty shopping arrangements through which companies are set up in a country in order to take advantage of the treaty network of that country rather than for carrying on business activities in that country. They will also prevent the use of structures involving the use of companies that claim to be resident of two treaty countries to achieve double non-taxation. Further, it will address unintended cases of non-taxation that result from tax treaties, in particular where countries eliminate double taxation through the exemption method.

The denial of treaty benefits in cases that could otherwise result in double non-taxation will ensure that the market country will be able to apply its domestic law unconstrained by treaty rules aimed at preventing double taxation. This is of relevance both in cases where the foreign company has claimed not to have a taxable presence in that country in the form of a permanent establishment (PE) or when there is indeed a taxable presence in the form of a PE or a group company, but the relevant taxable income is reduced by deductible payments. In cases where such deductible payments would be subject to a withholding tax under domestic law, the market country will be able to apply such a withholding tax without any treaty limitation.

\subsubsection{Prevent the artificial avoidance of PE Status (Action 7)}

The treaty definition of PE may limit the application of domestic law rules applicable to the taxation of the business profits of non-resident companies derived from sources in the market country. The work done with respect to Action 7 aims at preventing the artificial avoidance of the treaty threshold below which the market country may not tax. The objective of the work is to develop changes to the definition of PE to ensure that the intended scope of the definition and, therefore, domestic taxing rights, are not circumvented through artificial arrangements. This work is due to be delivered by September 2015.

The work would consider whether and how the definition of PE may need to be modified to address circumstances in which artificial arrangements relating to the sales of goods or services of one company in a multinational group effectively result in the conclusion of contracts, such that the sales should be treated as if they had been made by that company. This will be relevant where, for instance, an online seller of tangible products or an online provider of advertising services uses the sales force of a local subsidiary to negotiate and effectively conclude sales with prospective large clients. 
The work should also address the need to ensure that where essential business activities of an enterprise are carried on at a given location in a country, the enterprise cannot benefit from the list of exceptions usually found in the definition of PE (see e.g. Art. 5(4) of the OECD Model Tax Convention). It will also ensure that it is not possible to benefit from these exceptions through the fragmentation of business activities. In this context, the work should consider whether certain activities that were previously considered auxiliary for the purposes of these exceptions may be increasingly significant components of businesses in the digital economy. For example, if proximity to customers and the need for quick delivery to clients are key components of the business model of an online seller of physical products, the maintenance of a local warehouse could constitute a core activity of that seller. In addition to broader tax challenges (see Chapter 8), this raises BEPS issues when the lack of taxation in the market country is coupled with techniques that reduce or eliminate tax in the country of the recipient or of the ultimate parent.

\subsubsection{Measures that will restore taxation in both market and ultimate parent jurisdictions}

A number of measures in the BEPS Action Plan will contribute to restore taxation both at the level of the market jurisdiction and at the level of the parent company jurisdiction. These measures include the ones being developed in the course of the work on Action 2 (neutralise the effects of hybrid mismatch arrangements), Action 4 (limit base erosion via interest deductions and other financial payments), Action 5 (counter harmful tax practices more effectively), and Actions 8-10 (assure that transfer pricing outcomes are in line with value creation).

\subsubsection{Neutralise the effects of hybrid mismatch arrangements (Action 2)}

The BEPS Action Plan notes that hybrid mismatch arrangements can be used to achieve unintended double non-taxation or long-term tax deferral by, for example, creating two deductions for a single borrowing, generating deductions in one jurisdiction without corresponding income inclusions in another, or misusing foreign tax credit or participation exemption regimes. Existing structures within the digital economy take advantage of hybrid mismatch arrangements to achieve BEPS by stripping income from a market or intermediate jurisdiction or by avoiding application of controlled foreign company (CFC) rules or other anti-abuse regimes. The work done with respect to Action 2, which will be delivered by September 2014, will therefore, in effect, reduce opportunities for BEPS in the digital economy. 


\subsubsection{Limit base erosion via interest deductions and other financial payments (Action 4 and 9)}

The innovation that is key to success in the digital economy must be financed. Many large and well-established digital economy players are cash rich and they often finance new ventures, the acquisition of start-ups, or other assets with intra-group debt. It is often the case that taxpayers will establish and capitalise entities in low-tax environments that are then able to engage in transactions with associated enterprises that have the effect of eroding the tax base. For example, an affiliate in a low-tax environment might be established to lend to high-tax operating entities or to purchase intangibles and license them to affiliates. Excessive interest deductions on such loans, or excessive deductions for royalties paid to such low-tax entities can present BEPS concerns in countries where business operations take place. Where the capital contributed to the low-tax entity to fund these activities is borrowed from third party lenders, the base erosion effect of these arrangements may be exacerbated. The same effects can be created by the retention of earnings in low-tax entities that own intangibles or assume risk, where such retained earnings are loaned to other operating entities.

In other words, the existing rules allow affiliate entities in a low-tax environment to fund the profit generating activities of the group with intercompany debt, even though the MNE group as a whole may be much less heavily leveraged. This ultimately reduces tax at the level of the market jurisdiction and at the level of the parent company jurisdiction, with the interest often going untaxed anywhere for a number of reasons (such as the availability of preferential regimes, the use of hybrid instruments, and the availability of generous deductions). Existing tax planning arrangements within the integrated global businesses that characterise the digital economy take advantage of this type of structuring to achieve BEPS.

The work done with respect to Action 4 will make recommendations regarding best practices in the design of domestic rules, in order to reduce opportunities for BEPS via deductibility of interest and other financial payments. This work will address BEPS opportunities with respect to both interest paid to related parties and to third parties, and will address both inbound and outbound investment scenarios. In co-ordination with this work, the work under Action 9 of the BEPS Action Plan will consider whether these behaviours have any transfer pricing implications and, as necessary, identify mechanisms to address those implications, within or beyond the arm's length principle. Similarly, more detailed guidance on the application of transfer pricing principles to loans, guarantees, captive insurance and other financial transactions will be developed. In this respect, a formulary type of approach which ties the deductible interest payments to external debt payments may lead to results that better reflect the business reality of multinational 
enterprise (MNE) groups. Other approaches to address excessive interest deductions will also be analysed. The output of this work will be delivered by September 2015.

\subsubsection{Counter harmful tax practices more effectively (Action 5)}

Digital economy companies heavily rely on intangible assets to create value and produce income. Intangible assets, and income arising from the exploitation of intangibles, are by definition geographically mobile. Over the last decade, a number of OECD and non-OECD countries have introduced intangible regimes which provide for a preferential tax treatment for certain income arising from the exploitation of Internet Protocol (IP), generally through a $50 \%$ to $80 \%$ deduction or exemption of qualified IP income.

The work in the context of the BEPS Action Plan examines intangible regimes of the type described to determine whether they constitute harmful preferential tax regimes within the meaning of the OECD's 1998 Report "Harmful Tax Competition: An Emerging Global Issue". Action 5 of the BEPS Action Plan specifically requires substantial activity for any preferential regime and mandates that the existing substance factor to assess regimes be elaborated in the context of BEPS. IP regimes will be assessed against the elaborated substance factor and the other factors in the 1998 Report. The work on substantial activity and its application to IP regimes, as well as other preferential regimes, is under way. If any of the IP regimes under review were to be found harmful, the relevant country would be given the opportunity to abolish the regime or remove the features that create the harmful effect, as the case may be.

\subsubsection{Assure that transfer pricing outcomes are in line with value creation (Actions 8-10)}

The BEPS work on transfer pricing is intended to address BEPS issues that commonly arise among companies active in the digital economy as well as other taxpayers. Many of the structures involve separating business functions between different legal entities in the group, treating some of those entities as low-risk / low-profit entities, and others as high-risk / high-profit ones, making certain that the high-risk / high-profit entities do not conduct activities that trigger taxation in high-tax jurisdictions. Taken together, the overall objective of the transfer pricing actions is to bring the allocation of income within a multinational group of companies more directly in line with the location of the economic activity that gives rise to that income. This objective is pursued by focusing on key issues such as (i) intangibles, (ii) business risks, (iii) re-characterisation of transactions, (iv) base eroding payments, and $(v)$ global value chains and profit splits. 
i. Intangibles, including hard-to-value intangibles, and cost contribution arrangements

A key feature of many BEPS structures adopted by participants in the digital economy involves the transfer of intangibles or rights to intangibles to tax advantaged locations. Digital economy companies rely heavily on intangibles in creating value and producing income. Depending on the local law, below value transfers of intangibles can be facilitated through licensing arrangements, cost contribution arrangements or tax structures that separate deductions relevant to the development of the intangible from the income associated with it. Below value transfers of intangibles can occur (i) because of difficulties in valuing transferred intangibles at the time they are transferred; (ii) because of unequal access to information relating to value between taxpayers and tax administrations; and (iii) because some arrangements result in the transfer of hidden or unidentified intangibles without payment.

The BEPS work on intangibles will address these issues by taking several steps. First, the work will make it clear that the term intangibles should be defined broadly and clearly, and that any intangible item for which unrelated parties would provide compensation upon transfer must be compensated in transfers between associated enterprises. This will help ensure that transfers of hidden intangibles are not used to shift income. Second, the work will ensure that entities within an MNE group that contribute value to intangibles either by performing or managing development functions or by bearing and controlling risks are appropriately rewarded for doing so. It will also make clear that valuation techniques can be used when comparable transfers of intangibles cannot be identified. This first phase of the work will be delivered by September 2014. Third, in situations where partially developed intangibles or other hard-to-value intangibles are transferred, the work will consider whether the post-transfer profitability of intangibles should be taken into account in the valuation in specified circumstances in order to balance the availability of information between taxpayers and tax administrations. This second phase of the work on intangibles will be delivered by September 2015.

\section{ii. Business risks}

BEPS structures aimed at shifting income into low-tax environments often feature a contractual allocation of business risk into a low-tax affiliate. It is then often argued that these contractual allocations, together with legal ownership of intangibles, justify large allocations of income to the entity allocated the risk. Often this is accomplished by arguing that other entities in the group are contractually insulated from risk so that a low-tax affiliate is entitled to all residual income after compensating other low risk group members for their functions. The work will address questions related to contractual risk allocation by requiring control of risk, financial capacity to 
bear risk, and management of risk to be more closely aligned. The guidance will also identify risks that, by their nature, are borne by the MNE group as a whole and which therefore cannot be readily assigned to a single group entity. The output of this work will be delivered by September 2015 .

\section{iii. Recharacterisation of transactions}

The existing transfer pricing guidelines require an analysis that takes as its starting point the transactions entered into by the taxpayer. The guidelines permit recharacterising or disregarding the taxpayer's transactional form in only some exceptional circumstances, the exact boundaries of which are not fully clear. Consideration is being given to whether the scope of current guidance on recharacterising taxpayer transactions should be revisited to reframe or clarify the guidance, and in what particular circumstances those rules may require modification. It is worth noting that there are significant complexities associated with disregarding taxpayer transactional forms. A broad scope for dispute and double taxation could arise if the scope for recharacterisation were expanded significantly, especially if this expansion is based on principles that cannot be limited to transactions with entities in low-tax environments. This means that careful weighing is required regarding the particular circumstances where taxpayer designed transactions may make transfer pricing analyses so uncertain as to become unreliable, thereby opening opportunities for BEPS. The work will provide clearer guidance on the difference between appropriately identifying the specific nature of transactions undertaken based both on actual conduct and contracts, on the one hand, and disregarding or recharacterising a transaction on the other hand. Because an unlimited authority in the hands of tax authorities to recharacterise transactions may lead to unwanted double taxation and increased levels of controversy, guidance will make clear that understanding precisely what business activities individual entities undertake is a critical element in the process of analysing transfer pricing matters. The output of this work will be delivered by September 2015.

\section{iv. Base eroding payments}

Excessive cross-border payments to related parties in low-tax jurisdictions can erode the tax base of the countries from which such payments are made. While transfer pricing rules based on the arm's length principle are theoretically equipped to address the proper amount of such payments, in some circumstances a combination of inadequate data on comparable transactions, a lack of tax administration enforcement resources, complex fact patterns, and questionable assumptions about the attribution of risk can create conditions in which excessive payments are made. This can result in such payments not being subjected to tax either in the low-tax 
recipient country or the home country of the MNE group, while they still give rise to base eroding tax deductions in the payor country. Certain targeted measures could potentially be helpful in addressing this type of BEPS. Depending on the way they are designed, such measures could preserve a measure of reliance on the arm's length approach but depart from a strict adherence to the arm's length principle in targeted circumstances. Examples of such approaches could include caps on certain payments, or formula based allocations. It would therefore be necessary to evaluate the effectiveness of these types of provisions, the areas in which they might be applied, whether they would ease administrative burdens, and mechanisms that could be used to avoid or relieve double taxation in situations where it might otherwise arise. The output of this work will be delivered by December 2015 .

\section{v. Global value chains and profit methods}

When the arm's length principle was initially devised, it was common that each country in which an MNE group did business had its own fully integrated subsidiary to carry on the group's business in that country. This structure was dictated by a number of factors, including slow communications, currency exchange rules, customs duties, and relatively high transportation costs that made integrated global supply chains difficult to operate. With the advent of the development in information and communication technology (ICT), reductions in many currency and custom barriers, and the move to digital products and a service based economy, these barriers to integration broke down and MNE groups began to operate much more as single global firms. Corporate legal structures and individual legal entities became less important and MNE groups moved closer to the economist's conception of a single firm operating in a co-ordinated fashion to maximise opportunities in a global economy. Attention should therefore be devoted to the implications of this increased integration in MNEs and evaluate the need for greater reliance on value chain analyses and profit split methods. This work should also address situations where comparables are not available because of the structures designed by taxpayers and could also include simpler and clearer guidance on the use of profit methods, including profit splits along the lines that have been successfully applied in connection with global trading and other integrated financial services businesses. The output of this work will be delivered by September 2015.

\subsubsection{Measures that will restore taxation in the jurisdiction of the ultimate parent}

In addition to measures mentioned in Chapter 2, the work on strengthening $\mathrm{CFC}$ rules may also contribute to restoring taxation in the jurisdiction of the ultimate parent company. As noted in the BEPS Action Plan, one source of 
BEPS concerns is the possibility of creating affiliated non-resident taxpayers and routing income of resident enterprises through that non-resident affiliate. Although CFC rules have been introduced in many countries to address this, there remain many jurisdictions that lack CFC rules. Where CFC rules do exist, they do not always address BEPS in a comprehensive manner. The work on CFC rules will encourage more countries to adopt CFC rules and develop recommendations regarding their design. The work will also consider the need for anti-inversion rules and to ensure that CFC rules have appropriate provisions to prevent double taxation. The output of this work will be delivered by September 2015. This measure will seek to counteract profitshifting by restoring residence state taxation and may also have spill-over effects and hence at the same time protect the tax base of source countries. This is because effective CFC rules mean that taxpayers will have less of an incentive to shift profits from a source country into a low-tax jurisdiction.

To address BEPS issues within the digital economy, CFC rules must effectively address the taxation of mobile income typically earned in the digital economy. Although CFC rules vary significantly from jurisdiction to jurisdiction, income from digital products and services provided remotely is frequently not subject to current taxation under CFC rules. Accordingly, a multinational enterprise in a digital business can earn income in a CFC in a low-tax jurisdiction by locating key intangibles there and using those intangibles to sell digital goods and services without that income being subject to current tax, even without the CFC itself performing significant activities in its jurisdiction. As a result, a digital economy company may pay little or no tax in the CFC jurisdiction while also avoiding tax in the source country and the country of ultimate residence.

To address this situation, consideration should be given to CFC rules that target income typically earned in the digital economy, such as income earned from the remote sale of digital goods and services. Such income may be particularly mobile due to the importance of intangibles in the provision of such goods and services and the relatively few people required to carry out online sales activities. A CFC rule along these lines could include an exception for situations where the CFC, through its own employees, makes a substantial contribution to the value of the goods and services sold.

\subsection{Addressing BEPS issues in the area of consumption taxes}

The digitisation of the economy has greatly facilitated the ability of businesses to acquire a wide range of services and intangibles from suppliers in other jurisdictions around the world and to structure their operations in a truly global manner. These developments have allowed exempt businesses to avoid and minimise the amount of unrecoverable VAT they pay on their 
inputs. Section 5.3 of Chapter 5 outlined the BEPS concerns that may arise from the opportunity for businesses to structure their affairs in such a way that no or an inappropriately low amount of VAT is borne by exempt businesses on remotely delivered services and intangibles.

The implementation of Guidelines 2 and 4 of the OECD's "Guidelines on place of taxation for business-to-business (B2B) supplies of services and intangibles" would minimise BEPS opportunities for supplies of remotely delivered services and intangibles made to exempt businesses, including exempt entities that operate through establishments (branches) in multiple jurisdictions (multiple location entities (MLEs)).

Guideline 2 recommends that the taxing rights on cross-border supplies of services and intangibles between businesses be allocated to the jurisdiction where the customer has located its business establishment and that business customers be required to self-assess VAT on remotely delivered services or intangibles acquired from offshore suppliers according to the rules of the jurisdiction in which they are located.

Guideline 4 provides that when a supply is made to a business that is established in more than one jurisdiction, taxation should accrue to the jurisdiction where the customer's establishment (branch) using the service or intangible is located. These Guidelines set out the possible mechanisms for tax authorities to achieve the desired result in practice, which is allocation of the right to levy VAT on B2B services and intangibles to the jurisdiction where these services are used for business purposes irrespective of how the supply and acquisition of these services and intangibles were structured.

\section{Bibliography}

OECD (2013), Action Plan on Base Erosion and Profit Shifting, OECD Publishing, Paris, http://dx.doi.org/10.1787/9789264202719-en. 



\section{Chapter 7}

\section{Broader tax challenges raised by the digital economy}

This chapter discusses the challenges that the digital economy raises for direct taxation, with respect to nexus, the tax treatment of data, and characterisation of payments made under new business models. It also discusses the indirect tax challenges raised by the digital economy with respect to exemptions for imports of low-valued goods, and remote digital supplies to consumers. Finally, it lists certain administrative challenges faced by tax administrations in applying the current rules. 


\subsection{The digital economy and the challenges for policy makers}

The spread of the digital economy brings about many benefits, for example in terms of growth, employment and well-being more generally. At the same time it gives rise to a number of challenges for policy makers. These challenges extend well beyond domestic and international tax policy and touch upon areas such as international privacy law and data protection, as well as accounting and regulation.

From a strategic tax policy perspective, the uptake of digital technologies may potentially constrain the options available to policymakers in relation to the overall tax mix. For decades, companies have contributed to public expenses via a broad range of taxes in addition to corporate income tax. These taxes include employment taxes, environmental taxes, property and land taxes. The development of digital technologies has the potential to enable economic actors to operate in ways that avoid, remove, or significantly reduce, their tax liability within these bases. This may increase the pressure on a smaller number of taxpayers to compensate for the related loss of revenues. It also highlights the importance of designing corporate income and consumption tax systems that promote growth and investment, while reducing inequality and establishing a level playing field among economic actors.

The following sections examine a number of the tax challenges raised by the digital economy in relation to corporate income tax and consumption taxation.

\subsection{An overview of the tax challenges raised by the digital economy}

The evolution of business models in general, and the growth of the digital economy in particular, have resulted in non-resident companies operating in a market jurisdiction in a fundamentally different manner today than at the time international tax rules were designed. For example, while a non-resident company has always been able to sell into a jurisdiction without a physical presence there, advances in information and communication technology (ICT) have dramatically expanded the scale at which such activity is now possible. In addition, traditionally for companies to expand opportunities in a market jurisdiction, a local physical presence in the form of manufacturing, marketing, and distribution was very often required. These in-country operations would have engaged in potential high-value operations such as procurement, inventory management, local marketing, branding and other activities that earned a local return subject to tax in the market country. Advances in business practices, coupled with advances in ICT and liberalisation of trade policy, have allowed businesses to centrally manage many functions that previously required local presence, rendering the traditional model of doing business in market 
economies obsolete. The fact that existing thresholds for taxation rely on physical presence is partly due to the need in many traditional businesses for a local physical presence in order to conduct substantial sales of goods and services into a market jurisdiction formed. It is also due in part to the need to ensure that the source country has the administrative capability of enforcing its taxing rights over a non-resident enterprise. The fact that less physical presence is required in market economies in typical business structures today - an effect that can be amplified in certain types of businesses in the ICT sector therefore raises challenges for international taxation.

Other elements of the digital economy have also raised challenges for policy makers. As noted above, growing reliance in certain new business models on data may raise tax challenges in terms of characterisation of and attribution of value from data. Further, new revenue streams adopted in particular due to the spread of multi-sided business models or the use of massive computing power and broadband connection trigger questions regarding the appropriate characterisation of certain transactions and payments for tax purposes. Finally, digital technologies make it easier to do business across jurisdictions, as well as enabling consumers to access products and services from anywhere in the world, generating challenges in terms of collecting the appropriate amounts of consumption tax.

In general terms, in the area of direct taxation, the main policy challenges raised by the digital economy fall into three broad categories:

- Nexus: The continual increase in the potential of digital technologies and the reduced need in many cases for extensive physical presence in order to carry on business, combined with the increasing role of network effects generated by customer interactions, can raise questions as to whether the current rules to determine nexus with a jurisdiction for tax purposes are appropriate.

- Data: The growth in sophistication of information technologies has permitted companies in the digital economy to gather and use information across borders to an unprecedented degree. This raises the issues of how to attribute value created from the generation of data through digital products and services, and of how to characterise for tax purposes a person or entity's supply of data in a transaction, for example, as a free supply of a good, as a barter transaction, or some other way.

- Characterisation: The development of new digital products or means of delivering services creates uncertainties in relation to the proper characterisation of payments made in the context of new business models, particularly in relation to cloud computing. 
These challenges raise questions as to whether the current international tax framework continues to be appropriate to deal with the changes brought about by the digital economy and the business models that it makes possible, and also relate to the allocation of taxing rights between source and residence jurisdictions. These challenges also raise questions regarding the paradigm used to determine where economic activities are carried out and value is created for tax purposes, which is based on an analysis of the functions performed, assets used and risks assumed. At the same time, when these challenges create opportunities for achieving double non-taxation, for example due to the lack of nexus in the market country under current rules coupled with lack of taxation in the jurisdiction of the income recipient and of that of the ultimate parent company, they also generate BEPS issues.

Although the challenges related to corporate income tax (nexus, data and character) are distinct in nature, they may overlap with each other. For example, the characterisation of payments may trigger taxation in the jurisdiction where the payor is resident or established and hence overlap with the issue of nexus. Similarly, the collection of data from users located in a jurisdiction may trigger questions regarding whether it should give rise to nexus with that jurisdiction, and if so, whether and how the income generated from the use of these data should be attributed to that nexus. It also raises questions regarding how income from transactions involving data should be characterised for tax purposes.

The digital economy also creates challenges for value added tax (VAT) systems, particularly where goods, services and intangibles are acquired by private consumers from suppliers abroad. This is partly due to the absence of an effective international framework to ensure VAT collection in the jurisdiction of consumption. For economic actors, and in particular small and medium enterprises, the absence of an international standard for charging, collecting and remitting the tax to a potentially large number of tax authorities, creates difficulties and high compliance costs. From a government viewpoint, there is a risk of loss of revenue and trade distortion, as well as the challenge of managing tax liabilities generated by a high volume of low value transactions, which can create a significant administrative burden but marginal revenues.

In addition to these policy challenges, which are further discussed below, the Task Force has also identified a number of administrative issues raised by the digital economy. These latter issues are outlined in the box at the end of this chapter. 


\subsection{Nexus and the ability to have a significant presence without being liable to tax}

Advances in digital technology have not changed the fundamental nature of the core activities that businesses carry out as part of a business model to generate profits. To generate income, businesses still need to source and acquire inputs, create or add value, and sell to customers. To support their sales activities, businesses have always needed to carry out activities such as market research, marketing and advertising, and customer support. Digital technology has, however, had significant impact on how these activities are carried out, for example by enhancing the ability to carry out activities remotely, increasing the speed at which information can be processed, analysed and utilised, and, because distance forms less of a barrier to trade, expanding the number of potential customers that can be targeted and reached. Digital infrastructure and the investments that support it can be leveraged today in many businesses to access far more customers than before. As a result, certain processes previously carried out by local personnel can now be performed cross-border by automated equipment, changing the nature and scope of activities to be performed by staff. Thus, the growth of a customer base in a country does not always need the level of local infrastructure and personnel that would have been needed in a "predigital" age.

This increases the flexibility of businesses to choose where substantial business activities take place, or to move existing functions to a new location, even if those locations may be removed both from the ultimate market jurisdiction and from the jurisdictions in which other related business functions may take place. As a result, it is increasingly possible for a business's personnel, IT infrastructure (e.g. servers), and customers each to be spread among multiple jurisdictions, away from the market jurisdiction. Advances in computing power have also meant that certain functions, including decision-making capabilities, can now be carried out by increasingly sophisticated software programmes and algorithms. For example, contracts can in some cases be automatically accepted by software programmes, so that no intervention of local staff is necessary. As discussed below, this is also true in relation to functions such as data collection, which can be done automatically, without direct intervention of the employees of the enterprise.

Despite this increased flexibility, in many cases large multinational enterprises (MNEs) will indeed have a taxable presence in the country where their customers are located. As noted in Chapter 4, there are often compelling reasons for businesses to ensure that core resources are placed as close as possible to key markets. This may be because the enterprise wants to ensure a high quality of service and have a direct relationship with key clients. It may 
also be because minimising latency is essential in certain types of business, or because in certain industries regulatory constraints limit choices about where to locate key infrastructure, capital, and personnel. It is therefore important not to overstate the issue of nexus. Nevertheless, the fact that it is possible to generate a large quantity of sales without a taxable presence should not be understated either and it raises questions about whether the current rules continue to be appropriate in the digital economy.

These questions relate in particular to the definition of permanent establishment (PE) for treaty purposes, and the related profit attribution rules. It had already been recognised in the past that the concept of PE referred not only to a substantial physical presence in the country concerned, but also to situations where the non-resident carried on business in the country concerned via a dependent agent (hence the rules contained in paragraphs 5 and 6 of Article 5 of the OECD Model). As nowadays it is possible to be heavily involved in the economic life of another country without having a fixed place of business or a dependent agent therein, concerns are raised regarding whether the existing definition of PE remains consistent with the underlying principles on which it was based. For example, the ability to conclude contracts remotely through technological means, with no involvement of individual employees or dependent agents, raises questions about whether the focus of the existing rules on conclusion of contracts by persons other than agents of an independent status remains appropriate in all cases.

These concerns are exacerbated in some instances by the fact that in certain business models, customers are more frequently entering into ongoing relationships with providers of services that extend beyond the point of sale. This ongoing interaction with customers generates network effects that can increase the value of a particular business to other potential customers. For example, in the case of a retail business operated via a website that provides a platform for customers to review and tag products, the interactions of those customers with the website can increase the value of the website to other customers, by enabling them to make more informed choices about products and to find products more relevant to their interests.

Similarly, users of a participative networked platform contribute usercreated content, with the result that the value of the platform to existing users is enhanced as new users join and contribute. In most cases, the users are not directly remunerated for the content they contribute, although the business may monetise that content via advertising revenues (as described in relation to multi-sided business models below), subscription sales, or licensing of content to third parties. Alternatively, the value generated by user contributions may be reflected in the value of business itself, which is monetised via the sale price when the business is sold by its owners. Concerns that the changing nature of customer and user interaction allows greater participation in the 
economic life of countries without physical presence are further exacerbated in markets in which customer choices compounded by network effects have resulted in a monopoly or oligopoly.

Another specific issue raised by the changing ways in which businesses are conducted is whether certain activities that were previously considered preparatory or auxiliary (and hence benefit from the exceptions to the definition of PE) may be increasingly significant components of businesses in the digital economy. For example, as indicated in Chapter 6, if proximity to customers and the need for quick delivery to clients are key components of the business model of an online seller of physical products, the maintenance of a local warehouse could constitute a core activity of that seller. Similarly, where the success of a high-frequency trading company depends so heavily on the ability to be faster than competitors that the server must be located close to the relevant exchange, questions may be raised regarding whether the automated processes carried out by that server can be considered mere preparatory or auxiliary activities.

Although it is true that tax treaties do not permit the taxation of business profits of a non-resident enterprise in the absence of a PE to which these profits are attributable, the issue of nexus goes beyond questions of PE under tax treaties. In fact, even in the absence of the limitations imposed by tax treaties, it appears that many jurisdictions would not in any case consider this nexus to exist under their domestic laws. For example, many jurisdictions would not tax income derived by a non-resident enterprise from remote sales to customers located in that jurisdiction unless the enterprise maintained some degree of physical presence in that jurisdiction. As a result, the issue of nexus also relates to the domestic rules for the taxation of non-resident enterprises.

\subsection{Data and the attribution of value created from the generation of marketable location-relevant data through the use of digital products and services}

Digital technologies enable the collection, storage and use of data, and also enable data to be gathered remotely and from a greater distance from the market than previously. Data can be gathered directly from users, consumers or other sources of information, or indirectly via third parties. Data can also be gathered through a range of transactional relationships with users, or based on other explicit or implicit forms of agreement with users. Companies collect data through different methods. These can be proactive, requesting or requiring users to provide data and using data analytics, or primarily reactive, with the quantity and nature of the information provided largely within the control of users e.g. social networking and cloud computing. As set 
out in Chapter 3, data gathered from various sources is often a primary input into the process of value creation in the digital economy. Leveraging data can create value for businesses in a variety of ways, including by allowing businesses to segment populations in order to tailor offerings, to improve the development of products and services, to better understand variability in performance, and to improve decision making. The expanding role of data raises questions about whether current nexus rules continue to be appropriate or whether any profits attributable to the remote gathering of data by an enterprise should be taxable in the State from which the data is gathered, as well as questions about whether data is being appropriately characterised and valued for tax purposes.

While it is clear that many businesses have developed ways to collect, analyse, and ultimately monetise data, it may be challenging for purposes of an analysis of functions, assets, and risks, to assign an objective value to the raw data itself, as distinct from the processes used to collect, analyse, and use that data (OECD, 2013). For accounting purposes, the value of data collected by a business, like other self-created intangibles, would generally not appear on the balance sheet of the business, and would therefore not generally be relevant for determining profits for tax purposes. Although data purchased from another related or unrelated business would be treated as an asset in the hands of the buyer (and its subsequent sale would generate tax consequences), outright sale of data is only one of many ways in which collection and analysis of data can be monetised. For example, as with other user contributions, the value of data may be reflected in the value of the business itself, and may be monetised when the business is sold. Even where data itself is sold, the value of that data may vary widely depending on the capacity of the purchaser to analyse and make use of that data. The issue of valuing data as an asset is further complicated by existing legal questions about the ownership of personal data. Many jurisdictions have passed data protection and privacy legislation to ensure that the personal data of consumers is closely protected. Under most such legislation, this information is considered to be the property of the individual from which it is derived, rather than an asset owned by a company or a public good. Economic literature analysing intangible capital, in contrast, has tended to embrace modern business realities and value also assets whose ownership may not be protected by legal rules (Corrado et al., 2012).

The value of data, and the difficulties associated with determining that value, is also relevant for tax purposes in the cross-border context and triggers questions regarding whether the remote collection of data should give rise to nexus for tax purposes even in the absence of a physical presence, and if so (or in the case of an existing taxable presence) what impact this would have on the application of transfer pricing and profit attribution principles, which in turn require an analysis of the functions performed, assets used 
and risks assumed. The fact that the value of data can impact tax results places pressure on the valuation of data. Further, the fact that the value of data can impact tax results if attributable to a PE or if held by a local subsidiary and sold to a foreign enterprise, but not if collected directly by a foreign enterprise with no PE, places pressure on the nexus issues and raises questions regarding the location of data collection.

In addition, data, including location-specific data, may be collected from customers or devices in one country using technology developed in a second country. It may then be processed in the second country and used to improve product offerings or target advertisements to customers in the first country. Determining whether profit is attributable to each of these functions and the appropriate allocation of that profit between the first country and the second country raises tax challenges. These challenges may be exacerbated by the fact that in practice a range of data may be gathered from different sources and for different purposes by businesses and combined in various ways to create value, making tracing the source of data challenging. This data may be stored and processed using cloud computing, making the determination of the location where the processing takes place similarly challenging.

Additional challenges are presented by the increasing prominence in the digital economy of multi-sided business models. A key feature of twosided business models is that the ability of a company to attract one group of customers often depends on the company's ability to attract a second group of customers or users. For example, a company may develop valuable services, which it offers to companies and individuals for free or at a price below the cost of providing the service, in order to build a user base and to collect data from those companies and individuals. This data can then be used by the business to generate revenues by selling services to a second group of customers interested in the data itself or in access to the first group. For example, in the context of internet advertising data collected from a group of users or customers can be used to offer a second group of customers the opportunity to tailor advertisements based on those data. Where the two groups of customers are spread among multiple countries, challenges arise regarding the issue of nexus mentioned above and in determining the appropriate allocation of profits among those countries. Questions may also arise about the appropriate characterisation of transactions involving data, including assessing the extent to which data and transactions based on data exchange can be considered free goods or barter transactions, and how they should be treated for tax and accounting purposes.

The changing relationship of businesses with users/customers in the digital economy may raise other challenges as well. The current tax rules for allocating income among different parts of the same MNE require an analysis of functions performed, assets used, and risks assumed. This raises questions 
in relation to some digital economy business models where part of the value creation may lie in the contributions of users or customers in a jurisdiction. As noted above, the increased importance of users/customers therefore relates to the core question of how to determine where economic activities are carried out and value is created for tax purposes.

\subsection{Characterisation of income derived from new business models}

Products and services can be provided to customers in new ways through digital technology. The digital economy has enabled monetisation in new ways, as discussed in Chapters 3 and 4, and this raises questions regarding both the rationale behind existing categorisations of income and consistency of treatment of similar types of transactions.

Prior work by the Treaty Characterisation Technical Advisory Group (TAG), discussed further in Annex A, examined many characterisation issues related to e-commerce. Although this work remains relevant, new business models raise new questions about how to characterise certain transactions and payments for domestic and tax treaty law purposes. ${ }^{1}$ For example, although the TAG considered the treatment of application hosting, cloud computing has developed significantly since that work, and the character of payments for cloud computing is not specifically addressed in the existing Commentary to the OECD Model Tax Convention. The question for tax treaty purposes is often whether such payments should be treated as royalties (particularly under treaties in which the definition of royalties includes payments for rentals of commercial, industrial, or scientific equipment), fees for technical services (under treaties that contain specific provisions in that respect), or business profits. More specifically, questions arise regarding whether infrastructureas-a-service transactions should be treated as services (and hence payments characterised as business profits for treaty purposes), as rentals of space on the cloud service provider's servers by others (and hence be characterised as royalties for purposes of treaties that include in the definition of royalties payments for rentals of commercial, industrial, or scientific equipment), or as the provision of technical services. The same questions arise regarding payments for software-as-a-service or platform-as-a-service transactions.

In the future, development and increasing use of 3D printing may also raise character questions. For example, if direct manufacturing for delivery evolves into a license of designs for remote printing directly by purchasers, questions may arise as to whether and under what circumstances payments by purchasers may be classified as royalties rather than as business profits, or may be treated as fees for technical services.

Under most tax treaties, business profits would be taxable in a country only if attributable to a PE located therein. In contrast, certain other types of income, 
such as royalties, may be subject to withholding tax in the country of the payer, depending on the terms of any applicable treaty. Whether a transaction is characterised as business profits or as another type of income, therefore, can result in a different treatment for tax treaty purposes. There is therefore a need to clarify the application of existing rules to some new business models.

At the same time, when considering questions regarding the characterisation of income derived from new business models it may be necessary to examine the rationale behind existing rules, in order to determine whether those rules produce appropriate results in the digital economy and whether differences in treatment of substantially similar transactions are justified in policy terms. In this respect, characterisation has broader implications for the allocation of taxing rights. For example, if a new type of business is able to interact extensively with customers in a market jurisdiction and generate business profits without physical presence that would rise to the level of a $\mathrm{PE}$, and it were determined that the market jurisdiction should be able to tax such income, modifying the PE threshold could permit such taxation. Source taxation could also be ensured by creating a new category of income that is subject to withholding tax. As a result, the issue of characterisation has significant implications for the issue of nexus.

\subsection{Collection of VAT in the digital economy}

Cross-border trade in goods, services and intangibles (which include for VAT purposes digital downloads) creates challenges for VAT systems, particularly where such products are acquired by private consumers from suppliers abroad. The digital economy magnifies these challenges, as the evolution of technology has dramatically increased the capability of private consumers to shop online and the capability of businesses to sell to consumers around the world without the need to be present physically or otherwise in the consumer's country. This often results in no VAT being levied at all on these flows, with adverse effects on countries' VAT revenues and on the level playing field between resident and non-resident vendors. The main tax challenges related to VAT in the digital economy relate to (i) imports of low value parcels from online sales which are treated as VAT-exempt in many jurisdictions, and (ii) the strong growth in the trade of services and intangibles, particularly sales to private consumers, on which often no or an inappropriately low amount of VAT is levied due to the complexity of enforcing VAT-payment on such supplies.

\subsubsection{Exemptions for imports of low valued goods}

The first challenge regarding collection of VAT arises from the growth that has occurred in e-commerce and in particular, online purchases of physical goods made by consumers from suppliers in another jurisdiction. 
Countries with a VAT collect tax on imports of goods from the importer at the time the goods are imported using customs collection mechanisms. Many VAT jurisdictions apply an exemption from VAT for imports of low value goods as the administrative costs associated with collecting the VAT on the goods is likely to outweigh the VAT that would be paid on those goods. The value at which the exemption threshold is set varies considerably from country to country but regardless of the threshold value, many VAT countries have seen a significant growth in the volume of low value imports on which VAT is not collected.

Challenges arise from the ability of businesses to deliberately structure their affairs to take advantage of a country's low value thresholds and sell goods to consumers without the payment of VAT. For example, a domestic business selling low value goods online to consumers in its jurisdiction would be required to collect and remit that jurisdiction's VAT on its sales. The business could restructure its affairs so that the low value goods are instead shipped to its consumers from an offshore jurisdiction and therefore qualify under that VAT jurisdiction's exemption for low value importations. Similarly, a business starting up could structure its operations to deliberately take advantage of the low value exemption and locate offshore rather than in the jurisdiction in which its customers are located.

The exemption for low value imports results in decreased VAT revenues and the possibility of unfair competitive pressures on domestic retailers who are required to charge VAT on their sales to domestic consumers. As a consequence, the concern is not only this immediate loss of revenue and potential competitive pressures on domestic suppliers, but also the incentive that is created for domestic suppliers to locate or relocate to an offshore jurisdiction in order to sell their low value goods free of VAT. It should also be noted that such relocations by domestic businesses would have added negative impacts on domestic employment and direct tax revenues.

The exemptions for low value imports have therefore become increasingly controversial in the context of the growing digital economy. The difficulty lies in finding the balance between the need for appropriate revenue protection and avoidance of distortions of competition, which tend to favour a lower threshold and the need to keep the cost of collection proportionate to the relatively small level of VAT collected, which favours a higher threshold. At the time when most current low value import reliefs were introduced, internet shopping did not exist and the level of imports benefitting from the relief was relatively small. Over recent years, many VAT countries have seen a significant and rapid growth in the volume of low value imports of physical goods on which VAT is not collected resulting in decreased VAT revenues and potentially unfair competitive pressures on domestic retailers who are required to charge VAT on their sales to domestic consumers. 


\subsubsection{Remote digital supplies to consumers}

The second challenge regarding collection of VAT arises from the strong growth in cross-border B2C supplies of remotely delivered services and intangibles. The digital economy has increasingly allowed the delivery of such products by businesses from a remote location to consumers around the world without any direct or indirect physical presence of the supplier in the consumer's jurisdiction. Such remote supplies of services and intangibles present challenges to VAT systems, as they often result in no or an inappropriately low amount of VAT being collected and create potential competitive pressures on domestic suppliers.

Consider an example of an online supplier of streaming digital content such as movies and television shows. The supplies are made mainly to consumers who can access the digital content through their computers, mobile devices and televisions that are connected to the Internet. If the supplier is resident in the same jurisdiction as its customers, it would be required to collect and remit that jurisdiction's VAT on the supplies. However, if the supplier is a non-resident in the consumer's jurisdiction, issues may arise.

As noted in Chapter 2, broadly two approaches are used by countries for applying VAT to such cross-border supplies of services or intangibles: the first approach allocates the taxing rights to the jurisdiction where the supplier is resident whereas the second approach allocates the taxing rights to the jurisdiction where the customer is resident. If the first approach is applied to the supply of digital content in the example, then this supply will be subject to VAT in the supplier's jurisdiction at the rate that is applicable in that jurisdiction. If the jurisdiction of the supplier of the digital content in the example has no VAT or a VAT with a lower rate than that of the consumer's jurisdiction, then no or an inappropriately low amount of VAT would be collected on this supply and none of the VAT revenue would accrue to the jurisdiction where the final consumption takes place.

The approach that allocates the taxing rights to the jurisdiction where the customer is resident would, in principle, result in taxation in the jurisdiction of consumption. However, under this approach, it is challenging for the private consumers' jurisdictions to ensure an effective collection of the VAT on services and intangibles acquired by such consumers abroad. One option is to require the private consumer to remit, or "self-assess", the VAT in its jurisdiction at the rate applicable in this jurisdiction. However, such consumer self-assessment mechanism has proven to be largely ineffective and as result, it is highly likely that no VAT would be paid by the consumer in this scenario. The OECD's E-commerce Guidelines (OECD, 2003) therefore recommend a mechanism that requires the non-resident supplier to register, collect and remit VAT according to the rules of the jurisdiction in which the consumer is resident. This results in the correct amount of VAT being paid in 
the jurisdiction of consumption. This approach, however, is dependent on the non-resident supplier complying with the requirement to register, collect and remit the VAT. In other words, if taxing rights are allocated to the jurisdiction of consumer residence without implementing a suitable mechanism to collect the tax in this jurisdiction, no VAT would be paid. ${ }^{2}$

The example illustrates how domestic suppliers of competing services could face potential competitive pressures from non-resident suppliers. Domestic suppliers are required to collect and remit VAT on their supplies of services and intangibles to their domestic consumers while the nonresident supplier, depending on the scenario, could structure its affairs so that it collects and remits no or an inappropriately low amount of tax. The example also illustrates how an incentive could arise for domestic suppliers to restructure their affairs so that their supplies of services and intangibles are made from an offshore location, which could allow them to make the supplies with no or an inappropriately low amount of VAT. This incentive could arise as a response to competition from non-resident suppliers who are collecting no or an inappropriately low amount of VAT or as part of a strategy to gain a potential competitive advantage over domestic suppliers who are charging VAT. Such relocations by domestic businesses are likely to have a negative impact on domestic employment and direct tax revenues.

Against this background, jurisdictions are increasingly looking at ways to ensure the effective collection of VAT on services and intangible acquired by resident consumers from suppliers abroad, in line with the destination principle, relying primarily on a requirement for non-resident suppliers to register and collect and remit the tax. Compliance with these requirements is essentially voluntary as the consumers' jurisdictions have limited means to enforce compliance by non-resident non-established suppliers. The experience in countries that have implemented such an approach suggests that a significant number of suppliers comply by either registering in the VAT jurisdiction and collecting and remitting tax on their remotely delivered services or by choosing to establish a physical presence in the jurisdiction and effectively becoming a "domestic" supplier. It has been suggested that particularly the high-profile operators, which occupy a considerable part of the market, wish to be seen to be tax-compliant notably for reputational reasons.

However, it is difficult to assess compliance levels as data on the volume of taxable digital services to consumers are often not readily available. Some have suggested that it is currently impossible to track the supplies by non-resident vendors to private consumers on which VAT should be paid under a vendor collection mechanism in the consumer's jurisdiction. As a consequence, it is suggested that many non-resident suppliers are likely to fail to register and remit the VAT in the consumer's jurisdiction, without any real possibility for tax authorities to audit and sanction them (Lamensch, 2012). 
As a result, there is a loss of VAT revenue to these jurisdiction and potentially unfair competitive pressures on domestic suppliers.

It should also be noted that some VAT regimes that allocate taxing rights to the jurisdiction of the residence or the actual location of the consumer, have not implemented a mechanism for collecting the VAT on services acquired by private consumers from non-resident suppliers. This has notably been based on the consideration that it would be overly burdensome on tax administrations to operate such a collection mechanism. As a result, no VAT is paid on digital supplies imported in these jurisdictions by private consumers. The strong growth of the digital economy, particularly the growing scale of B2C trade in digital products, may render this approach increasingly unsustainable.

\section{Box 7.1. Administrative challenges in the digital economy}

The borderless nature of digital economy produces specific administrative issues around identification of businesses, determination of the extent of activities, information collection and verification, and identification of customers. There is a pressing need to consider how investment in skills, technologies and data management can help tax administrations keep up with the ways in which technology is transforming business operations. Operational work is underway with respect to these administrative issues within the Forum on Tax Administration.

- Identification: While global business structures in the digital economy involve traditional identification challenges, these challenges are magnified in the digital economy. For example, the market jurisdiction may not require registration or other identification when overseas businesses sell remotely to customers in the jurisdiction, or may have issues with implementing registration requirements, as it is often difficult for tax authorities to know that activities are taking place, to identify remote sellers and to ensure compliance with domestic rules. Difficulties in identifying remote sellers may also make ultimate collection of tax difficult.

- Determining the extent of activities: Even if the identity and role of the parties involved can be determined, it may be impossible to ascertain the extent of sales or other activities without information from the offshore seller, as there may be no sales or other accounting records held in the local jurisdiction or otherwise accessible by the local revenue authority. It may be possible to obtain this information from third parties such as the customers or payment intermediaries, but this may be dependent on privacy or financial regulation laws. 


\section{Box 7.1. Administrative challenges in the digital economy (continued)}

- Information collection and verification: To verify local activity, the market jurisdiction's tax administration may need to seek information from parties that have no operations in the jurisdiction and are not subject to regulation therein. While exchange of information can be a very useful tool where the proper legal basis is in place, this is predicated on knowledge of where the offshore entity is tax resident and information retained or accessible by the reciprocating tax authority. This can create challenges for a market jurisdiction revenue authority seeking to independently verify any information provided by the offshore entity.

- Identification of customers: There are in principle a number of ways in which a business can identify the country of residence of its client and/or the country in which consumption occurs. These could include freight forwarders or other customs documentation or tracking of Internet Protocol (IP) and card billing addresses. However, this could be burdensome for the business and would not work where customers are able to disguise their location.

\section{Notes}

1. In addition, the conclusions drawn in the TAG Report have not been accepted by all countries participating in the BEPS Project.

2. While the example deals with streaming movies and TV shows, the same issues arise with most, if not all supplies of remotely delivered services to consumers, such as cloud computing, gaming, software downloads. 


\section{Bibliography}

Corrado, C. et al. (2012), "Intangible capital and growth in advanced economies: measurement and comparative results", IZA Discussion Paper No. 6733.

Lamensch, M. (2012), "Are 'reverse charging' and the 'one shop scheme' efficient ways to collect VAT on digital supplies?" in World Journal of VAT Law, Vol. 1, Issue 1.

OECD (2013), OECD Communications Outlook 2013, OECD Publishing, Paris, http://dx.doi.org/10.1787/comms_outlook-2013-en.

OECD (2003), Electronic Commerce-Commentary on Place of Consumption for Business to Business Supplies (Business Presence), OECD, Paris. 



\section{Chapter 8}

\section{Potential options to address the broader tax challenges raised by the digital economy}

This chapter provides an overview of potential options that have been discussed by the Task Force. It then provides a brief framework for evaluating options to address the broader tax challenges raised by the digital economy. Finally, it provides an initial evaluation of the options discussed, along with a description of some of the issues that will need to be addressed in developing and evaluating those options. 


\subsection{Introduction}

The Task Force received proposals for several potential options to address the broader tax challenges raised by the digital economy. The proposals received were focused on several areas, including modifications of the permanent establishment (PE) threshold, the potential imposition of a withholding tax on certain types of digital transactions, and options in the area of consumption tax. As discussed in Chapter 7, there is in certain business models a substantial overlap between the challenges related to nexus, data, and characterisation. Many of the challenges related to data, for example, could alternatively be described as issues related to lack of nexus under existing rules or as issues with respect to characterisation of income. Similarly, because market country taxing rights depend heavily both on characterisation of income and on questions of nexus, issues with respect to nexus depend substantially on characterisation. As a result, options focused on addressing one of these challenges will inevitably impact the others as well.

There are likely to be certain advantages and disadvantages to approaching these challenges through indirect taxation and/or direct taxation. Ultimately, evaluation of the options therefore requires also an analysis of the economic incidence of value added tax (VAT) and corporate income taxation and its impact on the options to address the tax challenges raised by the digital economy.

Some of the proposals were also considered in the context of the work of the business profit Technical Advisory Group (BP TAG), which focused primarily on e-commerce. In that context, it noted that it "cannot address the issue of whether or not some countries may find that e-commerce has or will have an unacceptable effect on the international sharing of tax revenues," but that "there was a need to monitor the evolution of the impact of e-commerce on tax revenue." (OECD, 2005: 110-112). While the Task Force considers the work of the BP TAG useful, given the growth of e-commerce and developments in the digital economy more generally, the Task Force considers it important to examine these proposals again to evaluate whether the earlier analysis of those proposals is still valid in light of developments since that work was conducted.

The Task Force considered it important to develop a framework for evaluating options, to ensure a consistent and principled analysis and informed policy decisions. In this respect, as noted in Chapter 1, the Task Force considered the Ottawa framework principles of neutrality, efficiency, certainty and simplicity, effectiveness and fairness, and flexibility to be a good starting point for such a framework. 
This chapter describes the options considered by the Task Force, the framework to evaluate those options, and an initial analysis of those options in the context of the BEPS Project and of the tax challenges to which they relate.

\subsection{Options proposed to the Task Force}

The Task Force discussed several potential options, which were received from a variety of sources, including proposals from country delegates, proposals from stakeholders, discussions at meetings of the Task Force, and discussions of other working groups. These potential options and their technical details were discussed and analysed by the Task Force and are outlined below in simplified form. Additional work on these options will need to be carried out by the relevant subsidiary bodies of the CFA and the Task Force itself (see also Section 8.4 below).

\subsubsection{Direct tax options}

\subsubsection{Modifications to the exemptions from PE Status}

One potential option discussed by the Task Force would modify the exceptions contained in paragraph 4 of Article 5 of the OECD Model Tax Convention. As noted in Chapter 6, above, as the economy has evolved, some of the activities described in subparagraphs (a) through (d) of paragraph 4 that were previously preparatory or auxiliary in the context of conventional business models (such as sales through a storefront) may have become core functions of certain businesses. Where the exceptions to the PE definition contained in paragraph 4 no longer serve their intended purpose as a result of that evolution, they should not be available. Several variations of this potential option could be considered. One possible option would be to eliminate paragraph 4 entirely. Other possible options would be to eliminate subparagraphs (a) through (d), or make their availability subject to the condition that the character of the activity conducted be preparatory or auxiliary in nature, rather than one of the core activities of the enterprise in question. Another would eliminate the word "delivery" in Article 5(4)(a) and (b) in order to exclude from these subparagraphs certain types of warehouses.

\subsubsection{A new nexus based on significant digital presence}

Another potential option discussed by the Task Force focuses on establishing an alternative nexus to address situations in which certain business activities are conducted wholly digitally. Under such a proposal, an enterprise engaged in certain "fully dematerialised digital activities" could 
be deemed to have a taxable presence in another country if it maintained a "significant digital presence" in the economy of that country. Focusing on "fully dematerialised digital activities" is intended to target only those businesses that require minimal physical elements in the market jurisdiction for the performance of their core activities, regardless of the fact that physical elements (such as offices, buildings, or personnel) may be present in the market jurisdiction to conduct secondary functions.

Under this potential option, to address administrative concerns businesses performing such fully dematerialised digital activities would be deemed to have a PE only if they exceeded certain thresholds which would indicate a

\section{Box 8.1. Fully dematerialised digital activities}

Potential elements of a test for when a fully dematerialised digital activity was conducted could include the following:

- The core business of the enterprise relies completely or in a considerable part on digital goods or digital services.

- No physical elements or activities are involved in the actual creation of the goods or of the services and their delivery other than the existence, use, or maintenance of servers and websites or other IT tools and the collection, processing, and commercialisation of location-relevant data.

- Contracts are generally concluded remotely via the Internet or by telephone.

- Payments are made solely through credit cards or other means of electronic payments using on-line forms or platforms linked or integrated to the relative websites.

- Websites are the only means used to enter into a relationship with the enterprise; no physical stores or agencies exist for the performance of the core activities other than offices located in the parent company or operating company countries.

- All or the vast majority of profits are attributable to the provision of digital goods or services.

- The legal or tax residence and the physical location of the vendor are disregarded by the customer and do not influence its choices.

- The actual use of the digital good or the performance of the digital service do not require physical presence or the involvement of a physical product other than the use of a computer, mobile devices or other IT tools. 
substantial ongoing interaction with the economy of the market country. These thresholds could include, for example, measures of total contracts for digital goods and services that are concluded remotely, the active engagement of substantial numbers of users (for example, the number of active accounts for social platforms, the number of visitors to websites, or the number of users of online tools) as well as the overall level of consumption of the digital goods or services of the enterprise in the market country. As regards practicalities, this variation would rely on relevant provisions regarding protection of personal data.

\section{Box 8.2. Significant digital presence}

For an enterprise engaged in a fully dematerialised business, a significant digital presence could be deemed to exist in a country when, for example:

- A significant number of contracts for the provision of fully dematerialised digital goods or services are remotely signed between the enterprise and a customer that is resident for tax purposes in the country.

- Digital goods or services of the enterprise are widely used or consumed in the country.

- Substantial payments are made from clients in the country to the enterprise in connection with contractual obligations arising from the provision of digital goods or services as part of the enterprise's core business.

- An existing branch of the enterprise in the country offers secondary functions such as marketing and consulting functions targeted at clients resident in the country that are strongly related to the core business of the enterprise.

The Task Force also discussed a variation of this potential option to create a new tax nexus for enterprises engaged in fully dematerialised digital activity where the entity does a significant business in the country using personal data obtained by regular and systematic monitoring of Internet users in that country, generally through the use of multi-sided business models. This variation was proposed in order to address concerns that the existing tax rules do not adequately address the challenges posed by increased reliance on data and users participation in the digital economy, particularly where users provide personal data that can then be used to attract revenue from other users through multi-sided business models. 


\subsubsection{Replacing PE with significant presence}

One potential option proposed in public comments would be to replace the existing PE concept with a "significant presence" test intended to respond to the changing nature of customer relationships in the digital economy while continuing to rely in part on physical presence. The criteria for this test intend to reflect the contribution to value of these closer, more interactive customer relationships and would include:

- Relationships with customers or users extending over six months, combined with some physical presence in the country, directly or via a dependent agent.

- Sale of goods or services by means involving a close relationship with customers in the country, including (i) through a website in the local language, (ii) offering delivery from suppliers in the jurisdiction, (iii) using banking and other facilities from suppliers in the country, or (iv) offering goods or services sourced from suppliers in the country.

- Supplying goods or services to customers in the country resulting from or involving systematic data-gathering or contributions of content from persons in the country.

\subsubsection{Creation of a withholding tax on digital transactions}

Another potential option that has been suggested to address challenges related to nexus is to impose a final withholding tax on certain payments made by residents of a country for digital goods or services provided by a foreign provider. To avoid requiring withholding by individual consumers, one potential option to be considered would be to require withholding by the financial institutions involved with those payments. Such a withholding tax could be introduced as a standalone provision to address concerns that it may be possible to maintain substantial economic activity in a market without being taxable in that market under current PE rules due to lack of physical presence in that market. Alternatively, such a withholding tax could be used as a primary enforcement tool for one of the new nexus standards described above. If such an approach were taken, taxpayers providing digital goods and services covered by the withholding tax could file returns in order to ensure that they were ultimately taxed on a net basis.

\subsubsection{Introducing a bandwidth or "Bit" tax}

Another potential option proposed in public comments would be to tax websites' bandwidth use. Such a tax would be based on the number of bytes used by the website, although in order to introduce an element of progressivity, different tax levels would apply depending on the enterprise 
size or the turnover. For administrative purposes, such a tax would apply only to businesses that exceed minimum threshold of annual bandwidth used. In order to maintain equity between digital businesses and traditional businesses, the proposed bandwidth tax would be creditable against corporate income tax.

\subsubsection{Consumption tax options}

The digital economy has allowed businesses to significantly increase their ability to market and sell goods, services and intangibles from remote locations to consumers in foreign jurisdictions. It has also introduced payment mechanisms that facilitate online shopping by consumers. These developments have resulted in significant growth in cross-border businessto-consumer (B2C) supplies which present challenges to VAT systems as these supplies often result in no or an inappropriately low amount of VAT collected and create potential competitive pressures on domestic suppliers. As the digital economy continues to evolve, new challenges may also emerge.

\subsubsection{Exemptions for imports of low valued goods}

The thresholds for these exemptions vary widely across jurisdictions. When establishing these thresholds, jurisdictions attempt to find the balance that is appropriate for their jurisdiction between the administrative and compliance costs of taxing low value imports and the revenue loss and potential competitive distortions that the exemptions may create. The thresholds in many jurisdictions were established before the advent and growth of the digital economy and may require a review to ensure that they are still appropriate.

If tax authorities were to make significant improvements to the efficiency of processing such low value imports and of collecting the VAT on such imports, governments would be in a position to lower these thresholds and address the issues associated with their operation. This could notably be achieved by requiring non-resident vendors of low value parcels to charge, collect and remit the tax on the imports of these goods in the importing jurisdiction. Compliance by non-resident suppliers with their tax obligations in the country of importation would need to be facilitated through simplified registration and compliance mechanisms, using the possibilities offered by new technologies (e.g. on-line registration and filing, electronic payment). While countries may wish to consider the use of registration thresholds to minimise potential compliance burden on small and medium enterprises, such thresholds create their own complexity as they generally differ between countries. Countries should therefore ensure that simplified registration mechanisms are sufficiently clear and accessible so that non-resident vendors, including small and medium enterprises, may easily comply thereby eliminating the need for registration thresholds. 


\subsubsection{Remote digital supplies to consumers}

Past work carried out by international organisations, including the Organisation for Economic Co-operation and Development (OECD) and the European Union (see e.g. Annex A), and country experience indicate that the most effective and efficient approach to ensure an appropriate VAT collection on such cross-border B2C supplies of services and intangibles is to require the non-resident supplier to register and account for the VAT on these supplies in the jurisdiction of the consumer. While such a vendor collection mechanism was first recommended under the OECD's 2003 E-commerce Guidelines, experience since then, notably within the European Union, which has been the first to implement it, has shown that it still remains the most viable option today.

It is recognised that requiring non-resident suppliers to register and account for VAT in as many foreign jurisdictions as they have consumers of remotely delivered services and intangibles may impose compliance burdens on these suppliers, which may weigh particularly heavily on small and medium enterprises. Countries should therefore ensure that simplified registration mechanisms are sufficiently clear and accessible so that nonresident vendors, including small and medium enterprises, may easily comply thereby eliminating the need for registration thresholds. Nevertheless, it is recognised that certain businesses, particularly small and medium enterprises, may prefer to rely on the expertise of third-party intermediaries to assist them in complying with their requirements to register and remit VAT abroad. Thus third-party intermediaries could play an important role in facilitating and encouraging compliance by non-resident suppliers.

Administrations are likely to face a number of challenges in enforcing compliance with VAT requirements by non-resident suppliers. These challenges include identifying that supplies have been made, enforcing collection and remittance of tax by the non-resident supplier and follow up enforcement actions such as accessing books and records, auditing and collection procedures for outstanding taxes. Improved international co-operation between jurisdictions will be required to address these challenges. This should include enhanced exchange of information, assistance in recovery and simultaneous audits. The Convention on Mutual Administrative Assistance in Tax Matters, which was developed jointly by the Council of Europe and the OECD, also covers VAT matters and provides a useful platform for developing such improved international co-operation. 


\subsection{Framework for evaluating potential options}

For purposes of evaluating potential options, the Task Force agreed on a framework starting from the basic tax principles of neutrality, efficiency, certainty and simplicity, effectiveness and fairness, flexibility and sustainability, in light of the proportionality of the changes in relation to the tax challenges they are intended to address in the context of the existing international tax framework. Evaluating potential options using this framework is intended to ensure that the analysis can be done consistently and objectively. In evaluating potential options, no single principle can be given greater priority than any other. Instead, the assessment under this framework shall be based on an overall consideration of the individual factors that are part of the framework.

\subsubsection{Neutrality}

Potential options will be evaluated with respect to their neutrality between different forms of business activities, as compared with the existing tax framework. In particular, an option should be evaluated to ensure that its enactment would not result in discrimination in favour of or against particular ways of doing business. Taxpayers in similar situations carrying out similar transactions should be subject to similar levels of taxation, in order to avoid introducing distortions to the market. In other words, the same principles of taxation should apply to all forms of business, while taking into account specific features that may otherwise undermine an equal and neutral application of those principles.

\subsubsection{Efficiency}

Options will be evaluated with respect to their efficiency relative to the existing tax framework. The benefits of any reform should outweigh the costs of its adoption, including transitional and implementation costs. Taxation should ideally accomplish its intended purpose while minimising compliance costs for both business and administrations to the extent possible. Many existing tax rules were based on the practical considerations that applied at the time those rules were enacted. For example, the PE threshold was based in part on assumptions, rooted in the economic realities of the time, that a certain physical footprint was required before taxpayers and tax administrations could effectively determine the profits to be taxed. Evaluation of the efficiency of potential options relative to the existing framework should therefore take into account whether the administrative considerations underlying the existing rules are still applicable, or whether advances in technology may have made those practical constraints less important. 


\subsubsection{Certainty and simplicity}

Potential options will be evaluated with respect to their certainty and simplicity relative to the existing tax framework. Tax rules that are easily understood make it easier for taxpayers to anticipate the tax consequences of transactions in advance, and for administrators to evaluate compliance. As a result, businesses are more likely to make optimal decisions and respond to intended policy signals, minimising the potential for disputes. A simple tax system is also likely to involve lower compliance costs, resulting in a more efficient taxation system.

\subsubsection{Effectiveness and fairness}

Potential options will be evaluated with respect to their effectiveness and fairness relative to the existing tax framework. As recognised in the Ottawa framework conditions, taxes imposed should produce the right amount of tax at the right time. In assessing the fairness of any proposed options, it is important to consider who may bear the ultimate tax burden (i.e. shareholders, workers, or consumers) and in what proportion. In order to preserve fairness, it is also important to ensure that any tax imposed must be structured in a way that effectively ensures that taxes are imposed on persons from whom collection will be enforceable as a practical matter. Enforceability is important because a tax system that is difficult to enforce is unlikely to be either equitable or neutral, and may undermine the public perceptions of the fairness of the whole system in the long term. In the absence of enforceability, there is also a risk that tax avoidance may develop as taxpayers will face different tax liabilities depending on their scruples. In this respect, evaluation of potential options must also keep in mind the need to avoid creating new risks of double taxation or new opportunities to artificially avoid taxation.

\subsubsection{Flexibility and sustainability}

Potential options will be evaluated with respect to their flexibility and sustainability relative to the existing tax framework. It is important that a tax system is sustainable and flexible enough to meet the changing revenue needs of governments on an ongoing basis. Potential options should therefore be evaluated based not only on whether they address the tax challenges in the current environment, but, to the extent possible given the difficulty of predicting future developments, on whether they can be expected to be flexible and dynamic enough to adapt to future commercial and technological developments, so that they can continue to be effective. 


\subsubsection{Proportionality}

Potential options will be evaluated with respect to their proportionality to the tax challenges they are intended to address. The existing tax framework has endured in part because it has historically been possible to adapt within that framework to new business developments. Where the digital economy has raised tax challenges with respect to the application of that existing tax framework, it will be important to evaluate not only whether the proposed options address those tax challenges, but also what broader impact those options may have. Potential options should ideally be tailored to the scope of the particular challenges they are intended to address.

\subsection{Initial evaluation of potential options}

As described in Chapter 6, it is expected that the work to develop the direct tax measures envisaged in the base erosion and profit shifting (BEPS) Action Plan (OECD, 2013) will take into account the key features and business models that have emerged in the digital economy, and will therefore effectively address the BEPS concerns that arise in the digital economy. The work to address BEPS concerns is expected to result in substantial changes to existing international tax rules in order to tackle stateless income and address practices that artificially segregate taxable income from the activities that generate it. As a result, addressing BEPS concerns in the digital economy also has the potential to substantially affect the scope of several of the broader tax challenges raised by the digital economy.

The staggered time frame of the BEPS Project, the interaction among the various BEPS outputs, and their actual impact on BEPS therefore make it difficult to evaluate the ultimate scope of the broader tax challenges of the digital economy in the area of direct taxation. If the BEPS issues outlined in Chapter 5 are fully addressed through the measures envisaged in the BEPS Action Plan, addressing the challenges described in Chapter 7 may become less pressing. Indeed, one potential option in such a case would be to conclude that the broader tax challenges of the digital economy were reduced in scale to the point that no further action was necessary in the area of direct taxation. On the other hand, if BEPS issues in the context of the digital economy are not addressed fully, then addressing the broader tax challenges of the digital economy could become a more pressing issue. Work to evaluate the broader tax challenges described in Chapter 7, and to further develop and evaluate the potential options to address them, can be carried on alongside the work being done on the rest of the BEPS Action Plan, and it will ultimately need to take into account the results of that work.

As a result of these considerations, application of the framework described above to these potential options would be premature. Instead, 
with respect to certain of these potential options, discussion by the relevant working parties of the Committee on Fiscal Affairs (CFA) in the context of the BEPS Project will be necessary in order to advance the work further. With respect to other potential options, further development of the issues and the completion of other BEPS work will be necessary in order to make it possible to evaluate them in full. Because all potential options under consideration require additional discussion or the completion of additional work in order to permit full evaluation, neither final evaluation nor adoption of any options was made by the Task Force at this point in time.

\subsubsection{Options to be developed further by relevant working parties}

\subsubsection{Modifications to the exemptions from PE status}

With respect to the option to modify the exemptions from PE status, work has already begun under Action 7 of the BEPS Action Plan to determine whether modification or elimination of paragraph 4 of Article 5 is necessary to ensure that the exceptions to PE do not allow the artificial avoidance of PE status, for example by fragmenting operation among different locations or group entities. This work, which will be completed by 2015, should be expanded to address situations in which these exceptions inappropriately apply to activities that have become core functions, whether this relates to BEPS (due to lack of both source and residence taxation) or not.

\subsubsection{Consumption tax options}

The collection of VAT with respect to $\mathrm{B} 2 \mathrm{C}$ transactions is a pressing issue that needs to be addressed urgently to protect tax revenue and to level the playing field between foreign suppliers and domestic suppliers. Working Party No. 9 of the OECD CFA is already developing work with respect to the option relating to remote digital supplies to consumers in the context of its work on the OECD International VAT/GST Guidelines. This work should be completed by the end of 2015, should include Associates in the BEPS Project participating on an equal footing with the OECD member countries, and should also examine compliance issues. In parallel with its work on remote digital supplies, and as separate work stream from the development of the OECD International VAT/GST Guidelines, Working Party No. 9 should develop work on approaches and best practices for a possible implementation of the options relating to the exemption for imports of low value goods. 


\subsubsection{Options requiring further development by the Task Force}

As discussed above, issues related to nexus, data, and characterisation are closely related, and overlap significantly in scope in relation to certain business models brought about by the digital economy. The options to create a PE based on significant (digital) presence, the option to create a nexus for digital tax presence based on collection of data, as well as the option to impose withholding tax on digital transactions, all relate to those issues. In order to fully understand the scope of these issues and their interaction, and to be able to determine whether these options are proportionate to the tax challenges they are intended to address, the Task Force will need to more thoroughly evaluate: (i) the extent to which businesses in the digital economy are in fact able to achieve significant sales in a market country without maintaining physical presence; and (ii) the participation of users and consumers in value creation in the digital economy, including in particular the use of data provided by users in multi-sided business models.

As this work progresses, the Task Force will further develop the potential options to address these challenges, to ensure that these potential options are well tailored to the scope of the challenges they are intended to address. In this respect, several aspects of these options would need to be developed further.

In particular, with respect to the options to create or modify standards for nexus, consideration should be given to:

- How the scope of each option could be tailored in order to address the tax challenges presented by the key features of the digital economy without creating substantial tax incentives for particular ways of doing businesses.

- How to balance the need for a combination of factors broad enough to effectively address the tax challenges of the digital economy with the need to provide clear and objective standards in order to minimise potential dispute and to avoid double taxation.

- With respect to options to create a new standard for PE, how profits (including deductions and losses) would be attributed to such a $\mathrm{PE}$, notably with respect to the share of profits attributable to the collection of data, and whether doing so would require the current rules for attribution of profits to PEs to be substantially modified.

- How to manage administration and enforcement, particularly where a taxpayer has no or minimal physical presence in a jurisdiction.

- How to minimise the compliance burden on businesses that could potentially have a large number of PEs. 
With respect to the option to impose withholding tax on digital goods and services, consideration should be given to:

- How to define the scope of payments covered by such a tax in a way that avoids creating substantially different tax results for similar businesses and avoids dispute on the characterisation of payments covered.

- How to ensure consistency with trade obligations and other legal constraints.

- How to address the challenges of withholding in the case of transactions with individual customers.

- If financial institutions were required to withhold the tax in lieu of withholding by individual customers, how to ensure that those financial institutions could reliably determine which transactions were within scope.

- To the extent that such a tax would be imposed as a final withholding tax, whether thresholds or other methods could be used to mitigate the impact of gross-basis withholding tax in the context of an enterprise that may incur significant expenses or losses.

The additional work on these topics will be completed by 2015. This work, coupled with an analysis of the outcomes of the BEPS Project will allow the Task Force to take an informed decision on the relevance, urgency, and scope of these challenges and on the potential options to address them. If needed, any necessary work following the completion of the various elements of the BEPS Project will therefore be performed efficiently and within an agreed framework.

In addition, as noted in Chapter 7, the challenges related to nexus, data and characterisation may at the same time create opportunities for achieving BEPS, ${ }^{1}$ for example when the lack of taxation in the market country is coupled with the lack of taxation in the jurisdiction of the income recipient and in that of the ultimate parent company. This would be for example the case where a parent company in a jurisdiction with no controlled foreign company (CFC) rules establishes a subsidiary in a low-tax jurisdiction to operate a subscription-based online gaming service that relies substantially on user-contributed content and data contributed by users from a market country, but does not maintain any physical presence in that market country.

If further actions are necessary to address BEPS concerns with respect to the digital economy, one possible approach would be to limit the application of potential options to address the broader direct tax challenges referred to in Chapter 7 and 8 to situations in which such BEPS concerns arise. Similarly, such options could be pursued as domestic law measures to address 
situations where there is no relevant double tax treaty in place, e.g. in case of a no-tax jurisdiction or when the claimed benefits of the relevant tax treaty are not due. Limiting application of these measures to BEPS concerns could effectively address these concerns without changing the paradigm for the allocation of taxing rights between source and residence jurisdictions.

\section{Notes}

1. As indicated in the BEPS Action Plan, BEPS relates chiefly to instances where the interaction of different tax rules leads to double non-taxation or less than single taxation. It also relates to arrangements that achieve no or low-taxation by shifting profits away from the jurisdiction where the activities creating those profits take place. No or low-taxation is not per se a cause of concern, but it becomes so when it is associated with practices that artificially segregate taxable income from the activities that generate it. In other words, what creates tax policy concerns are cases in which, due to gaps in the interaction of different tax systems, and in some cases because of the application of bilateral tax treaties, income from cross-border activities may go untaxed anywhere, or be only unduly lowly taxed.

\section{Bibliography}

OECD (2013), Action Plan on Base Erosion and Profit Shifting, OECD Publishing, Paris, http://dx.doi.org/10.1787/9789264202719-en. 



\section{Conclusions}

\section{The digital economy, its business models, and its key features}

- The digital economy is the result of a transformative process brought by information and communication technology (ICT).

- Because the digital economy is increasingly becoming the economy itself, it would be difficult, if not impossible, to ring-fence the digital economy from the rest of the economy for tax purposes.

- The digital economy is in a continuous state of evolution and possible future developments need to be monitored to evaluate their impact on tax systems.

- The digital economy and its business models present some key features which are potentially relevant from a tax perspective. These features include mobility (with respect to intangibles, users, and business functions), reliance on data, network effects, the spread of multi-sided business models, tendency toward monopoly or oligopoly and volatility due to lower barriers to entry into markets and rapidly evolving technology.

- The digital economy has also accelerated the spread of global value chains in which MNEs integrate their worldwide operations.

\section{BEPS issues in the digital economy and how to address them}

- While the digital economy does not generate unique BEPS issues, some of its key features exacerbate BEPS risks.

- These BEPS risks are being addressed in the context of the BEPS Project, which will align taxation with economic activities and value creation. 
- Work on the BEPS Project also must examine a number of issues specifically linked to the digital economy, its business models and its key features. These include:

i. Ensuring that core activities cannot inappropriately benefit from the exception to PE status and that artificial arrangements relating to sales of goods and services cannot be used to avoid PE status.

ii. The importance of intangibles, the use of data, and the spread of global value chains and their impact on transfer pricing.

iii. The possible need to adapt CFC rules to the digital economy.

iv. Addressing opportunities for tax planning by businesses engaged in VAT-exempt activities by encouraging implementation of the OECD's Guidelines on the place of taxation for B2B supplies of services and intangibles.

\section{Broader tax policy challenges raised by the digital economy}

- The digital economy also raises broader tax challenges for policy makers relating in particular to nexus, data, and characterisation, as well as to collection of VAT.

- The challenges related to nexus, data and characterisation overlap with each other to a certain extent.

- Evolving ways of carrying on business raise questions about whether current nexus rules continue to be appropriate.

- Increasing reliance on data collection and analysis, and the growing importance of multi-sided business models raise questions about valuation of data, nexus, and profit attribution, as well as characterisation.

- The development of new business models raises questions regarding characterisation of income.

- Cross-border trade in goods, services and intangibles creates challenges for VAT collection, particularly where such products are acquired by private consumers from suppliers abroad.

- The Task Force discussed and analysed a number of potential options proposed by delegate countries to address these challenges. Options discussed regarding nexus and data in particular range from changes to the definition of PE to the introduction of a new nexus based on a "significant presence" in a market, and also include the introduction of a withholding tax on sales of digital goods and services. Because 
of the overlap between the issues of nexus, data, and characterisation, the options to address each of them would inevitably affect the others.

\section{Next steps}

Based on its discussion of these challenges and potential options to address them, the Task Force reached the following initial conclusions:

- The collection of VAT in business-to-consumer transactions is a pressing issue that needs to be addressed urgently to protect tax revenue and to level the playing field between foreign suppliers relative to domestic suppliers. Work initiated in this area by the Working Party No. 9 of the OECD Committee on Fiscal Affairs (CFA) shall be completed by the end of 2015, with the Associates in the BEPS Project participating on an equal footing with the OECD member countries.

- The work in the context of Action 7 of the BEPS Action Plan (OECD, 2013) (preventing the artificial avoidance of PE status) shall be expanded to consider whether activities that once may have been preparatory or auxiliary should be denied the benefit of the exceptions to the PE definition because they are core components of the business, both in cases where granting the exception would generate BEPS issues (i.e. when coupled with the lack of residence taxation) and otherwise, and whether a reasonable, administrable rule to this effect can be developed.

- Working Party No. 1 of the CFA shall clarify the characterisation under current tax treaty rules of certain cloud computing payments (including payments for infrastructure-as-a-service, software-as-aservice, and platform-as-a-service transactions), with the Associates in the BEPS Project participating on an equal footing with the OECD member countries.

- The staggered time frame of the BEPS Project and interaction among the various BEPS outputs makes it difficult at the time this report is delivered to analyse how effective the work on the BEPS Action Plan will be in addressing BEPS concerns in the digital economy, as well as to evaluate the ultimate scope of the more systemic tax challenges in the area of nexus, data, and characterisation and the possible options to address them. In that context, it is important for the Task Force to continue its work until the end of 2015 in order to ensure that work carried out in other areas of the BEPS Project tackles BEPS issues in the digital economy, and that it can assess the outcomes of that work, continue to work on the broader tax challenges related 
to nexus, data, and characterisation, evaluate how the outcomes of the BEPS Project impact the relevance, urgency, and scope of these broader tax challenges, and complete the evaluation of the options to address them.

\section{Bibliography}

OECD (2013), Action Plan on Base Erosion and Profit Shifting, OECD Publishing, Paris, http://dx.doi.org/10.1787/9789264202719-en. 


\section{Annex $A$}

\section{Prior work on the digital economy}

This annex summarises the content and output of the previous work on electronic commerce. Specifically, it presents the work that led to the 1998 Ministerial Conference on Electronic Commerce in Ottawa (Ottawa Conference) and its main outcomes. It then describes the follow-up work carried out in relation to tax treaty issues and to consumption tax issues. 


\section{A.1 1996-98: Work leading to the Ottawa Ministerial Conference on Electronic Commerce}

At its June 1996 meeting, the Committee on Fiscal Affairs (CFA) discussed the tax implications of the development of communications technologies. After a conference on electronic commerce organised by the Organisation for Economic Co-operation and Development (OECD) and the government of Finland in co-operation with the European Community (EC) Commission, the government of Japan and the Business and Industry Advisory Committee to the OECD (BIAC) in Turku in November 1997, the CFA adopted a series of proposals for the preparation of a Ministerial meeting on electronic commerce to be organised in Ottawa in October 1998. In preparation for that meeting, the CFA adopted the report: "Electronic Commerce: Taxation Framework Conditions" (OECD, 2001b), which drew the following main conclusions:

- The widely accepted general tax principles that guide governments in relation to conventional commerce should also guide them in relation to electronic commerce.

- Existing taxation rules can implement these principles.

- This approach does not preclude new administrative or legislative measures, or changes to existing measures, relating to electronic commerce, provided that those measures are intended to assist in the application of the existing taxation principles, and are not intended to impose a discriminatory tax treatment of electronic commerce transactions.

- The application of these principles to electronic commerce should be structured to maintain the fiscal sovereignty of countries, to achieve a fair sharing of the tax base from electronic commerce between countries and to avoid double and unintentional non-taxation.

- The process of implementing these principles should involve an intensified dialogue with business and with non-member economies.

\section{A.2 1998: The Ottawa Ministerial Conference on Electronic Commerce}

At the Ottawa Ministerial Conference on Electronic Commerce, leaders from governments ( 29 member countries and 11 non-member countries), heads of major international organisations, industry leaders, and representatives of consumer, labour and social interests discussed plans to promote the development of global electronic commerce. Ministers welcomed the 1998 CFA Report "Electronic Commerce: Taxation Framework Conditions" (OECD, 2001b), and endorsed a set of taxation principles (listed in Box A.1) which should apply to electronic commerce: 


\section{Box A.1. Ottawa taxation framework conditions - Principles}

Neutrality: Taxation should seek to be neutral and equitable between forms of electronic commerce and between conventional and electronic forms of commerce. Business decisions should be motivated by economic rather than tax considerations. Taxpayers in similar situations carrying out similar transactions should be subject to similar levels of taxation.

Efficiency: Compliance costs for taxpayers and administrative costs for the tax authorities should be minimised as far as possible.

Certainty and Simplicity: The tax rules should be clear and simple to understand so that taxpayers can anticipate the tax consequences in advance of a transaction, including knowing when, where and how the tax is to be accounted.

Effectiveness and Fairness: Taxation should produce the right amount of tax at the right time. The potential for tax evasion and avoidance should be minimised while keeping counteracting measures proportionate to the risks involved.

Flexibility: The systems for taxation should be flexible and dynamic to ensure that they keep pace with technological and commercial developments.

\section{A.3 Post-Ottawa: CFA work and technical advisory groups}

At its January 1999 meeting, the CFA decided that the work programme on electronic commerce would be taken forward by the Committee's existing subsidiary bodies, in their respective areas of responsibility. It also endorsed the establishment of the following "technical advisory groups" (TAGs), comprising representatives from OECD governments, non-OECD governments, business and science, thus comprising a broad range of interests and expertise:

- A consumption tax TAG, to advise on the practical implementation of the Ottawa principle of taxation in the place of consumption.

- A technology TAG, to provide expert technological input to the other TAGs.

- A professional data assessment TAG, to advise the feasibility and practicality of developing internationally compatible information and record-keeping requirements and tax collection arrangements.

- A business profits (BP) TAG, to advise on how the current tax treaty rules for the taxation of business profits apply in the context of electronic commerce and to examine proposals for alternative rules. 
- A treaty characterisation TAG, to advise on the characterisation of various types of electronic commerce payments under tax treaties with a view to providing necessary clarifications in the Commentary.

Given the relevance for the current work on the tax challenges of the digital economy, the sections below describe the main output of the work conducted by the BP TAG and by the Treaty Characterisation TAG.

\section{A.3.1. The work of the business profits $T A G$}

The work of the BP TAG produced discussion drafts on "Attribution of Profit to a Permanent Establishment Involved in Electronic Commerce Transactions" (OECD, 2001a), released in February 2001, and "Place of Effective Management Concept: Suggestions for Changes to the OECD Model Tax Convention" (OECD, 2003c), released in May 2003.

The TAG also produced a report, "Treaty Rules and E-Commerce: Taxing Business Profits in the New Economy" (OECD, 2005), which was released in 2005. In that report, the BP TAG recognised that some aspects of existing international tax rules presented concerns. The report first examined a number of relatively restricted approaches to address those concerns in a manner that would not require fundamental changes to international tax rules, and made recommendations with respect to those alternatives. The report also discussed more fundamental changes. After summarising the existing treaty rules for taxing business profits (liability to tax, permanent establishment (PE) concept, computation of profits, allocation of the tax base between countries), the report presented a critical evaluation of these rules against a number of specific criteria, which were derived from the Ottawa framework conditions. In assessing the current principles for taxing business profits against these criteria, the report highlighted a number of pros and cons of the current rules. For example, with respect to the important question where business profits originate ("the source issue") the report concluded that business profits should be viewed as originating from the location of the factors that allow the enterprise to realise business profits. The report therefore rejected the suggestion that the mere fact that a country provides the market where an enterprise's goods and services are supplied should allow that country to consider that a share of the profits of the enterprise is derived therefrom.

The BP TAG could, however, not agree on the related issue whether a supplier which is not physically present in a country may be considered to be using that country's legal and economic infrastructure and, if that is the case, whether and to what extent, such use of a country's legal and economic infrastructure should be considered to be one factor which would allow that country to claim source taxing rights on a share of the enterprise's profits. In addition, since the most "traditional" of business enterprises continue to 
incorporate electronic commerce business models, it was found not to be appropriate, nor possible, to design one set of nexus rules for "electronic commerce" companies, and another for non-electronic commerce companies. The final report also gave an overview of the various alternatives to the current treaty rules for taxing business profits that were discussed. These alternatives ranged from relatively minor changes to the existing rules to the adoption of complete new ones.

The following alternatives were found to entail relatively minor changes:

- Modification of the PE definition to exclude activities that do not involve human intervention by personnel, including dependent agents: This option would modify the PE definition to expressly exclude the maintenance of a fixed place of business used solely for the carrying on of activities that do not involve human intervention by personnel, including dependent agents.

- Modification of the PE definition to provide that a server cannot, in itself, constitute a PE: According to this alternative, the PE definition would not cover situations where a fixed place of business is used merely to carry on automated functions through equipment, data and software such as a server and website.

- Modification of the PE definition/interpretation to exclude functions attributable to software: paragraph 4 of Article 5 of the OECD Model Tax Convention provides a list of functions that are specifically excluded from the definition of a PE (the Article 5, paragraph 4 exceptions). This option would indirectly expand this list by excluding functions attributable to software when applying the Article 5, paragraph 4 exceptions.

- Elimination of the existing exceptions in paragraph 4 of Article 5 or making these exceptions subject to the overall condition that they be preparatory or auxiliary: One option would be to eliminate all the exceptions included in paragraph 4 of the definition of PE. A less radical option would be to make all the activities referred to in the existing exceptions subject to the overall limitation that they be of a preparatory or auxiliary nature.

- Elimination of the exceptions for storage, display or delivery in paragraph 4 of Article 5: This option suggested that paragraph 4 of Article 5 be amended so that the use of facilities solely for purpose of storage, display or delivery should no longer be considered not to constitute a PE.

- Modification of the existing rules to add a force-of-attraction rule dealing with electronic commerce: According to this alternative, 
paragraph 1 of Article 7 of the OECD Model Tax Convention would be amended to include a so-called "force-of-attraction" rule which would deal with electronic commerce operations. The aim would be to ensure that a country may tax profits derived from selling in that country, through an enterprise's website, products similar to those sold through a PE that the enterprise has in the country.

- Adopting supplementary nexus rules for purposes of taxing profits arising from the provision of services: The option would be to modify the OECD Model to include a provision, similar to that already found in the UN Model, that would allow for the taxation of income from services if the enterprise that provides such services is present in the other country for that purpose during a certain period of time. The rationale for the proposal was that service providers are very mobile and that the income-producing functions take place in foreign countries without the need to set up a physical facility or use a fixed base of operations.

After having examined these alternatives in light of the comments received, the report reached the following conclusions:

- The option to modify the PE definition to exclude activities that do not involve human intervention by personnel, including dependent agents would be unlikely to be adopted and did not need further consideration.

- As regards the options to modify the PE definition to provide that a server cannot, in itself, constitute a PE or to exclude functions attributable to software when applying the preparatory or auxiliary exception, the BP TAG concluded that while these options should not be pursued at that time, the application of the current rules to functions performed with the use of servers and software should be monitored to determine whether it raises practical difficulties or concerns, which could lead to further study of these alternatives or combinations or variants thereof.

- With respect to the option to eliminate all the existing exceptions in paragraph 4 of Article 5, the BP TAG concluded that this option should not be pursued.

- As regards the options to make all the existing exceptions in paragraph 4 of Article 5 subject to the overall condition that they be preparatory or auxiliary and to eliminate the exceptions for storage, display and delivery in paragraph 4 of Article 5, the BP TAG concluded the application of these exceptions should continue to be monitored to determine whether practical difficulties or concerns warrant any such changes. 
- With respect to the option to modify the existing rules to add a forceof-attraction rule dealing with electronic commerce, the BP TAG concluded that it should not be pursued.

- As regards the option to adopt supplementary nexus rules for purposes of taxing profits arising from the provision of services, the BP TAG noted that this option would be examined in the context of the work that the OECD was to undertake on the application of tax treaties to services.

The following alternatives were found to require a fundamental modification of the existing rules:

- Adopting rules similar to those concerning taxation of passive income to allow source taxation of payments related to some forms of electronic commerce (so as to subject them to source withholding tax): This alternative encompassed various approaches under which a withholding tax would be applied on all or certain cross-border payments related to electronic commerce. The discussion in the $\mathrm{BP}$ TAG focused on a general option under which a final withholding tax would be applied to electronic commerce payments made from a country, whether or not the recipient has personnel or electronic equipment in that country.

- A new nexus: base eroding payments arising in a country: This option contained a nexus rule that focuses only on whether the foreign enterprise is receiving a payment from an in-country payor that the payor may deduct for domestic tax purposes rather than on where the activities giving rise to the product or service are located. Under this nexus rule, the source state would be entitled to impose a withholding tax on all such cross-border payments.

- Replacing separate entity accounting and arm's length by formulary apportionment of profits of a common group: According to this alternative, the separate entity and arm's length principles would be replaced by a system based on formulary apportionment as the international method of allocating and measuring business profits that countries may tax. Under such formulary apportionment system, a formula would be used to divide the net profits of a company, or a group of related companies, doing business in more than one country among the countries where the corporation (or group) operates.

- Adding a new nexus of "electronic (virtual)PE": This concept of "virtual PE" was a suggestion of an alternative nexus that would apply to electronic commerce operations. This could be done in various ways, such as extending the definition to cover so-called "virtual fixed places of business", "virtual agencies" or "on-site 
business presences." All of them would require a modification of the PE definition (or the addition of a new nexus rule in treaties).

The report concluded that it would not be appropriate to embark on any such changes at that time. Electronic commerce and other business models resulting from new communication technologies were not perceived by the BP TAG to justify, by themselves, a dramatic departure from the current rules. There did not seem to be actual evidence that the communications efficiencies of the Internet had caused any significant decrease to the tax revenues of capital importing countries. Also, it was considered that fundamental changes should only be undertaken if there was a broad agreement that a particular alternative was clearly superior to the existing rules and none of the alternatives that had been suggested appeared to meet that condition. It was recognised, however, that there was a need to continue to monitor how direct tax revenues are affected by changes to business models resulting from new communication technologies and that some aspects of the existing international rules for taxing business profits raised concerns. More generally, the report noted that the effect of many of these alternatives would extend far beyond electronic commerce it would therefore be important to take account of their impact on all types of business activities when considering them.

\section{A.3.2 CFA work in the area of tax treaties}

In addition to the work of the TAGs, the CFA directed its Working Parties to discuss and propose solutions with respect to the issues that had been raised by the TAGs. This led to some changes to the OECD Model Tax Convention and its Commentary which were incorporated in the 2003 update. The changes related to the definition of $\mathrm{PE}$ and to the characterisation of payments in particular under the definition of royalties contained in the Model Tax Convention.

\section{A.3.2.1 Treaty rules for taxing business profits}

The main content of the changes to the Commentary on Article 5 was to provide that the definition of PE, which is typically defined as a "fixed place of business through which business is conducted," could, under certain conditions, cover servers. In contrast, the changes to the Commentary rejected the view that a website could be regarded as a PE. Paragraphs (shown in Box A.2) were added to the OECD Commentary on Article 5 of the OECD Model Tax Convention in 2003 and are also included in the Commentary to the UN Model Tax Convention (see paragraphs 36-37 of the Commentary on Article 5 of the UN Model Tax Convention). 


\section{Box A.2. Commentary on Article 5 of the OECD Model Tax Convention}

"42.1 There has been some discussion as to whether the mere use in electronic commerce operations of computer equipment in a country could constitute a permanent establishment. That question raises a number of issues in relation to the provisions of the Article.

42.2 While a location where automated equipment is operated by an enterprise may constitute a permanent establishment in the country where it is situated (see below), a distinction needs to be made between computer equipment, which may be set up at a location so as to constitute a permanent establishment under certain circumstances, and the data and software which is used by, or stored on, that equipment. For instance, an Internet website, which is a combination of software and electronic data, does not in itself constitute tangible property. It therefore does not have a location that can constitute a "place of business" as there is no "facility such as premises or, in certain instances, machinery or equipment" (see paragraph 2 above) as far as the software and data constituting that website is concerned. On the other hand, the server on which the website is stored and through which it is accessible is a piece of equipment having a physical location and such location may thus constitute a "fixed place of business" of the enterprise that operates that server.

42.3 The distinction between a website and the server on which the website is stored and used is important since the enterprise that operates the server may be different from the enterprise that carries on business through the website. For example, it is common for the website through which an enterprise carries on its business to be hosted on the server of an Internet Service Provider (ISP). Although the fees paid to the ISP under such arrangements may be based on the amount of disk space used to store the software and data required by the website, these contracts typically do not result in the server and its location being at the disposal of the enterprise (see paragraph 4 above), even if the enterprise has been able to determine that its website should be hosted on a particular server at a particular location. In such a case, the enterprise does not even have a physical presence at that location since the website is not tangible. In these cases, the enterprise cannot be considered to have acquired a place of business by virtue of that hosting arrangement. However, if the enterprise carrying on business through a website has the server at its own disposal, for example it owns (or leases) and operates the server on which the website is stored and used, the place where that server is located could constitute a permanent establishment of the enterprise if the other requirements of the Article are met. 


\section{Box A.2. Commentary on Article 5 of the OECD Model Tax Convention (continued)}

42.4 Computer equipment at a given location may only constitute a permanent establishment if it meets the requirement of being fixed. In the case of a server, what is relevant is not the possibility of the server being moved, but whether it is in fact moved. In order to constitute a fixed place of business, a server will need to be located at a certain place for a sufficient period of time so as to become fixed within the meaning of paragraph 1.

42.5 Another issue is whether the business of an enterprise may be said to be wholly or partly carried on at a location where the enterprise has equipment such as a server at its disposal. The question of whether the business of an enterprise is wholly or partly carried on through such equipment needs to be examined on a case-by-case basis, having regard to whether it can be said that, because of such equipment, the enterprise has facilities at its disposal where business functions of the enterprise are performed.

42.6 Where an enterprise operates computer equipment at a particular location, a permanent establishment may exist even though no personnel of that enterprise is required at that location for the operation of the equipment. The presence of personnel is not necessary to consider that an enterprise wholly or partly carries on its business at a location when no personnel are in fact required to carry on business activities at that location. This conclusion applies to electronic commerce to the same extent that it applies with respect to other activities in which equipment operates automatically, e.g. automatic pumping equipment used in the exploitation of natural resources.

42.7 Another issue relates to the fact that no permanent establishment may be considered to exist where the electronic commerce operations carried on through computer equipment at a given location in a country are restricted to the preparatory or auxiliary activities covered by paragraph 4. The question of whether particular activities performed at such a location fall within paragraph 4 needs to be examined on a case-by-case basis having regard to the various functions performed by the enterprise through that equipment. Examples of activities which would generally be regarded as preparatory or auxiliary include:

- providing a communications link - much like a telephone line - between suppliers and customers;

- advertising of goods or services;

- relaying information through a mirror server for security and efficiency purposes;

- gathering market data for the enterprise;

- supplying information. 


\section{Box A.2. Commentary on Article 5 of the OECD Model Tax Convention (continued)}

42.8 Where, however, such functions form in themselves an essential and significant part of the business activity of the enterprise as a whole, or where other core functions of the enterprise are carried on through the computer equipment, these would go beyond the activities covered by paragraph 4 and if the equipment constituted a fixed place of business of the enterprise (as discussed in paragraphs 42.2 to 42.6 above), there would be a permanent establishment.

42.9 What constitutes core functions for a particular enterprise clearly depends on the nature of the business carried on by that enterprise. For instance, some ISPS are in the business of operating their own servers for the purpose of hosting websites or other applications for other enterprises. For these ISPS, the operation of their servers in order to provide services to customers is an essential part of their commercial activity and cannot be considered preparatory or auxiliary. A different example is that of an enterprise (sometimes referred to as an "e-tailer") that carries on the business of selling products through the Internet. In that case, the enterprise is not in the business of operating servers and the mere fact that it may do so at a given location is not enough to conclude that activities performed at that location are more than preparatory and auxiliary. What needs to be done in such a case is to examine the nature of the activities performed at that location in light of the business carried on by the enterprise. If these activities are merely preparatory or auxiliary to the business of selling products on the Internet (for example, the location is used to operate a server that hosts a website which, as is often the case, is used exclusively for advertising, displaying a catalogue of products or providing information to potential customers), paragraph 4 will apply and the location will not constitute a permanent establishment. If, however, the typical functions related to a sale are performed at that location (for example, the conclusion of the contract with the customer, the processing of the payment and the delivery of the products are performed automatically through the equipment located there), these activities cannot be considered to be merely preparatory or auxiliary.

42.10 A last issue is whether paragraph 5 may apply to deem an ISP to constitute a permanent establishment. As already noted, it is common for ISPS to provide the service of hosting the websites of other enterprises on their own servers. The issue may then arise as to whether paragraph 5 may apply to deem such ISPs to constitute permanent establishments of the enterprises that carry on electronic commerce through websites operated through the servers owned and operated by these ISPS. While this could be the case in very unusual circumstances, paragraph 5 will generally not be applicable because the ISPS will not constitute an agent of the enterprises to which the websites belong, because they will not have authority to conclude contracts in the name of these enterprises and will not regularly conclude such contracts or because they will 


\section{Box A.2. Commentary on Article 5 of the OECD Model Tax Convention (continued)}

constitute independent agents acting in the ordinary course of their business, as evidenced by the fact that they host the websites of many different enterprises. It is also clear that since the website through which an enterprise carries on its business is not itself a "person" as defined in Article 3, paragraph 5 cannot apply to deem a permanent establishment to exist by virtue of the website being an agent of the enterprise for purposes of that paragraph."

\section{A.3.2.2 Treaty characterisation issues}

Amendments to the Commentary on Article 12 of the OECD Model Tax Convention were also made to clarify the delimitation between the application of Articles 12 and 7 in the context of new business models in electronic commerce. These clarifications were included in the 2013 update and deal with (i) payment for the use of, or the right to use, a copyright, (ii) payments for know-how, (iii) mixed payments. These paragraphs are also included in the UN Model Tax Convention (see paragraphs 12-16 of the Commentary on Article 12 of the UN Model Tax Convention), although it was noted that some members disagreed with the conclusions reached regarding the character of several types of payment.

\section{Box A.3. Commentary on Article 12 - Payment for the use of, or the right to use, a copyright}

The following paragraphs 17.1 to 17.4 are included immediately after paragraph 17 of the Commentary on Article 12:

"17.1 The principles expressed above as regards software payments are also applicable as regards transactions concerning other types of digital products such as images, sounds or text. The development of electronic commerce has multiplied the number of such transactions. In deciding whether or not payments arising in these transactions constitute royalties, the main question to be addressed is the identification of that for which the payment is essentially made.

17.2 Under the relevant legislation of some countries, transactions which permit the customer to electronically download digital products may give rise to use of copyright by the customer, e.g. because a right to make one or more copies of the digital content is granted under the contract. Where the consideration 


\section{Box A.3. Commentary on Article 12 - Payment for the use of, or the right to use, a copyright (continued)}

is essentially for something other than for the use of, or right to use, rights in the copyright (such as to acquire other types of contractual rights, data or services), and the use of copyright is limited to such rights as are required to enable downloading, storage and operation on the customer's computer, network or other storage, performance or display device, such use of copyright should not affect the analysis of the character of the payment for purposes of applying the definition of "royalties".

17.3 This is the case for transactions that permit the customer (which may be an enterprise) to electronically download digital products (such as software, images, sounds or text) for that customer's own use or enjoyment. In these transactions, the payment is essentially for the acquisition of data transmitted in the form of a digital signal and therefore does not constitute royalties but falls within Article 7 or Article 13, as the case may be. To the extent that the act of copying the digital signal onto the customer's hard disk or other non-temporary media involves the use of a copyright by the customer under the relevant law and contractual arrangements, such copying is merely the means by which the digital signal is captured and stored. This use of copyright is not important for classification purposes because it does not correspond to what the payment is essentially in consideration for (i.e. to acquire data transmitted in the form of a digital signal), which is the determining factor for the purposes of the definition of royalties. There also would be no basis to classify such transactions as "royalties" if, under the relevant law and contractual arrangements, the creation of a copy is regarded as a use of copyright by the provider rather than by the customer.

17.4 By contrast, transactions where the essential consideration for the payment is the granting of the right to use a copyright in a digital product that is electronically downloaded for that purpose will give rise to royalties. This would be the case, for example, of a book publisher who would pay to acquire the right to reproduce a copyrighted picture that it would electronically download for the purposes of including it on the cover of a book that it is producing. In this transaction, the essential consideration for the payment is the acquisition of rights to use the copyright in the digital product, i.e. the right to reproduce and distribute the picture, and not merely for the acquisition of the digital content." 


\section{Box A.4. Change to the Commentary on Article 12 - Payments for know-how}

Paragraph 11 of the Commentary on Article 12 was replaced by the following paragraphs 11 to 11.5 (additions to the existing text of paragraph 11 appear in bold italics):

"11. In classifying as royalties payments received as consideration for information concerning industrial, commercial or scientific experience, paragraph 2 alludes to the concept of "know-how". Various specialist bodies and authors have formulated definitions of know-how which do not differ intrinsically. One such definition, given by the "Association des Bureaux pour la Protection de la Propriété Industrielle" (ANBPPI), states that "know-how is all the undivulged technical information, whether capable of being patented or not, that is necessary for the industrial reproduction of a product or process, directly and under the same conditions; inasmuch as it is derived from experience, know-how represents what a manufacturer cannot know from mere examination of the product and mere knowledge of the progress of technique'.

11.1 In the know-how contract, one of the parties agrees to impart to the other, so that he can use them for his own account, his special knowledge and experience which remain unrevealed to the public. It is recognised that the grantor is not required to play any part himself in the application of the formulas granted to the licensee and that he does not guarantee the result thereof.

11.2 This type of contract thus differs from contracts for the provision of services, in which one of the parties undertakes to use the customary skills of his calling to execute work himself for the other party. Payments made under the latter contracts generally fall under Article 7.

11.3 The need to distinguish these two types of payments, i.e. payments for the supply of know-how and payments for the provision of services, sometimes gives rise to practical difficulties. The following criteria are relevant for the purpose of making that distinction:

- Contracts for the supply of know-how concern information of the kind described in paragraph 11 that already exists or concern the supply of that type of information after its development or creation and include specific provisions concerning the confidentiality of that information.

- In the case of contracts for the provision of services, the supplier undertakes to perform services which may require the use, by that supplier, of special knowledge, skill and expertise but not the transfer of such special knowledge, skill or expertise to the other party. 


\section{Box A.4. Change to the Commentary on Article 12 - Payments for know-how (continued)}

- In most cases involving the supply of know-how, there would generally be very little more which needs to be done by the supplier under the contract other than to supply existing information or reproduce existing material. On the other hand, a contract for the performance of services would, in the majority of cases, involve a very much greater level of expenditure by the supplier in order to perform his contractual obligations. For instance, the supplier, depending on the nature of the services to be rendered, may have to incur salaries and wages for employees engaged in researching, designing, testing, drawing and other associated activities or payments to subcontractors for the performance of similar services.

11.4 Examples of payments which should therefore not be considered to be received as consideration for the provision of know-how but, rather, for the provision of services, include:

- payments obtained as consideration for after-sales service,

- payments for services rendered by a seller to the purchaser under a guarantee,

- payments for pure technical assistance,

- payments for an opinion given by an engineer, an advocate or an accountant, and

- payments for advice provided electronically, for electronic communications with technicians or for accessing, through computer networks, a troubleshooting database such as a database that provides users of software with non-confidential information in response to frequently asked questions or common problems that arise frequently.

11.5 In the particular case of a contract involving the provision, by the supplier, of information concerning computer programming, as a general rule the payment will only be considered to be made in consideration for the provision of such information so as to constitute know-how where it is made to acquire information constituting ideas and principles underlying the program, such as logic, algorithms or programming languages or techniques, where this information is provided under the condition that the customer not disclose it without authorisation and where it is subject to any available trade secret protection.

11.6 In business practice, contracts are encountered which cover both knowhow and the provision of technical assistance. One example, amongst others, of contracts of this kind is that of franchising, where the franchisor imparts his knowledge and experience to the franchisee and, in addition, provides him with varied technical assistance, which, in certain cases, is backed up with financial 


\section{Box A.4. Change to the Commentary on Article 12 - Payments for know-how (continued)}

assistance and the supply of goods. The appropriate course to take with a mixed contract is, in principle, to break down, on the basis of the information contained in the contract or by means of a reasonable apportionment, the whole amount of the stipulated consideration according to the various parts of what is being provided under the contract, and then to apply to each part of it so determined the taxation treatment proper thereto. If, however, one part of what is being provided constitutes by far the principal purpose of the contract and the other parts stipulated therein are only of an ancillary and largely unimportant character, then it seems possible to apply to the whole amount of the consideration the treatment applicable to the principal part." [paragraph 45 below includes suggested changes to this last sentence]

\section{Box A.5. Commentary on Article 12 - Mixed payments}

The last sentence of paragraph 11 of the Commentary on Article 12 was replaced by the following (deletions appear in strikethrough and additions in bold italics):

"If, however, one part of what is being provided constitutes by far the principal purpose of the contract and the other parts stipulated therein are only of an ancillary and largely unimportant character, then the treatment applicable to the principal part should generally be applied to the whole amount of the consideration. then it seems possibte to apply to the whote amount of the consideration the treatment applicable to the principal part."

\section{A.3.3 CFA work in the area of consumption taxes}

This section first looks at the elements of the 1998 Ottawa Taxation Framework Conditions (OECD, 2001b) specifically related to consumption taxes and discusses the E-commerce Guidelines (OECD, 2003b) and the Consumption tax guidance papers (OECD 2003c-e-f) that were developed to implement these conditions.

The need for an international co-ordination of the application of domestic value added tax (VAT) systems to international trade first became apparent following the emergence and strong growth of e-commerce. In the field of consumption taxes, the core elements of the Taxation Framework Conditions (OECD, 2001b) can be summarised as follows: 
- Rules for the consumption taxation of cross-border trade should result in taxation in the jurisdiction where consumption takes place and an international consensus should be sought on the circumstances under which supplies are held to be consumed in a jurisdiction.

- For the purpose of consumption taxes, the supply of digitised products should not be treated as a supply of goods.

- Where business and other organisations within a country acquire services and intangibles from suppliers outside the country, countries should examine the use of reverse charge, self-assessment or other equivalent mechanisms where this would give immediate protection of their revenue base and of the competitiveness of domestic suppliers.

These framework conditions were broad statements of general principle which required further elaboration to facilitate their practical application. As a follow-up to this work, in 2003 the CFA released its E-commerce Guidelines (2003b). The CFA also released the Consumption Tax Guidance Series (OECD 2003c-e-f) along with these Guidelines, consisting of three papers providing guidance on the implementation of the Guidelines in practice. These Guidelines and Guidance papers are summarised in the following sections.

\section{A.3.3.1. The E-commerce Guidelines}

Destination based taxation of cross-border e-business was the governing principle of the E-commerce Guidelines (2003b) Under the destination principle, tax is ultimately levied only on the final consumption within the jurisdiction where such consumption is deemed to occur. Exports are not subject to tax with refund of input taxes (that is, "free of VAT" or "zero-rated"), and imports are taxed on the same basis and at the same rates as domestic supplies. The E-commerce Guidelines (2003b)provide that:

- For business-to-business transactions, the place of consumption for cross-border supplies of services and intangibles that are capable of delivery from a remote location made to a non-resident business recipient should be the jurisdiction in which the recipient has located its business presence. This was referred to as the "main criterion". The Guidelines (2003b) indicated that countries may, in certain circumstances, use a different criterion to determine the actual place of consumption, where the application of the main criterion "would lead to a distortion of competition or avoidance of tax." This was referred to as the "override criterion".

- For business-to-consumer transactions, the place of consumption for cross-border supplies of services and intangibles that are capable of delivery from a remote location made to a non-resident private recipient should be the jurisdiction in which the recipient has its usual residence. 
These Guidelines (2003b) were explicitly not applicable to (i) sub-national consumption taxes, (ii) suppliers who were registered or required to be registered in the customer's jurisdiction, (iii) services that are not capable of direct delivery from a remote location (such as hotel accommodation, transportation or vehicle rental), (iv) services for which the place of consumption could be readily identified, (v) services for which the place of consumption could be more appropriately determined by other criteria, (vi) specific types of services for which more specific approaches might be needed.

\section{A.3.3.2 The consumption tax guidance papers}

The CFA released three Consumption Tax Guidance (OECD, 2003c-e-f) papers along with the E-commerce Guidelines, to support their implementation in practice. These Guidance papers deal with: (i) Identifying place of taxation for business-to-business supplies by reference to the customer's business presence (OECD, 2003c); (ii) Simplified registration guidance (OECD, 2003e); and (iii) Verification of customer status and jurisdiction (OECD, 2003f). These papers are briefly summarised below:

- Guidance paper on identifying place of taxation by reference to the customer's business presence: the Guidelines on the Definition of Place of Consumption (OECD, 2003c) described "business presence" as, "in principle, the establishment (for example, headquarters, registered office, or a branch of the business) of the recipient to which the supply is made." The Guidance paper on business presence underlined the importance of contracts in determining the business presence to which the supply is made. Normal commercial practices as evidenced in the terms of contracts (e.g. invoicing, terms of payment, use of intellectual property rights), should normally provide sufficient indicative evidence to assist both business and revenue administrations in determining the jurisdiction of consumption. The Guidance paper also discussed the "override criterion". It considered the case where a customer with branches in several jurisdictions that are not entitled to recover the input tax on a transaction, routed this transaction through branches in jurisdictions with no or a low VAT, "thus avoiding a significant amount of tax." The Guidance Paper suggested that a pure place of consumption override could be applied in such a case, according to which a country may require "a business presence" in its jurisdiction to account for tax to the extent that the supply is used in that jurisdiction. In addition, and in order to avoid double taxation, the country of the business presence that has acquired the supply may then choose to provide a correction proportionately equivalent to the tax collected by the other country under the application of this test. 
- Guidance paper on simplified registration systems (OECD, 2003e): This guidance paper explored the possible implementation of a system for taxing e-commerce business-to-consumer (B2C) crossborder transactions in the customer's jurisdiction, based on vendor collection. It considered registration and declaration procedures and record-keeping requirements and recommended the use of simplified registration regimes and registration thresholds to minimise the potential compliance burden. It suggested that governments that implement simplified registration systems consider using electronic registration and declaration and encourages tax administrations to review and develop a legal basis to allow for the use of electronic record keeping systems.

- Guidance paper on Verification of Customer Status and Jurisdiction (OECD, 2003f): This Guidance Paper provided practical guidance on mechanisms that may be used to establish the status (business or private) and jurisdiction of customers, for low value electronic commerce transactions where vendors do not have an established relationship with the customer. It does not apply to high value B2B transactions where the vendor and the customer were assumed to have an established relationship. In these cases the supplier was assumed to be normally aware of the customer's status and jurisdiction and no additional verification process of the customer's declaration was considered necessary. The Paper concluded that the status and jurisdiction of a customer should be based on customer self-identification, supported by a range of other criteria including payment information, tracking and geo-location software, the nature of the supply and digital certificates.

\section{Bibliography}

United Nations (2011), United Nations Double Tax Convention between Developed and Developing Countries, The United Nations, New York.

OECD (2005), Are the Current Treaty Rules for Taxing Business Profits Appropriate for E-commerce? Final Report, OECD, Paris.

OECD (2003a), Commentary on Place of Consumption for Business-toBusiness Supplies (Business Presence), OECD, Paris. 
OECD (2003b), Consumption Taxation of Cross Border Services and Intangible Property in the context of E-commerce, Guidelines on the Definition of Place of Consumption, OECD, Paris.

OECD (2003c), Place of Effective Management Concept: Suggestions for Changes to the OECD Model Tax Convention, OECD, Paris.

OECD (2003d), Model Tax Convention on Income and on Capital: Condensed Version 2003, OECD Publishing, Paris, http://dx.doi. org $/ 10.1787 / \mathrm{mtc}$ ccond-2003-en.

OECD (2003e), Simplified Registration Guidance, OECD, Paris.

OECD (2003f), Verification of customer status and jurisdiction, OECD, Paris.

OECD (2001a), Attribution of Profits to Permanent Establishments, OECD Publishing, Paris, http://dx.doi.org/10.1787/9789264184527-en.

OECD (2001b), Taxation and Electronic Commerce: Implementing the Ottawa Taxation Framework Conditions, OECD Publishing, Paris, http:// dx.doi.org/10.1787/9789264189799-en. 


\section{Annex B}

\section{Typical tax planning structures in integrated business models}

The simplified examples below are based on what a number of tax administrations have observed. They are intended to provide an illustration of ways in which the implementation of business models through legal and tax structures may place pressure on the existing international tax framework. They are not exhaustive, and do not pretend to reflect the full scope of structures that may be used to achieve base erosion and profit shifting (BEPS). 


\section{B.1 Online retailer}

RCo Group is a multinational enterprise (MNE) engaged in the online sale of physical goods and digital products. The websites of the Group display the products offered in the markets that they serve in local languages and allow customers to acquire these products on line through credit card payments. Physical products are delivered through independent courier services. Digital products are downloaded from one of RCo group's websites to the consumer's computer. RCo Group collects data on customer preferences on the basis of goods purchased, added to a list of "favorites", or browsed by customers. Using sophisticated proprietary software, RCo Group analyses the data it collects in order to make recommendations of goods to its potential customers and provide personalised advertising.

All intangibles used in operating the RCo Group websites and fulfilling orders are developed by employees of RCo, a company resident in State R. RCo also remotely co-ordinates the procurement and sale activities of the Group to minimise purchasing costs, maintain consistency among the various businesses and websites, improve efficiency of inventory management, and minimise overhead on the payment processing and back office functions. These co-ordination services are generally provided to regional operating lower-tier sales subsidiaries in return for a management service fee covering related expenses plus a markup.

Rights to existing and future intangibles used in operating the websites serving customers in a region that includes, among others, State T and State S (the State T/S region) are held by RCo Regional Holding, a subsidiary resident in State T. RCo Regional Holding acquired the rights through a cost-sharing arrangement in which it made a "buy in" payment to RCo equal to the value of the existing intangibles and agreed to share the cost of future development (to be performed exclusively by RCo personnel in State R) on the basis of the anticipated future benefit from the use of the technology in the State T/S region. RCo remains the legal owner of the intangibles from the MNE group and is responsible for functions pertaining to the registration and defence of Intellectual Property, RCo Regional Holdings' only acquires the rights to commercially exploit the Internet Protocol (IP) and not the legal ownership of the intangibles. In practice, RCo Regional Holding does not perform any supervision of the development activities carried out by RCo in State R. RCo Regional Holding acts as an IP manager for the T/S region and sublicenses the intangibles necessary for its various subsidiaries to operate their various country- or region-targeted websites. RCo Regional Holding also acts as a holding company for all subsidiaries in the State T/S region, although in practice, most co-ordination services continue to be performed at the level of RCo, and RCo Regional Holding's involvement with the subsidiaries is very limited. RCo Regional Holding has only one employee on its payroll, and the 
premises are limited to an "office hotel" where the company regularly rents different offices for the purpose of organising board meetings.

Orders from customers in State S, State T, and the rest of the State T/S region are handled by a subsidiary of RCo Regional Holding, RCo Regional $\mathrm{OpCo}$, also resident in State T. RCo Regional OpCo is a hybrid entity that is treated as a company for tax purposes under the domestic law of State T, and as a transparent entity under the domestic law of State R. RCo Regional OpCo handles the sales, payment processing and settlement and has legal title to the physical and digital products sold on the websites serving customers in the State $\mathrm{T} / \mathrm{S}$ region. Changes and updates to the websites are done from State $\mathrm{T}$ by employees of RCo Regional OpCo, who have overall responsibility for managing the various websites serving customers in the region. These functions are performed with minimal skilled personnel. Other functions related to the online sale activity rely on automated processes conducted by sophisticated Internet-powered software applications regularly upgraded by employees of RCo in State R. Orders and sales are concluded electronically by customers in State $\mathrm{T} / \mathrm{S}$ region on the basis of standardised contracts, the terms of which are set by $\mathrm{RCo}$, and require no intervention from RCo Regional OpCo. Mirrors of the websites are hosted on servers in a number of countries in the region. RCo Regional OpCo staff very rarely have any contact with customers in the local market jurisdiction.

SCo, a subsidiary of RCo Regional OpCo resident in State S, provides services to RCo Regional OpCo in respect of logistics and after sales support with respect to orders from customers in State S. Orders for physical goods placed by customers in State S via the website managed by RCo Regional $\mathrm{OpCo}$, are generally fulfilled from a warehouse located in State S owned and operated by SCo. Where products are not available in a State S warehouse, the order is generally fulfilled from the closest warehouse to the customer. After-sales support is handled by SCo through a call center. Orders for digital products placed by State S customers are generally downloaded from servers located in State $\mathrm{S}$ or in neighbouring countries, depending on network traffic at the time of the transaction. These servers are owned and operated by third parties through hosting arrangements with RCo Regional OpCo. SCo is remunerated on a cost-plus basis by RCo Regional OpCo.

The structure used by the RCo Group can be depicted as shown in Figure B.1.

The manner in which RCo Group's business activity is structured as a legal matter has significant consequences for the Group's worldwide tax burden. Due to the contractual arrangements transferring and assigning the intangibles for the State T/S region (and related returns) to RCo Regional Holding and the lack of taxable presence of RCo Regional Holding in State S, most of the taxable income generated by the Group is concentrated in State T. 
Figure B.1. Online retailer

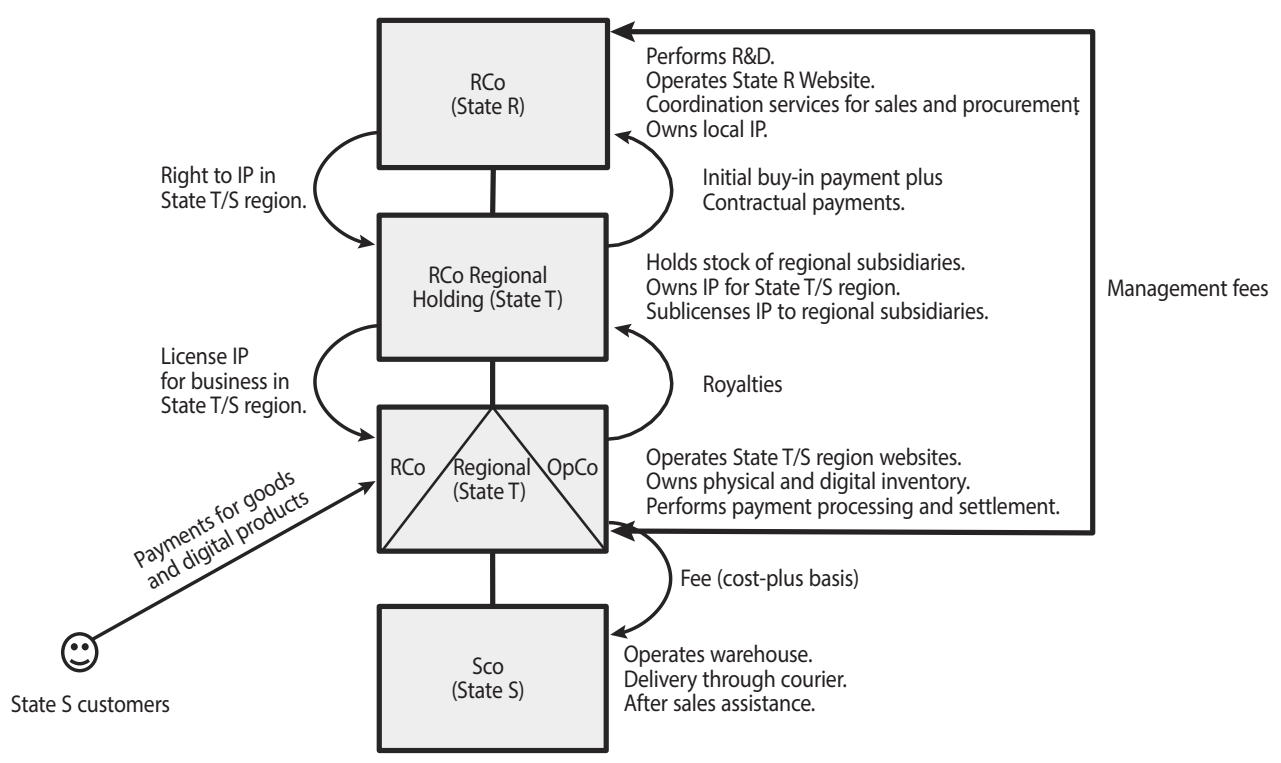

More specifically, the following paragraphs describe the consequences that would arise in the different States concerned.

\section{Direct tax consequences in state $S$}

- SCo is allocated minimal taxable income, based on the position that SCo's risk and function profile is limited to routine services provided to RCo Regional OpCo.

- All revenues derived from the online sales of products to customers in State S are treated as income of RCo Regional OpCo, due to its role as the counterparty to the transactions. Because RCo Regional OpCo has no physical presence in State S, and SCo has no interaction with State $\mathrm{S}$ customers, State $\mathrm{S}$ does not tax the profits derived from these activities either because it has no right to do so under its domestic law or because the relevant double tax treaty prevents it from doing so in the absence of a permanent establishment (PE) of TCo in State $\mathrm{S}$ to which the income is attributable. 


\section{Direct tax consequences in state T}

- State T imposes corporate tax on the profits earned by RCo Regional Holding. However, by virtue of a preferential regime available in State T for income derived from certain intangibles, RCo Regional Holding is entitled to a rate substantially less than the generally applicable corporate tax rate for the royalties included in its taxable profits.

- State T imposes corporate tax on the profits earned by RCo Regional OpCo from its online sale activities. RCo Regional OpCo's income, however, is almost entirely offset by the royalty payments made to RCo Regional Holding for the right to use the intangibles necessary to operate the regional websites, and the management fees paid to $\mathrm{RCo}$ for co-ordinating sales and procurement.

- The payments made by RCo Regional OpCo are not subject to any withholding since the royalty income is paid to RCo Regional Holding, a company resident in State T, and the management fee is paid to RCo, a non-resident company whose business profits may not be taxed in State $T$ under the relevant tax treaty. No withholding is imposed under the relevant double tax treaty on the payments by RCo Regional Holding to RCo.

\section{Direct tax consequences in state $R$}

- State R imposes corporate income tax on the profits derived by RCo, including the buy-in payment received for the transfer of existing intangibles to RCo Regional Holding. However, because of the absence of a significant track record of RCo's performance at the time of the transaction, RCo may take the position that the value of those intangibles was very low, so that the actual amount of gain subject to corporate tax in State R would be very small.

- RCo also receives annual payments from RCo Regional Holding under the cost sharing arrangement, which may be at a rate much lower than the amount of royalties received by RCo Regional Holding. In addition, depending on the domestic law of State R, RCo may be entitled to $R \& D$ tax credits for a significant fraction of its expenditures, thereby significantly reducing its tax liability for corporate tax purposes.

- Under its controlled foreign company (CFC) rules, State R would under some circumstances treat royalties received by RCo Regional Holding as passive income subject to current taxation in the hands of RCo. However, because RCo Regional OpCo is treated as a transparent entity for tax purposes in State R, the income of RCo Regional OpCo is treated as having been earned directly by RCo Regional Holding and 
is therefore treated as active income taxable in State R only when paid to RCo. This result would also be reached if State R imposed tax only on a territorial basis and did not have CFC rules.

\section{VAT consequences}

- With respect to value added tax (VAT), the treatment of the businessto-business (B2B) transactions is relatively straightforward, with the VAT levied either through the supplying business charging the tax or the recipient business self-assessing it. The input tax levied would generally be recoverable by the businesses through the input tax credit mechanism.

- The VAT treatment of the supplies to private consumers (businessto-consumer (B2C)) in State S will generally be different for supplies of physical products and supplies of digital products. Supplies by RCo Regional OpCo of physical goods stored in SCo's warehouse to consumers in State $\mathrm{S}$ would be subject to VAT in State S. State S may allow SCo to account for State S VAT on behalf of RCo Regional OpCo (e.g. as a fiscal representative). If the physical products would be shipped to consumers in State S from abroad, e.g. from State T, then these supplies would be zero rated in the exporting state and would be subject to VAT at the time of importation into State S. Depending on the value of the goods and the thresholds operated by State S, they may qualify for a VAT exemption under the relief for importations of low value goods. Also the supplies of digital products to final consumers in State $\mathrm{S}$ should in principle be subject to VAT in State S, in accordance with the destination principle. However, State $\mathrm{S}$ will have considerable difficulty enforcing the payment of the VAT on these supplies, as the supplier is not resident in State $S$ and collecting the tax from the final consumers is ineffectual. While certain jurisdictions operate a mechanism requiring non-resident suppliers to register and remit the tax on supplies to resident private consumers, it is recognised that it is often challenging for tax authorities to enforce compliance with such requirements.

\section{B.2 Internet advertising}

The RCo Group provides a number of Internet services (e.g. search engines) to customers worldwide. Many of these online services are offered free of charge to consumers, whose use of the online services provides the RCo Group with a substantial amount of data, including location-based data, data based on online behaviour, and data based on personal information provided by users. Over the course of many years of data collection, refinement, processing, 
and analysis, the RCo Group has developed a sophisticated algorithm that targets advertisements to those users who are most likely to be interested in the products advertised. RCo Group derives substantially all of its revenues from the sale of advertising through its online platform, for a fee that is generally based on the number of users who click on each advertisement.

The technology used in providing the advertisement services, along with the various algorithms used to collect and process data in order to target potential buyers were developed by staff of RCo, the parent company of the Group situated in State R. The rights to exploit this technology in the $\mathrm{T} / \mathrm{S}$ region are owned by a dual resident subsidiary of the group, XCo. The latter company is incorporated in State T but effectively managed in State X. The technology rights for the $\mathrm{T} / \mathrm{S}$ region were acquired by $\mathrm{XCo}$ under a cost-sharing arrangement whereby XCo agreed to make a "buy in" payment equal to the value of the existing technology and to share the cost of future enhancement of the transferred technology on the basis of the anticipated future benefit from the use of the technology in the T/S region. In practice, $\mathrm{XCo}$ does not actually perform any supervision of the development activities carried out by RCo in State R.

XCo licenses all of the rights in the technology used to operate the platform to a foreign subsidiary resident in State Y, YCo. The latter then sublicenses the technology to TCo, a company organised and resident in State T, earning a small "spread" between the royalties it receives and the royalties it pays on to XCo. YCo and TCo are hybrid entities that are treated as corporations for tax purposes in State $\mathrm{Y}$ and State $\mathrm{T}$, but as transparent for tax purposes in State R. The physical presence of XCo in State $\mathrm{X}$ is minimal, both in terms of personnel and tangible assets (equipment, premises, etc.). In fact, neither XCo nor YCo has any employees on its payroll, and each company's activities are limited to board meetings taking place in an "office hotel" where the company regularly rents different offices.

TCo acts as the regional headquarters for the RCo group's operations in the $\mathrm{T} / \mathrm{S}$ region, and employs a substantial number of people in managing the group's activities in that region. It operates the websites offering free online services to consumers in the T/S region, and serves as the legal counterparty for all sales of advertising in the T/S region. However the servers that host these websites may be placed throughout the region and/or located in State $\mathrm{R}$ and operated by RCo. Dependent on the time of the day, different members of the group may be responsible the maintenance of the website and fixing any network issues in the region.

Advertisement services contracts with TCo can be concluded electronically through TCo's websites on the basis of standard agreements, the terms of which are generally set by RCo. Advertisers located in the T/S region that wish to purchase advertising targeting users of RCo's products can 
thus do so directly through a website operated by TCo without having any interaction with the personnel located in State T. This advertising is available to local businesses in the T/S region, whether they are targeting customers in the $\mathrm{T} / \mathrm{S}$ region or customers elsewhere.

For larger markets and in order to deal with key clients, the group has established a number of local subsidiaries. To promote the purchase of such advertising by businesses active in the T/S region, TCo has local affiliates, such as SCo, a company resident in State $\mathrm{S}$, whose purpose is to promote the RCo family of products, including in particular the advertising services offered in the region. Local subsidiaries like SCo provide education and technical consulting to users and potential advertising clients, as well as marketing support in order to generate demand for the RCo advertising services. Local staff members have substantial and ongoing one-on-one interaction with local businesses, particularly the largest customers in the local market, many of which end up purchasing advertising. Compensation for the staff is partially based on the number of advertising contracts

Figure B.2. Internet advertising

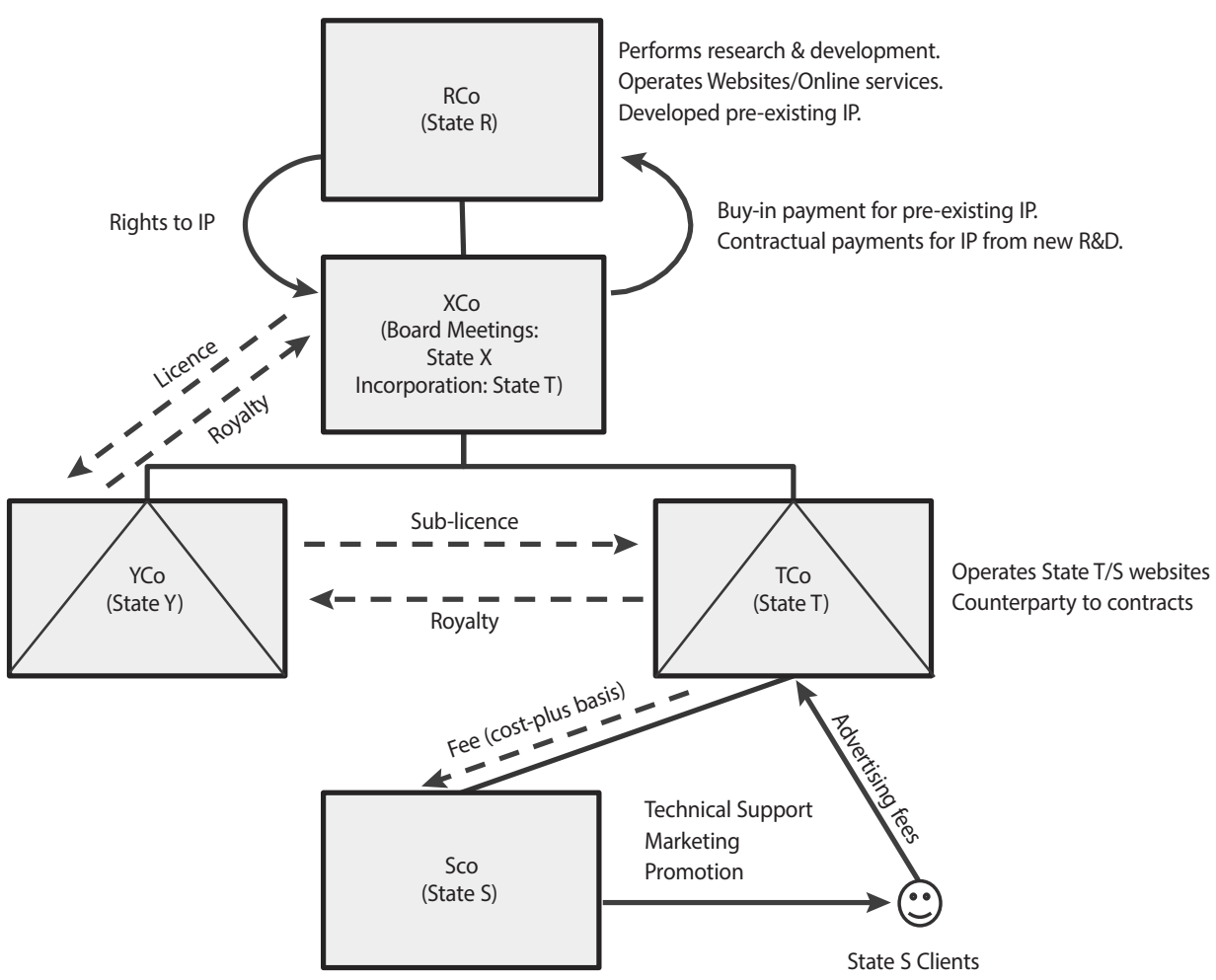


concluded between TCo and customers in State S and the income generated by TCo from the clients they support. In consideration for its promotion activities and technical support, TCo pays SCo a fee covering its expenses plus a mark-up. In general, customers supported by local affiliates such as SCo have no interaction with TCo staff.

The structure used by the RCo Group can be depicted as shown in Figure B.2.

The manner in which RCo's business activity is structured has significant consequences from a tax perspective. Due to contractual arrangements among the different group companies, the bulk of the Group's income is allocated to State X, and only minimal taxable profits are allocated to State S, State R, and State T. More specifically, the following paragraphs describe the consequences that would arise in the different States concerned.

\section{Direct tax consequences in state $S$}

- SCo is allocated minimal taxable income, based on the position that SCo's functions are limited to those of a service provider.

- All revenues from sales of advertising in State $\mathrm{S}$, including advertising purchased by State $\mathrm{S}$ residents and other regional customers, are treated as the revenues of TCo. The lack of authority for SCo staff to legally conclude contracts and the use of standardised contracts and on line contract acceptance by TCo result in TCo not being considered to have a PE in State S. As a result, State S does not tax the profits derived from these activities either because it has no right to do so under its domestic law or because the relevant double tax treaty prevents it from doing so in the absence of a PE of TCo in State $\mathrm{S}$ to which the income is attributable.

\section{Direct tax consequences in state $T$}

- State T imposes corporate tax on the profits earned by TCo from its various activities in the T/S region. TCo's income, however, is almost entirely offset by the royalty paid to YCo for its sublicense of the technology used by TCo to provide Internet services.

- This payment is not subject to withholding under the relevant double tax treaty.

- State T does not impose corporate income tax on XCo, due to it not being a resident under State T's domestic legislation. 


\section{Direct tax consequences in state $Y$}

- State Y imposes corporate income tax on the profits of YCo, but those profits are limited to a small "spread" between the royalties received by YCo and the royalties paid by YCo to XCo.

- State Y does not impose any withholding on the payment of royalties under its domestic law.

\section{Direct tax consequences in state $X$}

- State $X$ does not impose a corporate income tax.

\section{Direct tax consequences in state $R$}

- State $\mathrm{R}$ imposes corporate income tax on the profits derived by $\mathrm{RCo}$, notably the buy-in payment received in consideration for the transfer of pre-existing technology to XCo and the annual payments received under the cost sharing arrangement. However, because of the absence of a significant track record of RCo's performance at the time of the transaction, RCo may take the position that the value of those intangibles was very low, so that the actual amount of gain subject to corporate tax in State R would be very small. Further, the annual payment - compensation for the costs supported by RCo for developing the intangibles without any markup - could potentially be at a rate much lower than the amount of royalties received by XCo. Finally, depending on the domestic law of State R, RCo may be entitled to R\&D tax credits for a significant fraction of its expenditures, thereby further reducing its tax liability for corporate tax purposes.

- Under its controlled foreign company (CFC) rules, State R would under some circumstances treat royalties received by XCo as passive income subject to current taxation in the hands of RCo. However, because YCo and TCo are considered for tax purposes as transparent entities in State R, the latter's CFC rules would disregard the royalty transactions concluded between XCo, YCo and TCo. The income of YCo and TCo would be considered as having been earned directly by $\mathrm{XCo}$, and would be treated as active income that would be taxable in State R only when paid to RCo.

\section{VAT consequences}

- With respect to VAT, the treatment of the B2B transactions is relatively straightforward with the VAT levied either through the supplying business charging the tax or the recipient business self-assessing it. 
The input tax levied would generally be recoverable by the businesses through the input tax credit mechanism. The exception would be where the business is engaged in making exempt supplies and therefore not entitled to recover the tax.

- The online services provided free of charge by TCo to consumers in the $\mathrm{S} / \mathrm{T}$ region have in principle no VAT consequences, unless it is considered that TCo is providing consumers with Internet services for non-monetary consideration, in which case the customers' State may claim VAT on the fair market value of that consideration.

\section{B.3 Cloud computing}

The RCo Group is a developer of software (online games) which it operates on servers around the world and makes available to customers through various client interfaces in exchange for subscription fees.

The software itself, along with all technology associated with processing payment and maintaining security of customer data, was developed principally by engineers of RCo, a company resident in State R. In addition, RCo remotely co-ordinates marketing and selling activities in the various regions to minimise costs, maintain consistency among its various businesses and websites, and improve efficiency. Those co-ordination services are provided to regional operating lower-tier subsidiaries in return for a management service fee covering related expenses plus a markup.

RCo transferred the employees responsible for the management of the technology used in operating the client interfaces to PE Y, a foreign branch of RCo situated in State Y. RCo provides the rights to use the software and knowledge associated with the cloud computing services to various regional subsidiaries through licensing and sub-licensing arrangements.

TCo is a regional operating subsidiary of RCo resident in State T. Even though State T's market is small in relation to RCo's business, TCo employs a substantial number of people to operate the websites used to sell access to RCo's hosted software in the T/S region, which includes State S and other States. TCo has obtained under a public tender in State S all the licenses required to exercise certain regulated activities (online gaming). Contracts with customers in State S are concluded electronically through TCo's websites on the basis of standard agreements, the terms of which are set by RCo. TCo manages all payment processing and security associated with permitting access to the hosted software. Fees paid by the subscribers are collected through local bank accounts. In addition, TCo's personnel perform all required localisation of the software for use in markets in the State S. TCo operates a "server farm" located in State T, which is used as the primary 
datacentre to run the software, process customer transactions, and store customer data. Mirror servers owned by third parties (ISPs) are also regularly used in other locations around the world to ensure the most efficient possible access at all times by customers, as well as to decrease the risk of loss of data.

To promote demand for the use of RCo's hosted software in State S, a very significant market for RCo's business, TCo has a local subsidiary, SCo, whose stated purpose is to promote the hosted software services in the region and offer online customer's care services. SCo does this both through local advertising and through direct interaction with prospective customers. SCo is compensated for its activities via a fee calculated on a cost-plus basis.

The structure used by the RCo Group can be depicted as shown in Figure B.3.

Figure B.3. Cloud computing

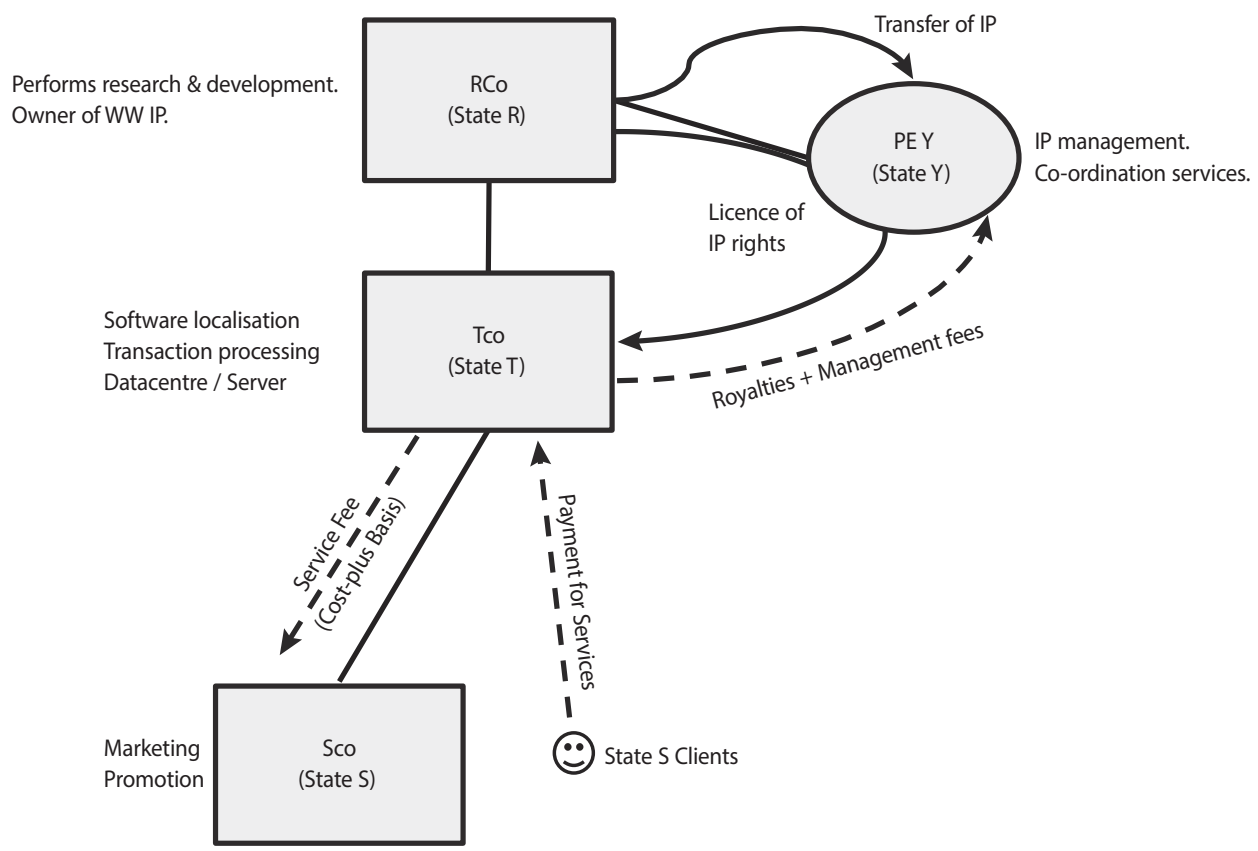

The manner in which RCo Group's business activity is structured as a legal matter has significant consequences for the Group's worldwide tax burden. Due to contractual arrangements and allocation of key functions most of the profits generated by the Group's business activity is allocated to State Y, thereby ensuring that minimal tax is being paid in States S T and R. 
More specifically, the following paragraphs describe the consequences that would arise in the different States concerned.

\section{Direct tax consequences in state $S$}

- SCo is allocated minimal taxable income, based on the position that its risk and function profile is limited to routine marketing and customer care services. All revenues from sales of cloud computing services in State $\mathrm{S}$ are treated as income of TCo, due to its role as the counterparty to the transactions with local customers and administrator of the websites. State $\mathrm{S}$ does not tax the profits derived from these activities because it has no right to do so under its domestic law or because the relevant double tax treaty prevents it from doing so in the absence of a PE of TCo in State S to which the income is attributable.

\section{Direct tax consequences in state $T$}

- State T imposes corporate income tax on the profits derived by TCo from its sales activities but TCo's income is largely offset by the royalty paid to $\mathrm{RCo}$ for its license of the technology used in providing the cloud computing services to customers, as well as by the management fees paid to RCo for its co-ordination services.

- Although the income from the royalties and fees paid by TCo is attributed to the PE in State $\mathrm{Y}$, State $\mathrm{T}$ does not impose any withholding on those royalties and fees under the terms of the relevant tax treaty between State $\mathrm{T}$ and State $\mathrm{R}$, as it considers the payment to be received by $\mathrm{RCo}$, a resident of State $\mathrm{R}$.

\section{Direct tax consequences in state $Y$}

- $\quad$ State Y imposes corporate income tax on the profits attributable to $\mathrm{PE} Y$ at a low rate. In addition, by virtue of a preferential regime available in State $Y$ for income derived from certain intangibles, the income attributable to the PE Y is entitled to a rate substantially less than the generally applicable corporate tax rate for the royalties included in its taxable profits.

\section{Direct tax consequences in state $R$}

- State R imposes corporate tax on the profits derived by RCo on a territorial basis. As a result, and in accordance with the relevant double tax treaty, all the royalty income and management fees 
derived by RCo are treated as attributable to PE Y and, as such, excluded from RCo's corporate tax base in State R.The capital gain derived by RCo from the transfer of the existing technology to $\mathrm{PE}$ Yis not taxed in State R under the rules applicable to cross-border transfers of assets in the $\mathrm{R} / \mathrm{Y}$ region. Further, RCo may be entitled to $R \& D$ tax credits for a significant fraction of its $R \& D$ expenditures, thereby reducing its tax liability in respect of the management fees.

- State R's domestic law does not provide for any CFC regime.

\section{VAT consequences}

- For VAT purposes, as in the previous examples, the VAT on the B2B transactions will be levied either through the supplying business charging the tax or the recipient business self-assessing it. The input tax levied would generally be recoverable by the businesses through the input tax credit mechanism. The exception would be where a business is engaged in making exempt supplies and therefore not entitled to recover the tax.

- In respect of B2C transactions, TCo's supplies to final consumers in State S should in principle be subject to VAT in there. However, States S will often have considerable difficulty in enforcing the collection of VAT on cloud services acquired from abroad by resident final consumers.

\section{B.4 Internet app store}

RCo Group is the creator of an operating system for mobile phones and other portable devices. It maintains a widely used Internet app store, through which users of RCo Group's phones and devices may pay to download applications (including both applications developed and owned by RCo Group and by third-party developers) that enhance the function of their devices. In order to develop and sell applications through RCo Group's marketplace, third-party developers must use software provided by RCo Group in order to ensure compatibility with its operating system and consistency with standards set by RCo Group. Pricing for third-party applications is set by the third-party developers subject to guidelines set by RCo Group, with the developer receiving $75 \%$ of the revenues from sales through the app store, and RCo Group receiving 25\%. Third-party developers may choose which markets their products will be sold in.

The development of the operating system and the Internet app store, as well as self-made applications sold through the app Store, was performed substantially by employees of RCo, a company resident in State R. The 
development of the third-party applications is performed around the world, depending on the location of the developers, most of which are individuals or small businesses.

Early in the life of the Group, RCo sold its rights to the technology used in developing and running its app Store, along with the developing tools and other software used to work with third-party developers around the world to a subsidiary, TCo, resident in State T, a very small market in relation to RCo Group's business. Simultaneously to the sale agreement, RCo concluded a service agreement whereby it continues to upgrade and develop the technology used in the app stores for the benefit of TCo in exchange for a fee covering its $R \& D$ expenses plus a markup. All the risks assumed related to the development of the technology were contractually allocated to TCo, which employs a substantial number of people to operate the various local versions of the application marketplace (tailored and developed by RCo) and steer the marketing strategy, but does not perform any supervision of the development activities carried out by RCo in State R. The app stores are hosted on servers located in State $\mathrm{T}$ and owned by TCo or, depending on network traffic at the time of the transaction, on third-party servers generally located in countries distinct from the country of the customer. TCo handles all transaction processing with customers and third party developers around the world (including State R). Contracts for purchase of applications are concluded electronically, through automated processes, on the basis of standardised terms set by TCo.

In larger markets, TCo has established local affiliates to assist the group with promoting the RCo operating system and the Internet app store to thirdparty developers, sellers and prospective purchasers of mobile devices. These local affiliates, such as SCo, a company established in State S, are never formally involved in the sales of specific applications and/or negotiation of agency agreements with third-party developers, though some face-to-face interactions may occur with local customers. The remuneration of these local affiliates is generally based on a fee covering their expenses plus a markup.

The structure used by the RCo Group can be depicted as shown in Figure B.4.

The manner in which RCo's business activity is structured as a legal matter has significant consequences for the Group's worldwide tax burden. RCo Group takes the position that due to contractual arrangements an affiliated company resident in State T, TCo, is entitled to all residual profits after compensating the other members of the group for their functions, thereby reducing the group's tax burden to a minimum in the other States involved. More specifically, the following paragraphs describe the consequences that would arise in the different States concerned. 
Figure B.4. Internet app store

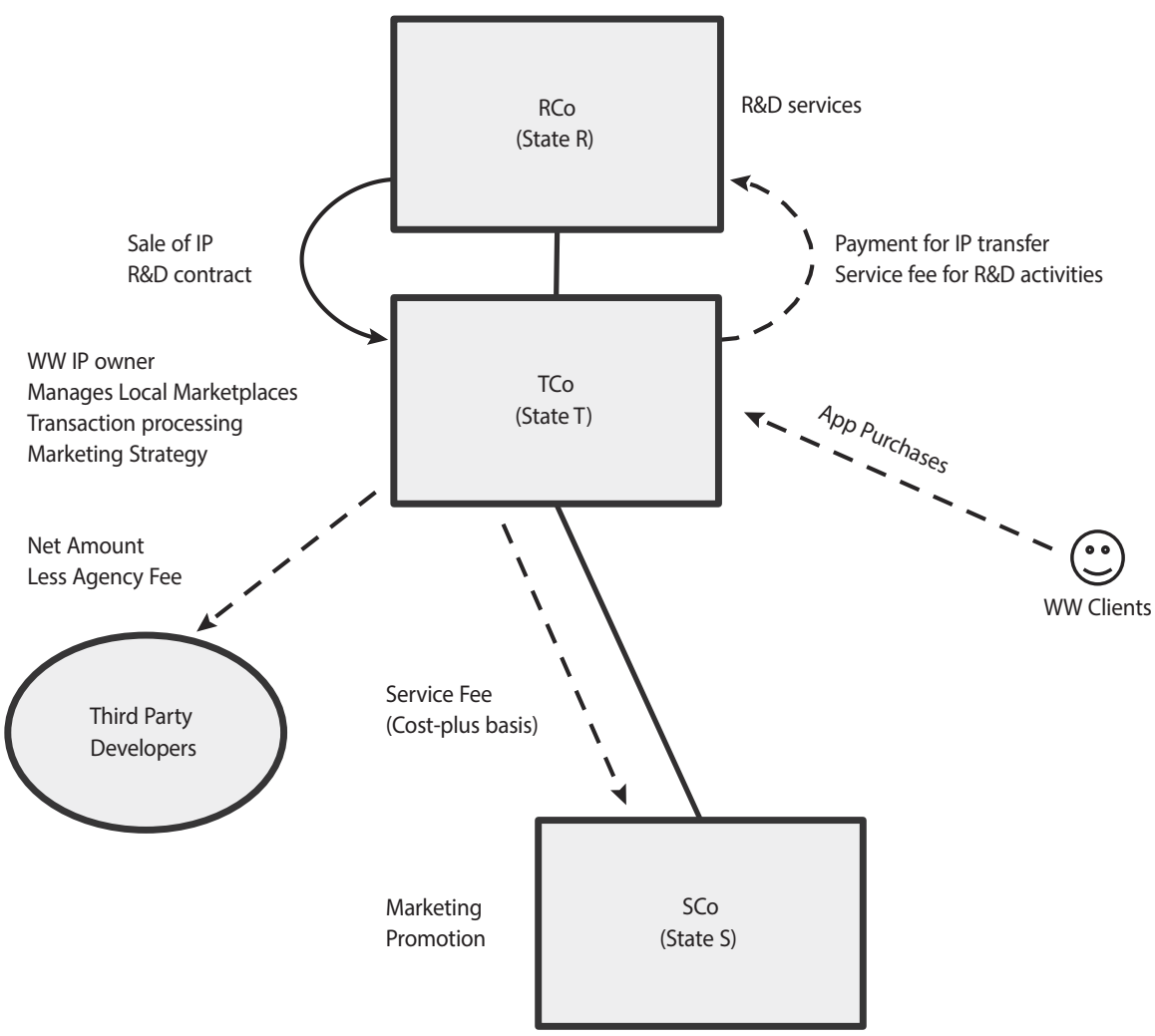

\section{Direct tax consequences in state $S$}

- SCo is allocated minimal taxable income, based on the position that the function profile of this local affiliate is limited to providing routine marketing and promotion services, with no direct selling activity to State $\mathrm{S}$ customers.

- All revenues from sales of applications in State S and State R are treated as income of $\mathrm{TCo}$, due to its role as the counterparty to the transactions with local customers and administrator of local app stores. State $\mathrm{S}$ does not tax the profits derived from these activities either because it has no right to do so under its domestic law or because the relevant double tax treaty prevents it from doing so in the absence of a PE of TCo in State $\mathrm{S}$ to which the income is attributable. 


\section{Direct tax consequences in state T}

- State $\mathrm{T}$ imposes corporate tax on the significant profits earned by $\mathrm{TCo}$, but at a rate which is roughly $50 \%$ of the rates of State $\mathrm{R}$ and State S.

- No withholding is imposed on the various service fees paid by TCo to RCo and SCo under the relevant double tax treaty.

\section{Direct tax consequences in state $R$}

- State R imposes corporate income tax on the profits derived by RCo, notably the capital gain derived from the sale of the technology to TCo and the service fee received for its R\&D activities. However, because of the absence of a significant track record of RCo's performance at the time of the transaction, RCo may take the position that the value of those intangibles was very low, so that the actual amount of gain subject to corporate tax in State R would be very small. In addition, depending on the domestic law of State R, RCo may be entitled to $R \& D$ tax credits in State $R$ for a significant fraction of its expenditures, thereby reducing its tax liability for corporate tax purposes.

- State R imposes corporate tax on a territorial basis and does not have any $\mathrm{CFC}$ rules. As a result, $\mathrm{RCo}$ is exempt from tax both on income earned by TCo and on dividends received from TCo.

\section{VAT consequences}

- For VAT purposes, as in the previous examples, the VAT on the business-to-business transactions will be levied either through the supplying business charging the tax or the recipient business selfassessing it. The input tax levied would generally be recoverable by the businesses through the input tax credit mechanism. The exception would be where a business is engaged in making exempt supplies and therefore not entitled to recover the tax.

- In respect of B2C transactions, TCo will generally be considered as the supplier of the applications to the consumers for VAT purposes, rather than the third party developers of these applications. The transactions between TCo and the third party developers will then be treated as business-to-business supplies, although the turn-over of many third party developers may remain under the VAT-registration threshold, in which case these transactions may effectively not be subject to VAT. 
- TCo would be required to collect and remit State T VAT on sales of any services to private consumers in State T. Supplies to consumers abroad will either be zero-rated in State $\mathrm{T}$ or will be subject to State T's (low) VAT rate. Supplies to such final consumers in other states should in principle be subject to VAT in these final consumers' state. These consumers' states, however, will often have considerable difficulty enforcing the collection of VAT on supplies of applications to consumers within their jurisdiction. This may result in consumers in these states being able to acquire the applications free of VAT or at a lower (foreign) VAT rate than if they had acquired the product domestically. 


\section{ORGANISATION FOR ECONOMIC CO-OPERATION AND DEVELOPMENT}

The OECD is a unique forum where governments work together to address the economic, social and environmental challenges of globalisation. The OECD is also at the forefront of efforts to understand and to help governments respond to new developments and concerns, such as corporate governance, the information economy and the challenges of an ageing population. The Organisation provides a setting where governments can compare policy experiences, seek answers to common problems, identify good practice and work to co-ordinate domestic and international policies.

The OECD member countries are: Australia, Austria, Belgium, Canada, Chile, the Czech Republic, Denmark, Estonia, Finland, France, Germany, Greece, Hungary, Iceland, Ireland, Israel, Italy, Japan, Korea, Luxembourg, Mexico, the Netherlands, New Zealand, Norway, Poland, Portugal, the Slovak Republic, Slovenia, Spain, Sweden, Switzerland, Turkey, the United Kingdom and the United States. The European Union takes part in the work of the OECD.

OECD Publishing disseminates widely the results of the Organisation's statistics gathering and research on economic, social and environmental issues, as well as the conventions, guidelines and standards agreed by its members. 


\section{OECD/G20 Base Erosion and Profit Shifting Project}

\section{Addressing the Tax Challenges of the Digital Economy}

Addressing base erosion and profit shifting is a key priority of governments around the globe. In 2013, OECD and G20 countries, working together on an equal footing, adopted a 15-point Action Plan to address BEPS. This report is an output of Action 1.

Beyond securing revenues by realigning taxation with economic activities and value creation, the OECD/G20 BEPS Project aims to create a single set of consensus-based international tax rules to address BEPS, and hence to protect tax bases while offering increased certainty and predictability to taxpayers. A key focus of this work is to eliminate double non-taxation. However in doing so, new rules should not result in double taxation, unwarranted compliance burdens or restrictions to legitimate cross-border activity.

\section{Contents}

\section{Executive summary}

Chapter 1. Introduction to tax challenges of the digital economy

Chapter 2. Fundamental principles of taxation

Chapter 3. Information and communication technology and its impact on the economy

Chapter 4. The digital economy, new business models and key features

Chapter 5. Identifying opportunities for BEPS in the digital economy

Chapter 6. Tackling BEPS in the digital economy

Chapter 7 . Broader tax challenges raised by the digital economy

Chapter 8. Potential options to address the broader tax challenges raised by the digital economy

Conclusions

Annex A. Prior work on the digital economy

Annex $B$. Typical tax planning structures in integrated business models

www.oecd.org/tax/beps.htm

Consult this publication on line at $\boldsymbol{h t t p : / / d x . d o i . o r g / 1 0 . 1 7 8 7 / 9 7 8 9 2 6 4 2 1 8 7 8 9 - e n . ~}$

This work is published on the OECD iLibrary, which gathers all OECD books, periodicals and statistical databases.

Visit www.oecd-ilibrary.org for more information.

OECDpublishing

www.oecd.org/publishing
ISBN 978-92-64-21877-2

$232014251 \mathrm{P}$

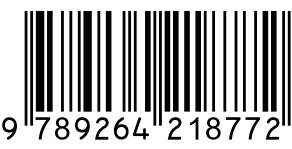

